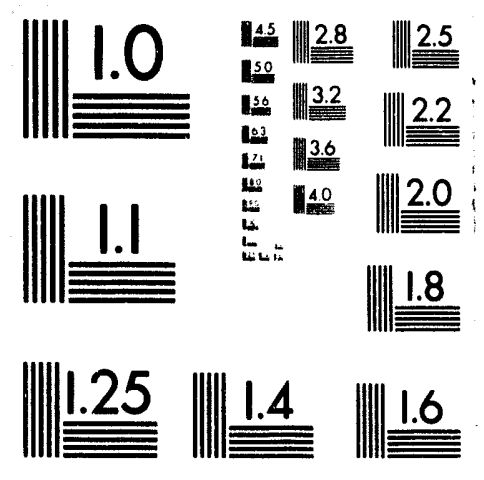



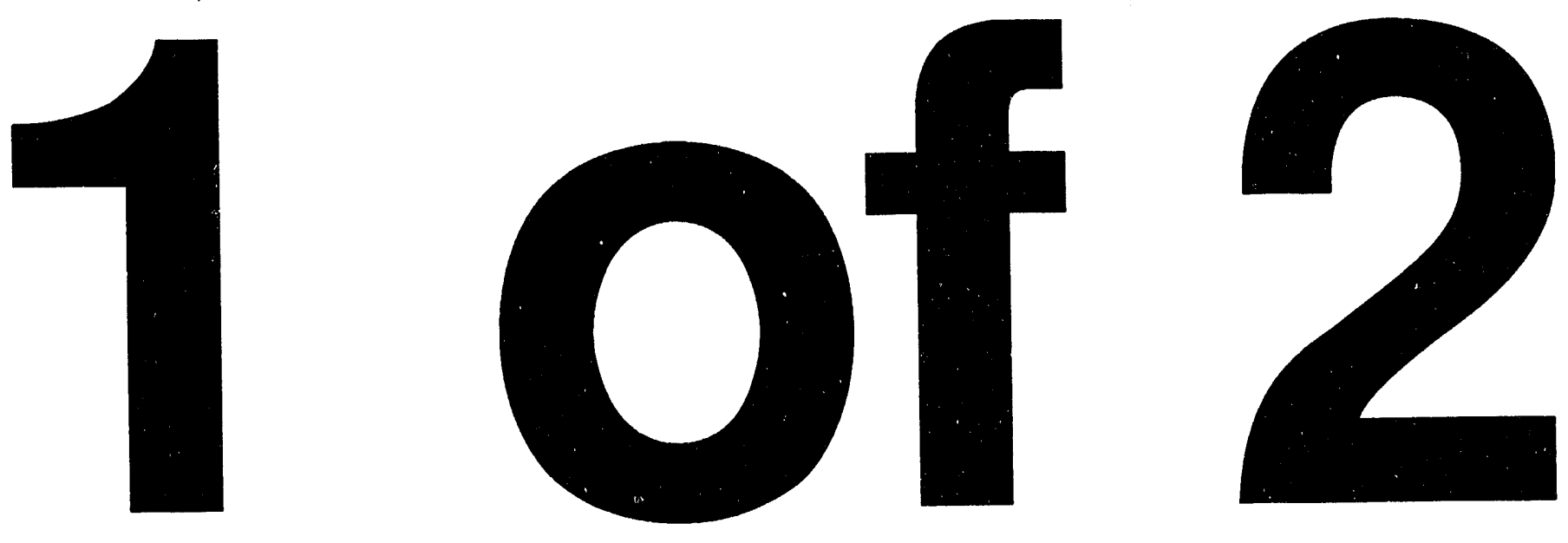


\title{
Validation Procedures Used in the Background Soil Characterization Project on the Oak Ridge Reservation, Oak Ridge, Tennessee
}

\author{
Environmental Restoration Division \\ P.O. Box 2003 \\ Oak Ridge, Tennessee 37831-7298
}

Date Issued-December 1993

\author{
Prepared for \\ U.S. Department of Energy \\ Office of Environmental Restoration and Waste Management \\ under budget and reporting code EW 20 \\ MAR'TIN MARIETTA ENERGY SYSTEMS, INC. \\ managing the \\ Oak Ridge K-25 Site \\ Oak Ridge Y-12 Plant \\ Oak Ridge National Laboratory \\ under contract DE-AC05-84OR21400 \\ for the \\ U.S. DEPARTMENT OF ENERGY
}

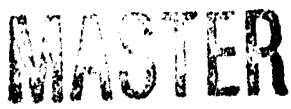

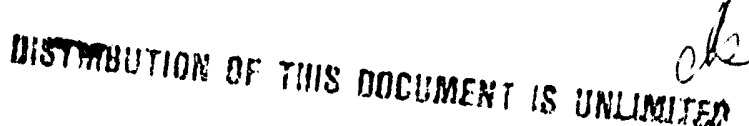


Authors

A.R. Barnard-Hatmaker

J.L. Engels

G.S. Fleming

S.B. Gadson

T.L. Hatmaker

C.W. Kimbrough

L.M. Potter

D.B. Shehee

D.E. Vance

D.R. Watkins

\section{Author Afiliations}

A.R. Barnard-Hatmaker, J.L. Engels, G.S. Fleming, S.B. Gadson, L.Mi. Potter, and D.B. Shehee are members of the Oak Ridge K-25 Site Analytical Environmental Support Group; T.L. Hatmaker is with the Measurement Applications and Development Group of the Health Sciences Research Division at ORNL; C.W. Kimbrough is Manager of Energy Systems' Analytical Projects Office; D.E. Vance is with the Oak Ridge Y-12 Plant Analytical Services Organization; and D.R. Watkins is Manager of the Background Soil Characterization Project and is affiliated with the Environmental Sciences Division at ORNL.

\section{Acknowiedgments}

A number of individuals served as data validators and coordinators in this project in addition to the authors. These were A. Halouma, T. Borges, J. Broussard, C. Turner, D. Hoffman, T. French, D. Mann, and B. Mitchell. The authors wish also to express their appreciation to A.L. Harkey and D.M. Adams of Information Management Services for their efforts in producing this document. 


\section{CONTENTS}

ABBREVIATIONS $\ldots \ldots \ldots \ldots \ldots \ldots \ldots \ldots \ldots \ldots \ldots \ldots \ldots \ldots \ldots \ldots \ldots \ldots \ldots$ vii

EXECUTIVE SUMMARY $\ldots \ldots \ldots \ldots \ldots \ldots \ldots \ldots \ldots \ldots \ldots \ldots \ldots$ ix

1. INTRODUCTION $\ldots \ldots \ldots \ldots \ldots \ldots \ldots \ldots \ldots \ldots \ldots \ldots \ldots \ldots \ldots \ldots \ldots$

1.1 PURPOSE ........................................ 1

1.2 DATA QUALIFIER DEFINITIONS $\ldots \ldots \ldots \ldots \ldots \ldots \ldots \ldots \ldots \ldots \ldots$

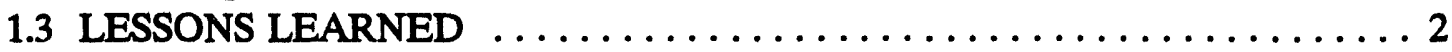

2. ANALYTICAL DATA EVALUATION AND TECHNICAL

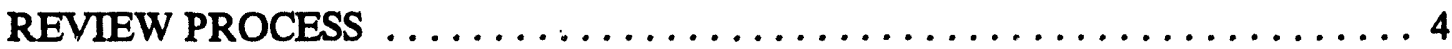

2.1 DEVELOPMENT OF VALIDATION GUIDELINES $\ldots \ldots \ldots \ldots \ldots \ldots \ldots 4$

2.2 USABILITY EVALUATION OF DATA PACKAGES $\ldots \ldots \ldots \ldots \ldots \ldots 5$

2.3 VALIDATION PROCEDURES $\ldots \ldots \ldots \ldots \ldots \ldots \ldots \ldots \ldots \ldots \ldots$

2.4 ADMINISTRATIVE AND CUSTODY PRACTICES FOR PHASE I $\ldots \ldots \ldots 6$

2.4.1 Organization and Responsibilities $\ldots \ldots \ldots \ldots \ldots \ldots \ldots \ldots \ldots \ldots$

2.4.2 Data Evaluation and Technical Review Process ............. 8

3. DATA VALIDATION OF CHLORINATED PESTICIDES AND

AROCLORS IN SOIL SAMPLES $\ldots \ldots \ldots \ldots \ldots \ldots \ldots \ldots \ldots \ldots \ldots, 10$

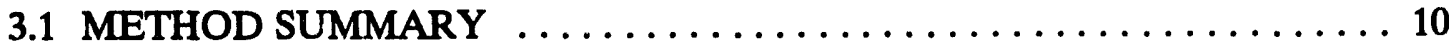

3.2 LEVEL D DELIVERABLES $\ldots \ldots \ldots \ldots \ldots \ldots \ldots \ldots \ldots \ldots \ldots \ldots \ldots \ldots \ldots$

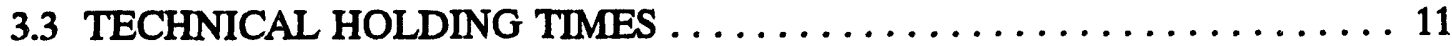

3.4 GC/ECD INSTRUMENT PERFORMANCE CHECK $\ldots \ldots \ldots \ldots \ldots \ldots \ldots$

3.5 INITIAL CALIBRATION $\ldots \ldots \ldots \ldots \ldots \ldots \ldots \ldots \ldots \ldots \ldots \ldots \ldots \ldots \ldots$

3.6 CONTINUING CALIBRATION $\ldots \ldots \ldots \ldots \ldots \ldots \ldots \ldots \ldots \ldots \ldots \ldots$

3.7 BLANKS ....................................... 21

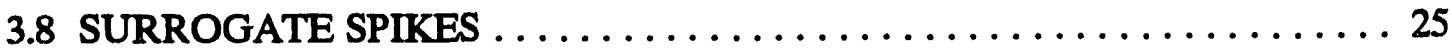

3.9 MATRIX SPIKES/MATRIX SPIKE DUPLICATES $\ldots \ldots \ldots \ldots \ldots \ldots \ldots 27$

3.10 LABORATORY CONTROL SAMPLES $\ldots \ldots \ldots \ldots \ldots \ldots \ldots \ldots \ldots 29$

3.11 PESTICIDE CLEANUP CHECKS $\ldots \ldots \ldots \ldots \ldots \ldots \ldots \ldots \ldots \ldots \ldots \ldots \ldots \ldots \ldots$

3.12 TARGET COMPOUND IDENTIFICATION $\ldots \ldots \ldots \ldots \ldots \ldots \ldots \ldots, 32$

3.13 COMPOUND QUANTITATION AND REPORTED

CONTRACT REQUIRED QUANTITATION LIMITS $\ldots \ldots \ldots \ldots \ldots, 35$

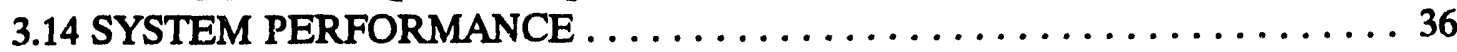

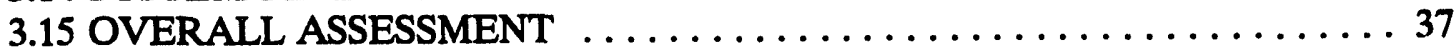

4. DATA VALIDATION OF CHLORINATED HERBICIDES IN

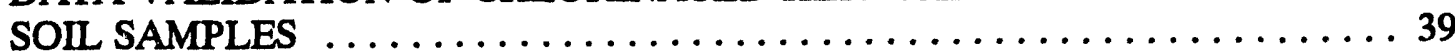

4.1 METHOD SUMMARY $\ldots \ldots \ldots \ldots \ldots \ldots \ldots \ldots \ldots \ldots \ldots \ldots, \ldots \ldots \ldots$

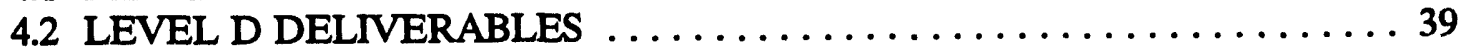

4.3 TECHNICAL HOLDING TIMES ...................... 40

4.4 INSTRUMENT CALIBRATION AND CALIBRATION

VERIFICATION $\ldots \ldots \ldots \ldots \ldots \ldots \ldots \ldots \ldots \ldots \ldots \ldots \ldots \ldots \ldots \ldots \ldots \ldots \ldots$

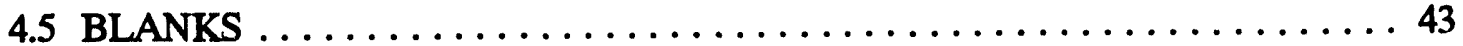


4.6 SURROGATE RECOVERY $\ldots \ldots \ldots \ldots \ldots \ldots \ldots \ldots \ldots \ldots \ldots$

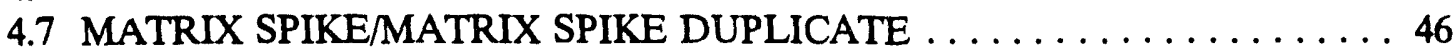

4.8 LABORATORY CONTROL SAMPLES $\ldots \ldots \ldots \ldots \ldots \ldots \ldots \ldots \ldots$

4.9 COMPOUND IDENTIFICATION $\ldots \ldots \ldots \ldots \ldots \ldots \ldots \ldots \ldots \ldots \ldots$

4.10 COMPOUND QUANTITATION AND REPORTED CONTRACT

REQUIRED QUANTITATION LIMITS $\ldots \ldots \ldots \ldots \ldots \ldots \ldots \ldots \ldots \ldots$

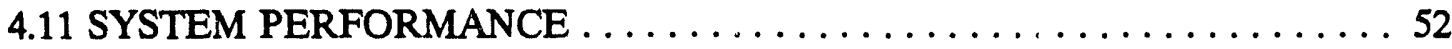

4.12 OVERALL ASSESSMENT OF DATA FOR A CASE .......... 53

5. DATA VALIDATION OF POLYNUCLEAR AROMATIC

HYDROCARBONS IN SOIL SAMPLES $\ldots \ldots \ldots \ldots \ldots \ldots \ldots \ldots \ldots$

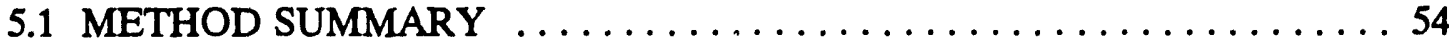

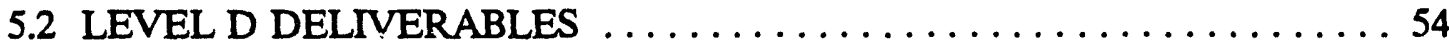

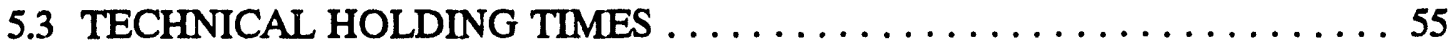

5.4 INSTRUMENT CALIBRATION AND CALIBRATION VERIFICATION . 56

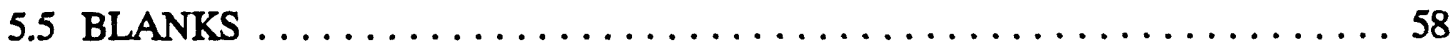

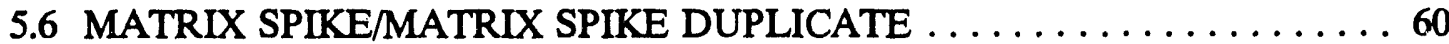

5.7 LABORATORY CONTROL SAMPLES $\ldots \ldots \ldots \ldots \ldots \ldots \ldots \ldots \ldots$

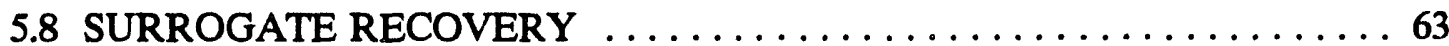

5.9 COMPOUND IDENTIFICATION $\ldots \ldots \ldots \ldots \ldots \ldots \ldots \ldots \ldots \ldots \ldots \ldots$

5.10 COMPOUND QUANTITATION AND REPORTED CRQLS . . . . . . 65

5.11 SYSTEM PERFORMANCE ...................... 67

5.12 OVERALL ASSESSMENT OF DATA FOR A CASE . . . . . . . . 67

6. VALIDATION OF SULFATE DATA $\ldots \ldots \ldots \ldots \ldots \ldots \ldots \ldots \ldots \ldots \ldots$

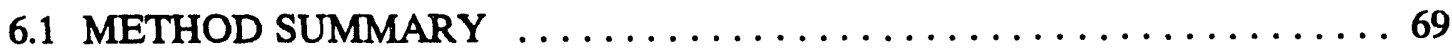

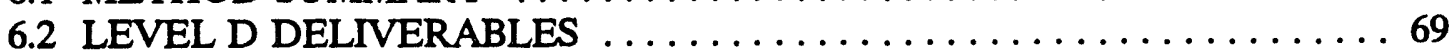

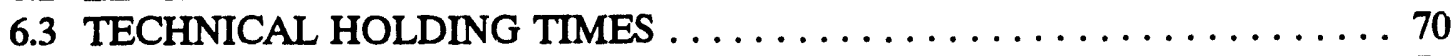

6.4 INITIAL AND CONTINUING CALIBRATION $\ldots \ldots \ldots \ldots \ldots \ldots \ldots 71$

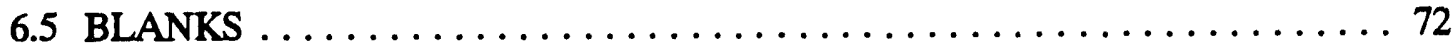

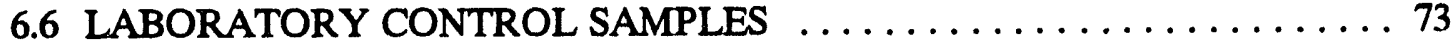

6.7 MATRIX SPIKE/MATRIX SPIKE DUPLICATE $\ldots \ldots \ldots \ldots \ldots \ldots \ldots \ldots$

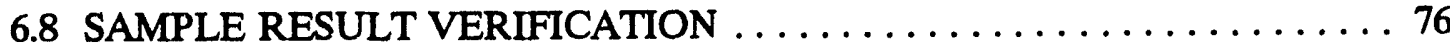

6.9 OVERALL ASSESSMENT OF DATA FOR A CASE . . . . . . . . . 77

7. DATA VALIDATION OF ANALYTES BY NEUTRON

ACTIVATION ANALYSIS $\ldots \ldots \ldots \ldots \ldots \ldots \ldots \ldots \ldots \ldots \ldots \ldots \ldots$

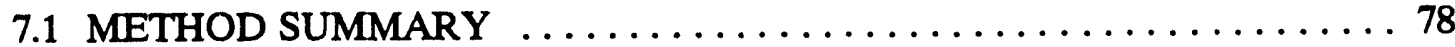

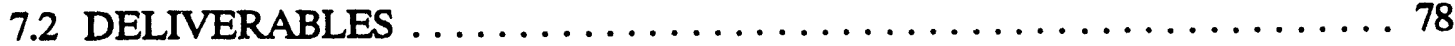

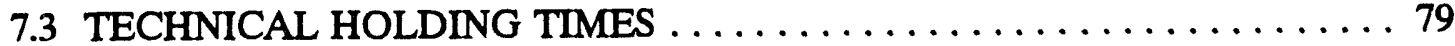

7.4 INSTRUMENT CALIBRATION $\ldots \ldots \ldots \ldots \ldots \ldots \ldots \ldots \ldots \ldots \ldots \ldots \ldots \ldots \ldots \ldots$

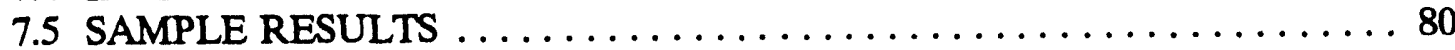

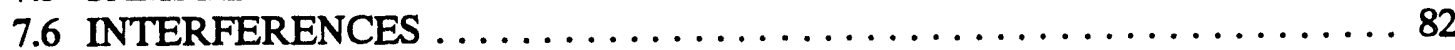

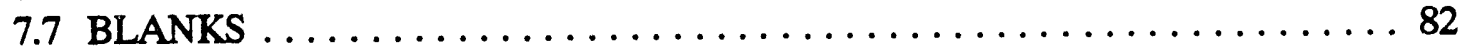

7.8 LABORATORY CONTROL SAMPLES $\ldots \ldots \ldots \ldots \ldots \ldots \ldots \ldots$

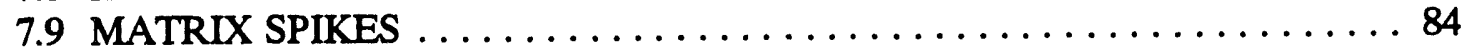

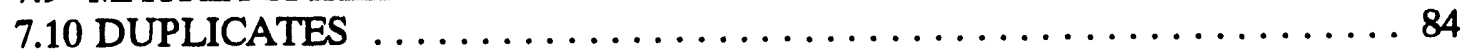

7.11 OVERALL ASSESSMENT OF DATA $\ldots \ldots \ldots \ldots \ldots \ldots \ldots \ldots$

8. DATA VALIDATION OF INORGANICS BY ICP/MS METHOD $\ldots \ldots \ldots . \ldots 8$ 
8.1 HOLDING TIMES AND PRESERVATION $\ldots \ldots \ldots \ldots \ldots \ldots \ldots \ldots 86$

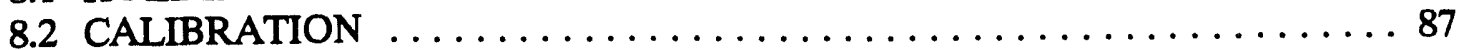

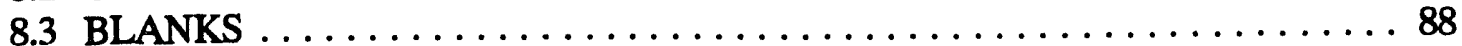

8.4 ICP INTERFERENCE CHECK SAMPLE $\ldots \ldots \ldots \ldots \ldots \ldots \ldots \ldots 89$

8.5 LABORATORY CONTROL SAMPLE $\ldots \ldots \ldots \ldots \ldots \ldots \ldots \ldots, \ldots$

8.6 DUPLICATE SAMPLE ANALYSIS $\ldots \ldots \ldots \ldots \ldots \ldots \ldots \ldots \ldots \ldots \ldots$

8.7 MATRIX SPIKE SAMPLE ANALYSIS $\ldots \ldots \ldots \ldots \ldots \ldots \ldots \ldots \ldots 2$

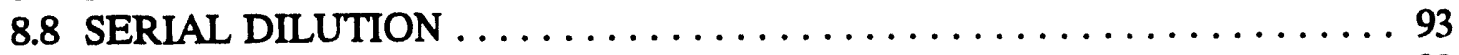

8.9 SAMPLE RESULT VERIFICATION $\ldots \ldots \ldots \ldots \ldots \ldots \ldots \ldots \ldots \ldots, 93$

8.10 INTERNAL STANDARDS $\ldots \ldots \ldots \ldots \ldots \ldots \ldots \ldots \ldots \ldots \ldots \ldots \ldots$

8.11 OVERALL ASSESSMENT OF DATA FOR A CASE ............ 94

9. DATA VALIDATION OF RADIONUCLIDES BY

GAMMA SPECTROSCOPY $\ldots \ldots \ldots \ldots \ldots \ldots \ldots \ldots \ldots \ldots \ldots \ldots$

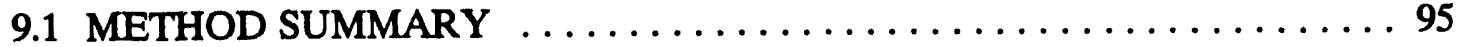

9.2 LEVEL D DELIVERABLES $\ldots \ldots \ldots \ldots \ldots \ldots \ldots \ldots \ldots \ldots \ldots \ldots \ldots$

9.3 TECHNICAL HOLDING TIMES $\ldots \ldots \ldots \ldots \ldots \ldots \ldots \ldots \ldots \ldots \ldots \ldots$

9.4 INSTRUMENT CALIBRATION $\ldots \ldots \ldots \ldots \ldots \ldots \ldots \ldots \ldots \ldots . \ldots 9 . \ldots$

9.5 DAILY INSTRUMENT CALIBRATION CHECK $\ldots \ldots \ldots \ldots \ldots \ldots \ldots 98$

9.6 BACKGROUND CHECK $\ldots \ldots \ldots \ldots \ldots \ldots \ldots \ldots \ldots \ldots \ldots \ldots$

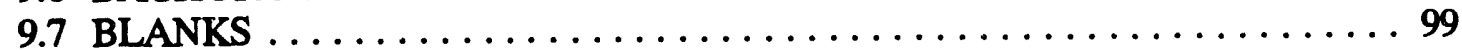

9.8 DUPLICATES .................................. 100

9.9 COUNTS FOR SAMPLES: EVALUATION OF RESULTS,

COUNTING ERROR, AND MDA ................... 101

9.10 OVERALL ASSESSMENT OF DATA FOR A CASE $\ldots \ldots \ldots \ldots \ldots \ldots 103$

9.11 CALCULATIONS $\ldots \ldots \ldots \ldots \ldots \ldots \ldots \ldots \ldots \ldots \ldots \ldots \ldots \ldots$

10. DATA VALIDATION OF RADIONUCLIDES BY

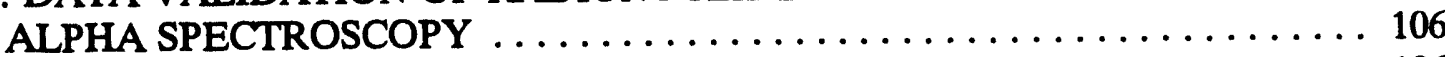

10.1 METHOD SUMMARY $\ldots \ldots \ldots \ldots \ldots \ldots \ldots \ldots \ldots \ldots \ldots \ldots \ldots \ldots, 106$

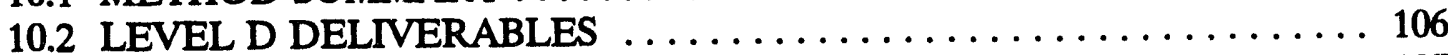

10.3 TECHNICAL HOLDING TIMES ....................... 107

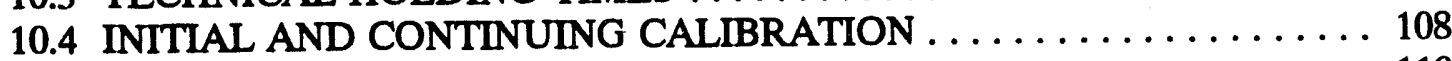

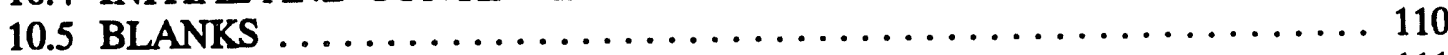

10.6 MATRIX SPIKES/MATRIX SPIKE DUPLICATES $\ldots \ldots \ldots \ldots \ldots \ldots, 111$

10.7 DUPLICATES . . . . . . . . . . . . . . . . . . . . . . . . 113

10.8 LABORATORY CONTROL SAMPLES/BLANK SPIKES $\ldots \ldots \ldots \ldots \ldots$

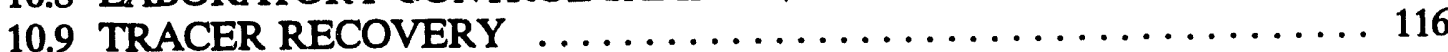

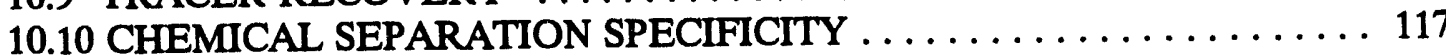

10.11 RADIONUCLIDE QUANTITATION AND ESTIMATED

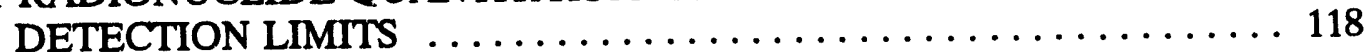

10.12 SYSTEM PERFORMANCE . . . . . . . . . . . . . . . . . . 119

10.13 OVERALL ASSESSMENT OF DATA FOR A CASE $\ldots \ldots \ldots \ldots \ldots 120$

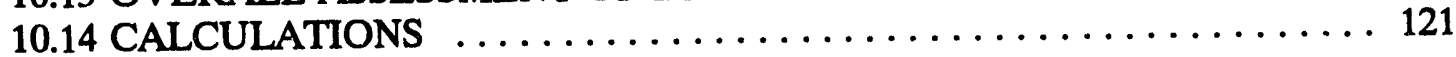

11. STANDARD OPERATING PROCEDURE FOR DATA

VALIDATION OF STRONTIUM-89 AND STRONTIUM-90 $\ldots \ldots \ldots \ldots \ldots 124$

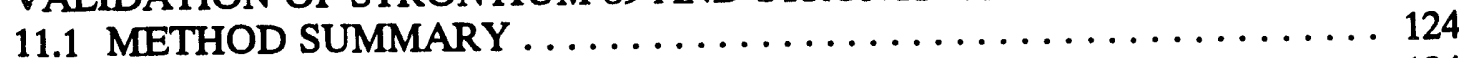

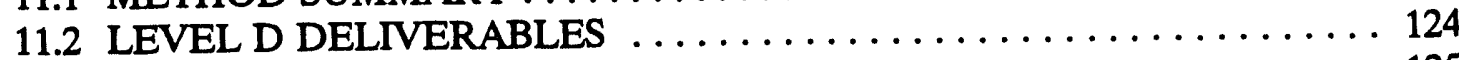

11.3 TECHNICAL HOLDING TIMES ...................... 125 
11.4 INSTRUMENT CALIBRATION AND DAILY INSTRUMENT

PERFORMANC CHECK . . . . . . . . . . . . . . . . . . . . 126

11.5 SAMPLE AND BACKGROUND RESULTS $\ldots \ldots \ldots \ldots \ldots \ldots \ldots \ldots$

11.6 BLANKS . . . . . . . . . . . . . . . . . . . . . . . 129

11.7 MATRIX SPIKE/MATRIX SPIKE DUPLICATES . . . . . . . . . 130

11.8 LABORATORY CONTROL SAMPLES/BLANK SPIKE $\ldots \ldots \ldots \ldots \ldots 131$

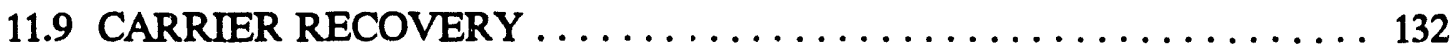

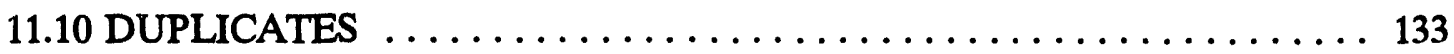

11.11 OVERALL ASSESSMENT OF DATA FOR A CASE . . . . . . . 134

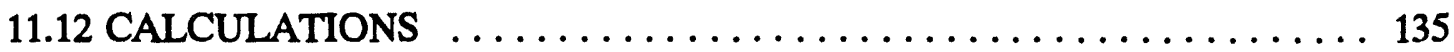

12. DATA VALIDATION OF RADIONUCLIDES USING LIQUID

SCINTILLATION COUNTING $\ldots \ldots \ldots \ldots \ldots \ldots \ldots \ldots \ldots \ldots \ldots \ldots \ldots$

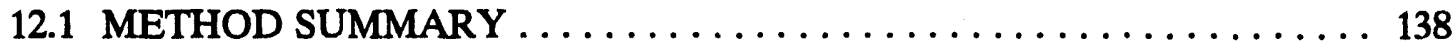

12.2 LEVEL D DELIVERABLES $\ldots \ldots \ldots \ldots \ldots \ldots \ldots \ldots \ldots \ldots \ldots \ldots \ldots$

12.3 TECHNICAL HOLDING TIMES $\ldots \ldots \ldots \ldots \ldots \ldots \ldots \ldots \ldots \ldots \ldots$

12.4 INSTRUMENT CALIBRATION $\ldots \ldots \ldots \ldots \ldots \ldots \ldots \ldots \ldots \ldots \ldots \ldots$

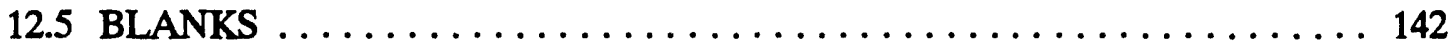

12.6 COMPOUND QUANTITATION, COUNTING ERROR,

MINIMUM DETECTIBLE ACTIVITY, AND

COUNTING EFFICIENCY . . . . . . . . . . . . . . . . 143

12.7 LABORATORY CONTROL SAMPLES $\ldots \ldots \ldots \ldots \ldots \ldots \ldots \ldots \ldots \ldots$

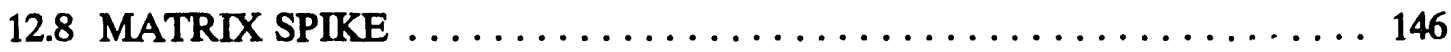

12.9 DUPLICATES . . . . . . . . . . . . . . . . . . . 147

12.10 OVERALL ASSESSMENT OF DATA FOR A CASE . . . . . . . 148

13. DATA VALIDATION OF TOTAL URANIUM BY PULSED

LASER PHOSPHORIMETRY $\ldots \ldots \ldots \ldots \ldots \ldots \ldots \ldots \ldots \ldots \ldots \ldots \ldots$

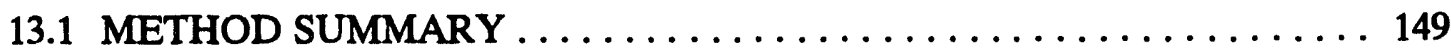

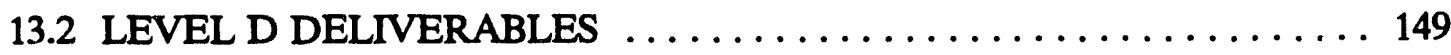

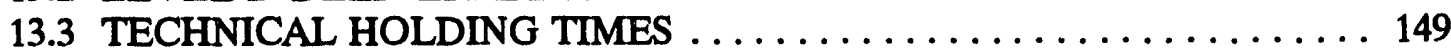

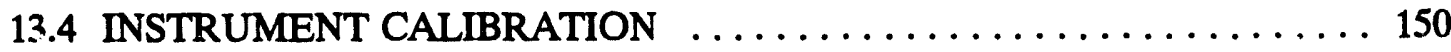

13.5 INSTRUMENT CALIBRATION CHECK $\ldots \ldots \ldots \ldots \ldots \ldots \ldots \ldots \ldots \ldots$

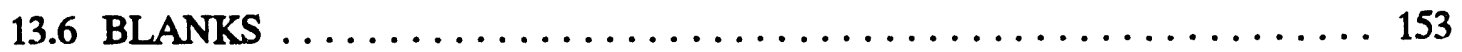

13.7 LABORATORY CONTROL SAMPLES $\ldots \ldots \ldots \ldots \ldots \ldots \ldots \ldots \ldots$

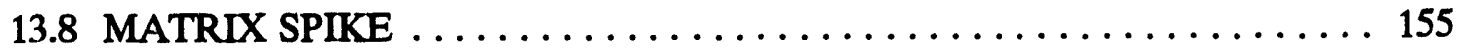

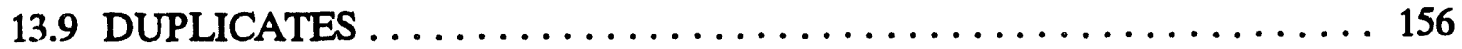

13.10 OVERALL ASSESSMENT OF DATA FOR A CASE . . . . . . . . 157

14. RELATED DOCUMENTS ....................... 159

Appendix A. DATA ASSESSMENT FORMS $\ldots \ldots \ldots \ldots \ldots \ldots \ldots \ldots \ldots \ldots \ldots$

Appendix B. MULTIMEDIA, MULTICONCENTRATION CONTRACTUAL

REQUIREMENTS AND EQUATIONS FOR PESTICIDE

DATA REVIEW 


\section{ABBREVIATIONS}

\begin{tabular}{ll} 
AESG & Analytical Environmental Support Group \\
BSCP & Background Soil Characterization Project \\
CCS & contract compliance screen \\
CCV & continuing calibration verification \\
CLP & Contract Laboratory Program \\
COC & chain of custody \\
CRDL & contract required detection limit \\
CRQL & contract required quantitation limit \\
D & dilution factor \\
\%D & percent difference \\
DCB & decachlorobiphenyl \\
DDD & dichlorodiphenyldichloroethane \\
DDE & dichlorodiphenylethane \\
DDT & dichlorodiphenyltrichloroethane \\
DVR & data validation report \\
ECD & electron capture detector \\
EDTA & ethylenediaminetetraacetic acid \\
EPA & U.S. Environmental Protection Agency \\
FWHM & full width at half-maximum \\
GPC & gel permeation chromatography \\
HPLC & high performance liquid chromatography \\
ICP/MS & inductively coupled plasma/mass spectroscopy \\
ICS & interference check sample \\
ICV & initial calibration verification \\
IPA & instrument performance assessment \\
LCS & laboratory control sample \\
Level D & EPA analytical Level IV \\
MAD & Measurement and Applications Development Group \\
MDA & minimum detectable activity \\
MS & matrix spike \\
MSD & matrix spike duplicate \\
NAA & neutron activation analysis \\
NIST & National Institute of Standards and Technology \\
ORNL & Oak Ridge National Laboratory \\
PAH & polynuclear aromatic hydrocarbon \\
PCB & polychlorinated biphenyl \\
PEM & performance evaluation mixture \\
PEST & pesticide \\
QAPjP & Quality Assurance Project Plan \\
QC & quality control \\
\%R & percent recovery \\
RIC & reconstructed ion chromatogram \\
RPD & relative percent difference \\
RSD & relative standard deviation \\
& \\
\hline
\end{tabular}


RT retention time

SAP sampling and analysis plan

SDG sample delivery group

SNC system normalization and calibration

SOP standard operating procedure

TCMX tetrachloro-m-xylene

UV ultraviolet

VTSR validated time of sample receipt 


\section{EXECUTIVE SUMMARY}

The Background Soil Characterization Project's (BSCP's) requirement for fully validated and defensible analytical laboratory data [U.S. Environmental Protection Agency (EPA) analytical Level IV, discussed in the BSCP Plan (Energy Systems 1992 ${ }^{1}$ )] necessitated development of select project-specific validation guidelines and criteria where utilization of existing EPA data validation guidelines was not available. Project data include organics [pesticides, herbicides, polychlorinated biphenyls (PCBs), and polynuclear aromatic hydrocarbons (PAHs)]; inorganics (metals and cyanide/sulfate); and radionuclides, both naturally occurring and fallout components, determined from the EPA target analyte list and target compound list and from site program risk assessment considerations. Analytical methods included a wide range of EPA/Contract Laboratory Program (CLP) methods and non-CLP methods, as well as the neutron activation analysis (NAA) and inductively coupled plasma/mass spectroscopy (ICP/MS) methods.

In addition to utilization of available and applicable CLP validation criteria for pesticides, PCBs, metals, and cyanide consistent with analytical Level IV (Level D), data validation for the BSCP required development of criteria to validate pesticide/PCB, herbicide, $\mathrm{PAH}$, sulfate, radiochemical, NAA, and ICP/MS results. The objective was to produce a consistent set of validation criteria and procedures that could be used for future Environmental Restoration (ER) projects.

Data validation criteria in this effort relied upon the following:

- organics: - pesticides/PCBs-EPA Functional Guidelines for Evaluating Organics Analyses;

- herbicides and PAHs-project specific guidelines based on EPA Functional Guidelines for Evaluating Organics Analyses, the BSCP Plan (Energy Systems 1992), and analytical methods;

- inorganics: - metals (and cyanide)-EPA Functional Guidelines for Evaluating Inorganics Analyses;

- sulfate-project specific guidelines based on the BSCP Plan (Energy Systems 1992), and the analytical method; and

- radiochemicals: - project specific guidelines based on the BSCP Plan (Energy Systems 1992) and radiochemical analytical methods.

${ }^{1}$ Energy Systems (Martin Marietta Energy Systems, Inc.) 1992. Project Plan for the Background Soil Characterization Project at the Oak Ridge Reservation, Oak Ridge, Tennessee, ES/ER/TM-26/R1, August. 
Computerized data validation procedures were developed to permit validation to be done in near real time (1) to allow for quick response and interaction with the analytical laboratories to make changes and adjustments in procedure and data records in pending analyses and data packages and (2) to shorten the time required for producing project data reports and fulfilling other Environmental Restoration (ER) project reporting requirements.

The BSCP's overall data validation process was conducted in three distinct steps. The first step consisted of technical validation of data according to specified criteria and responding to laboratory action items issued to address validation concerns. The second step was a peer review of the previously validated data packages and included checking flagged data, assessing the rationale for professional judgements, and verifying reasonableness with respect to project data quality objectives. The third step consisted of the validation oversight function and included assessing overall rationale of the approach used and reasonableness of the validation of each data package. This three-step validation process provided an exceptionally high level of comprehensiveness, rigor, and consistency in the data of this project. 


\section{INTRODUCTION}

\subsection{PURPOSE}

The purpose of this report is (1) to document the data validation process developed for the Background Soil Characterization Project (BSCP); (2) to offer members of other project teams and potential data users the benefit of the experience gained in the BSCP in the area of developing project-specific data validation criteria and procedures based on best available guidance and technical information; and (3) to provide input and guidance to the efforts under way within Martin Marietta Energy Systems, Inc., to develop standard operating procedures to streamline and optimize the analytical laboratory data validation process for general use by making it more technically rigorous, consistent, and cost effective. Lessons learned from the BSCP are also provided to meet this end (Sect. 1.3).

The data review process provides information on analytical limitations of data based on specific quality control (QC) criteria. To provide more specific usability ${ }^{2}$ statements, the reviewer must have a complete understanding of the intended use of the data. For this reason, it is recommended that whenever possible the reviewer obtain clarification of usability issues from the user before reviewing the data. When this is not possible, the user is encouraged to communicate any questions to the reviewer.

The laboratory contract compliance screening (CCS) process applied in the BSCP was conducted in accordance with established Contract Laboratory Program (CLP) functional guidelines. CCS was performed as part of the overall technical evaluation conducted in this project and was not delineated as a specific objective in the guidelines or the data review/evaluation process discussed in Sect. 2.

At times, there may be an urgent need to use data that do not meet all contract requirements and technical criteria. Use of these data constitutes neither a new requirement nor full acceptance of the data. Any decision to utilize data for which performance criteria have not been met fully is strictly to facilitate the progress of projects requiring the availability of data. Samples that were run out of specification may have been rerun, or data were resubmitted, even if the previously submitted data have been utilized due to urgent program needs. Data that did not meet specified requirements were not accepted by the project.

\section{DATA QUALIFIER DEFINITIONS}

The following definitions provide brief explanations of the nationally accepted qualifiers assigned to results in the data evaluation and technical review process. If additional qualifiers were used, a complete explanation of those qualifiers accompanied the data validation report (DVR).

${ }^{2}$ Data usability as used in this report refers to applicability of analytical laboratory data consistent with any restrictions or limitations imposed by the qualifiers affixed to the data. 
U - The analyte was analyzed for hilt not detected above the reported sample quantitation limit.

J - The analyte was positively identified; the associated numericai value is the approximate concentration of the analyte in the sample.

$\mathrm{N}$ - The analysis indicates the presence of an analyte for which there is presumptive evidence to make a "tentative identification."

JN - The analysis indicates the presence of an analyte that has been "tentatively identified," and the associated numerical value represents its approximate concentration.

UJ - The analyte was not detected above the reported sample quantitation limit. However, the reported quantitation limit is approximate and may or may not represent the actual limit of quantitation necessary to accurately and precisely measure the analyte in the sample.

R - The sample results are rejected due to serious deficiencies in the ability to analyze the sample and meet QC criteria. The presence or absence of the analyte cannot be verified.

\subsection{LESSONS LEARNED}

The analytical laboratory procurement process and analysis operations implemented by the Analytical Projects Office worked well for the BSCP. The following represent project successes associated with analytical results obtained in this project:

- prequalification of commercial analytical laboratories and competitive final selection,

- developing neutron activetion analysis (NAA) laboratory procedures in-house to provide supporting data for inorganics,

- developing data validation procedures geared toward providing real-time feedback to the laboratories, and

- developing versatile data validation procedures applicable across Environmental Restoration projects.

Lessons learned from this project indicating that which could work better in future projects are discussed in the following paragraphs.

The major area requiring more emphasis and improvement in future projects is the area of interactive coordination and real-time feedback between the project analytical coordinator and the laboratory well before data are officially received and processed through the data validation phase. The primary reason for this suggested requirement is to facilitate early detection and correction of data anomalies and inconsistencies that may be the result of variable interpretation of standard U.S. Environmental Protection Agency (EPA) procedures 
by the analytical laboratories or any idiosyncrasies pertaining to instrumentation calibration or the operation/interpretation of automated system outputs.

The following lessons were learned in the BSCP, specifically with respect to data validation.

- All data validation criteria must be available and in place at the time of development of the project plan.

- Closer liaison and real-time interaction between the analytical coordinator and the laboratory counterpart need to be maintained at all times, especially during critical sample holding time periods and when addressing technical issues, questions, and concerns of the data validators.

Other areas for improvement are detailed in the following list.

- More planning is needed in the beginning to meet evolving analytical QA/QC requirements and data quality objective process needs.

- CLP-qualified laboratories might not meet project-specific requirements, even with EPA standard analytical methods.

- Project-specific preaudits need to be conducted:

- conduct extensive, detailed, on-site reviews of the laboratory's operating procedures and QA implementation procedures and

- provide project-specific performance evaluation samples to evaluate laboratory performance ard data deliverables.

- A need exists to be more realistic in providing adequate time in the project schedule for analytical laboratories to perform and report required analyses, especially with respect to turnaround times allotted in internal laboratory schedules for conducting radiochemical analyses. (Actual turnaround for rad analyses can be from 45 to $60 \mathrm{~d}$; only $30 \mathrm{~d}$ were allowed in the BSCP Plan.)

In negotiations with commercial analytical laboratories supporting future projects, it is recommended that provisions be made to carry out the following:

- conduct preaudit surveillances that include laboratory facilities, instrumentation, operating procedures, training technicians, and record keeping with laboratory management and staff members and

- revise contract laboratory statements of work to include necessary detail beyond CLP requirements. 


\section{ANALYTICAL DATA EVALUATION AND TECHNICAL REVIEW PROCESS}

To ensure that the analytical data were acceptable in technical and regulatory respects, and met the needs of the BSCP, $100 \%$ of the data underwent analytical Level IV (Level D) validation (full review of QC and laboratory data). The Analytical Environmental Support Group (AESG) provided all validation services for all data produced during Phase I of the BSCP. Validation of Phase II data was performed by the Oak Ridge National Laboratory (ORNL) Biomedical and Environmental Information Analysis Section and ORNL Measurement and Applications Development Group (MAD) with AESG providing validation guidelines, technical support, and limited oversight.

Several operational aspects were established for the validation. This work fell in the following areas (described in more detail in the following sections):

- development of validation guidelines,

- usability evaluation of data packages,

- validation procedures, and

- administrative and custody practices.

\section{DEVELOPMENT OF VALIDATION GUIDELINES}

Data being validated resulted from the following analyses:

- pesticides/polychlorinated biphenyls (PCBs) by CLP OLM01.8,

- metals by CLP ILM02.1,

- polynuclear aromatic hydrocarbons (PAHs) by SW-846 Method 8310, and

- herbicides by SW-846 Method 8150.

Radiochemical analyses were all done by laboratory-adapted methods; comprehensive, standardized procedures * re not available as they were for the other analyses, especially in a soil matrix. The radiochemical analytical methods used were the following:

- gamma spectroscopy,

- alpha spectroscopy,

- liquid scintillation,

- pulsed-laser phosphorimetry, and

- gas proportional counter.

Of all these analyses, EPA Data Validation Functional Guidelines were available only for the metals, cyanide, and pesticides/PCBs. Validation criteria contained in AESG Standard Operating Procedure (SOP) No. 7703, Validation of Analytical Data, Attachment 8, addresses metals. The criteria were taken from the EPA's Functional Guidelines for Evaluating Inorganics Analysis. AESG SOP No. 7703 was supplemented by parts of AESG Draft SOP No. 8716, Review of Performance Evaluation Sample Data. 
Validation criteria given in EPA Draft Functional Guidelines for Evaluating Onganics Analysis OLM01.0, Rev. 6/91 were the basis of validation of pesticides/PCBs analyzed according to OLM01.8.

AESG personnel developed validation guidelines for the remaining analyses. Validation criteria had to be consistent with those contained in the BSCP Plan (Energy Systems $1992^{3}$ ). Format of guidelines was similar to those in the EPA Functional Guidelines. The basis for validating sulfate data was AESG SOP 7703, Attachment 9E, and the BSCP Plan (Energy Systems 1992).

The basis of the guidelines for herbicides and PAHs was Attachment 7 of AESG SOP No. 7703, which was the 7/88 version of CLP pesticides/PCBs. From there, the guidelines were changed to reflect differences in method requirements, analytes, and, in the case of PAHs, instrumentation.

Radiochemical guidelines were not available beyond the general criteria given in the BSCP Plan (Energy Systems 1992). Initial attempts to develop guidelines by analyte were complicated by the diversity of possible preparation and analytical choices. A modular approach was developed based on procedural steps. For instance, alpha spectroscopy analysis might be a base module, but evaluation of the preparation of each analyte might be by different modules. Also, it was necessary to review the laboratory-modified methods and incorporate information from them, along with project objectives as stated in the BSCP Plan (Energy Systems 1992), to produce final laboratory- and project-customized guidelines.

\section{USABIITY EVALUATION OF DATA PACKAGES}

Concurrent with the development of validation guidelines, a given data package was reviewed for each analytical method to ensure that the guidelines were consistent with the information provided by the laboratory, that significant deficiencies in deliverables or analytical work were identified and, if possible, corrected. In this process, some significant issues possibly affecting data quality of entire sample delivery groups (SDGs) or perhaps all SDGs were identified, and resolutions and outstanding problems were documented. All resolutions of major problems were verified with concurrence of another reviewer, regulator, or analytical expert. This was especially important if resolution required data to be qualified and flagged appropriately.

\subsection{VALIDATION PROCEDURES}

The following practices were established to ensure that validations performed were complete and technically consistent.

All Form Is were photocopied onto paper marked with large, bold type "Validated Data" to distinguish annotated pages from original data package pages. Writing on the originals was

${ }^{3}$ All citations of Energy Systems 1992 refer to Martin Marietta Energy Systems, Inc. 1992. Project Plan for the Background Soil Characterization Project at the Oak Ridge Reservation, Oak Ridge, Tennessee, ES/ER/TM-26/R1, August. 
prohibited. Validation qualifiers were entered on the Validated Form Is. These pages were part of the validation submission.

Validation guidelines for the method were followed point-by-point. Entry of the reviewer's name on the validation reports attested to complete review according to the guidelines.

Data qualifications based on the guidelines were entered in the validation notes. All professional judgements were documented also in the validation notes, whether they resulted in qualification or not. Professional judgements were sometimes called for in the guidelines for issues too complex for checklist resolution; they were also needed when the laboratory did not follow protocols on which the guidelines were based. This was especially true for CLP work, and to a lesser degree for non-CLP, SW-846 work.

At the request of the analytical coordinator, the suitability of using existing data remark codes was assessed. It was Sound that the parameters and protocol revisions were sufficiently different and that the only BSCP results for which the existing data remark codes could be used were for metals. Therefore, data remark codes were used for metals only.

If a problem was noted during validation that would result in qualification of data, and it appeared that the problem could be resolved by further information from the laboratory, an action form was completed and submitted to the analytical services coordinator. Especially in the case of radiochemical validation, additional information made it possible to substantially reduce the amount of qualification.

Each validation package at this point consisted of a cover page or letter with identifying information (project, SDGs, laboratory, etc.), validated Form Is, and validator comments. Validator comments were written as general comments, and specific comments were in a designated format. Specific comments indicated the data points or data package pages pertaining to the concern.

\subsection{ADMINISTRATIVE AND CUSTODY PRACTICES}

Forms were developed to document removal and return of data packages from the MAD locked storage area. Progress in completion of the validation process was tracked by SDG and parameter. After the first few data packages of each type were reviewed, schedules for completion were determined based on the time allotted for the validation and the number of data packages.

\subsection{Organization and Responsibilities}

The organization of the validation team allowed for a tiered review of the data, as well as designation of administrative responsibility. In implementing this process, AESG obtained data packages from the MAD group once it was determined that all deliverables were present. The AESG organization for Phase I of the BSCP consisted of an overall coordinator and coordinators for each type of data (organics, inorganics, and radiochemical), primary and peer or support reviewers, and an oversight reviewer. Coordinator roles were administrative; reviewer roles were technical. For all roles, individuals had applicable background experience and education; if additional expertise was needed, technical experts from other groups were 
matrixed to AESG. For Phase II of the BSCP, AESG provided technical assistance and validation oversight primarily.

\subsubsection{Validation coordinator}

The validation coordinator is responsible for ensuring that the data validation is performed according to the BSCP Plan and requirements detailed in this document. The validation coordinator is responsible for assembling the validation team and preparing the project-specific criteria for the validation. The validation coordinator is also responsible for ensuring that validation is performed in a timely and cost effective manner. The validation coordinator is responsible for reporting any quality related issues to the analytical coordinator.

\subsubsection{Organic validation coordinator}

The organic validation coordinator is responsible for preparing the project-specific criteria for the organic parameters and ensuring that the developed criteria are in accordance with the BSCP Plan. The organic validation coordinator either assembles personnel to assist in the validation or performs the validation. The organic validation coordinator is also responsible for reporting any quality related issues to the validation ccordinator.

\subsubsection{Inorganic validation coordinator}

The inorganic validation coordinator is responsible for preparing the project-specific criteria for the inorganic parameters and ensuring that the developed criteria are in accordance with the BSCP Plan. The inorganic validation coordinator either assembles personnel to assist in the validation or performs the validation. The inorganic validation coordinator is also responsible for reporting any quality related issues to the validation coordinator.

\subsubsection{Radiological validation coordinator}

The radiological validation coordinator is responsible for preparing the project-specific criteria for the radiological parameters and ensuring that the developed criteria are in accordance with the BSCP Plan. The radiological validation coordinator either assembles personnel to assist in the validation or performs the validation. The radiological validation coordinator is also responsible for reporting any quality related issues to the validation coordinator.

\subsubsection{Organic validator}

The organic validator is responsible for performing the validation of the organic data. The organic validator is responsible for initiating action items found during the validation process. The organic validator is also responsible for reporting any quality related issues to the organic validation coordinator.

\subsubsection{Inorganic validator}

The inorganic validator is responsible for performing the validation of the inorganic data. The inorganic validator is responsible for initiating action items found during the validation 
process. The inorganic validator is also responsible for reporting any quality related issues to the inorganic validation coordinator.

\subsubsection{Radiological validator}

The radiological validator is responsible for performing the validation of radiological data. The radiological validator is responsible for initiating action items found during the validation process. The radiological validator is also responsible for reporting any quality related issues to the radiological validation coordinator.

\subsubsection{Data coordinator}

The data coordinator is responsible for the ORNL/MAD sample tracking program and for performing the CCS. The data coordinator is also responsible for reporting any quality related issues to the analytical coordinator.

\subsubsection{Validation oversight corsidinator}

The validation oversight coordinator is responsible for the final review of the data packages. The validation oversight coordinator reviews the data packages to ensure that the qualifications of the data are based on sound rationale and are reasonable. The validation oversight coordinator will report action items and concerns to the validation coordinator who will, in collaboration with the validation oversight coordinator, decide upon the final qualification of the data.

\subsection{Data Evaluation and Technical Review Process}

The data evaluation process (see Fig. 1) was initiated by the receipt of data from the contract laboratory. The data packages were already checked for completeness before the validators receive any data.

After it is determined that all deliverables have been provided, the primary validator performs the initial validation of the data with reference to the written validation guidelines and according to the procedure given in Sect. 1.3. General and specific comments along with validation qualifiers were prepared as draft data validation deliverables.

During the initial validation, problems may have been found. Such problems were communicated on Data Assessment Forms (Appendix A) to the project analytical coordinator. The analytical coordinator then prepares and sends Action Item Forms (Appendix A) to the appropriate laboratory. When the laboratory responds to the action items, the analytical coordinator provides the validator with the information.

The first draft and the data package next went to a peer reviewer. The peer reviewer checked the correctness of the flagged data and validation notes, rationale for professional judgements, and reasonableness of the findings in light of data quality objectives. The peer reviewers were sometimes also consulted as resources or for second opinions during the initial validation. The peer reviewer did not normally perform a complete second review of raw data but referred to raw data to resolve specific concerns. 
A predetermined $20 \%$ of the peer-reviewed data packages went to validation oversight for a final review. This review concentrated on rationale, consistency, and reasonableness. If any problems were found, the resolution was applied to the validation for that parameter in all data packages.

Assigned functions each had back-ups to ensure that the validation occurred in a timely manner. The layered review improved the reliability of the qualification process.

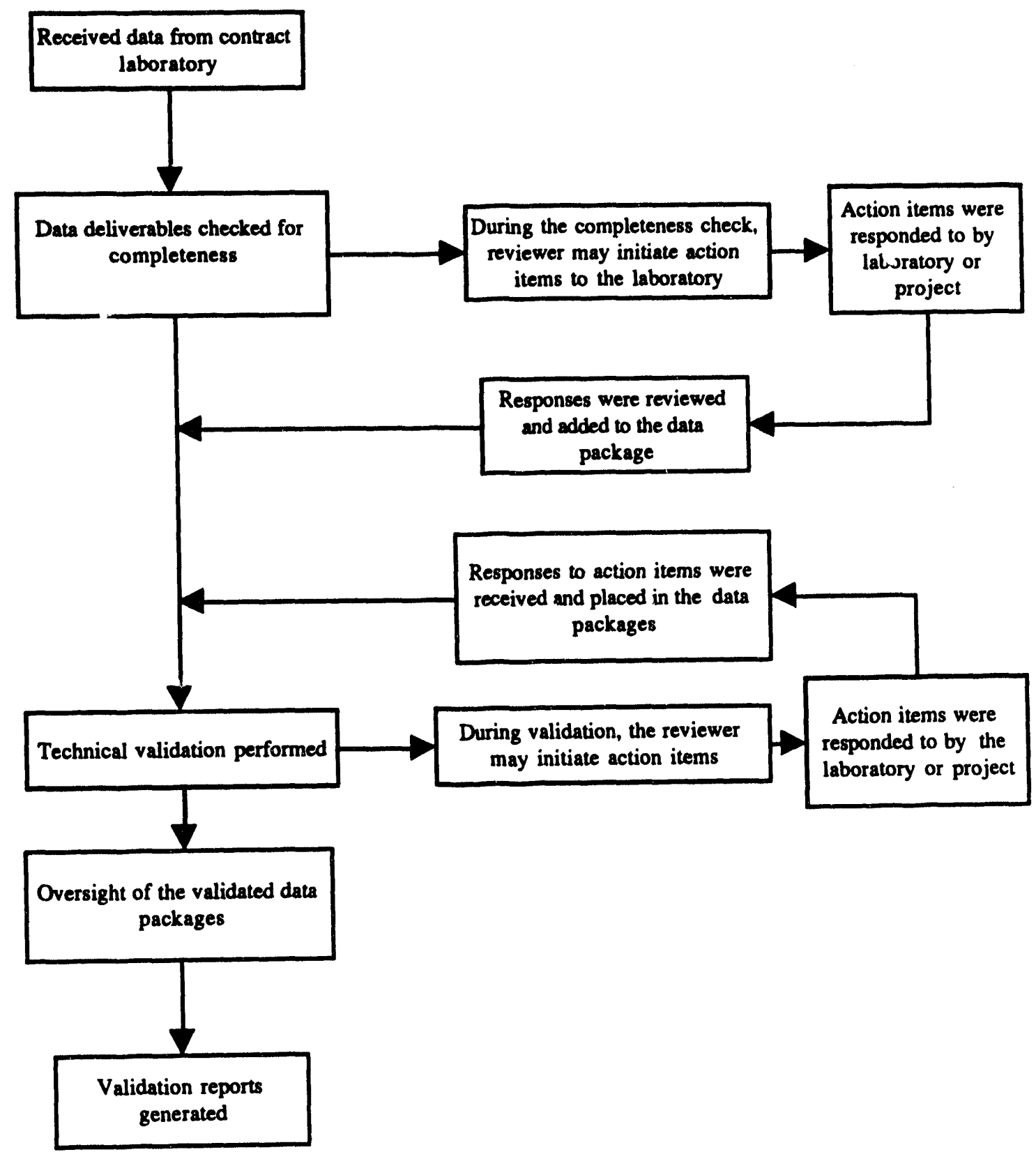

Fig. 1. Data Validation Process Flow Diagram. 


\section{DATA VALIDATION OF CHLORINATED PESTICIDES AND AROCLORS IN SOIL SAMPLES}

\subsection{METHOD SUMMARY}

Sonication extraction is required for soil/sediment samples. The method specifies Gel permeation chromatography (GPC) Florisil adsorption column cleanup, and sulfur cleanup techniques.

The chlorinated pesticides and Aroclors are determined by a two-column GC/electron capture detector (ECD) technique.

Sample extracts, standards, and blanks must be analyzed within an analytical sequence. GC/ECD analysis begins with an initial demonstration of instrument performance and the calibration of all pesticides and Aroclors. Initial calibration must be repeated whenever the calibration verification stipulated fails.

An instrument blank and Performance Evaluation Mixture (PFM) are analyzed no less than once every 12-h analytical sequence to monitor retention times (RTs), calibration factors, and column performance. If two consecutive unacceptable PEMs are run, all extracts run since the previous acceptable PEM must be reanalyzed.

Matrix spike (MS) and matrix spike duplicate (MSD) analyses must be prepared and analyzed at least once for each SDG.

Standards for all tentatively identified Aroclors must be run within $72 \mathrm{~h}$ of the sample analysis in which they were observed.

Quantitative analysis of pesticides/Aroclors must be accomplished by the external method. Three point calibration curves for single component analytes and the surrogates must be generated during the initial calibration. A linear response range must be demonstrated from the contract required quantitation limit (CRQL) to high point at least 16 times greater then the CRQL. Single point calibrations for multicomponent analytes are sufficient for quantitation.

Absolute RTs are used for the identification of pesticides/Aroclors. The absolute RT window is calculated during initial calibration from the mean RT of the standard, using the RT window specifications.

\subsection{LEVEL D DELIVERABLES}

The following information should be included in the data package. This information should be accompanied by all raw data, including chromatograms and control charts.

QC Summary Package:

Form II or surrogate recoveries 
Form III or MS/MSD recoveries

Form IV or Method Blank Summary

Sample Data:

Form I or Sample Analysis Results

Chromatograms and Data System Printouts

Standards Data:

Form VI or Initial Calibration Data

Form VII or Calibration Verification Data

Form VIII or Pesticide/Aroclor Analytical Sequence

Form IX or Pesticide Cleanup Data

Form $\mathrm{X}$ or Positively Identified Compounds

Raw QC Data:

Blank Data

MS Data

MSD Data

Other Information:

Laboratory control sample (LCS) Information

Internal Chain of Custody (COC) Forms

Preparation and Analysis Data

Additional Questions:

1. Are data sets paginated?

2. Does the Sample Data Summary Package contain the SDG narrative?

3. Are all required forms present and in the correct order for the Data Summary Package?

4. Are all required forms present and in the order listed in Exhibit B for the Sample Data Package?

5. Is the signed $\mathrm{COC}$ present?

\subsection{TECHNICAL HOLDING TIMES}

\section{A. Review Items}

Form I PEST (or equivalent), Sample Traffic Report, and/or COC, raw data, and SDG Narrative.

\section{B. Objective}

The objective is to ascertain the validity of results based on the holding time of the sample from time of collection to time of sample extraction and analysis. 


\section{Criteria}

Technical requirements for sample holding times have only been established for water matrices. The holding times for soils are currently under investigation. When the results are available they will be incorporated into the data evaluation process. Additionally, results of holding time studies will be incorporated into the data review criteria as the studies are conducted and approved. The maximum holding time, as stated in the current 40 CFR Part 136, for pesticides and Aroclors in cooled (@ $4^{\circ} \mathrm{C}$ ) samples in soil be extracted within $14 \mathrm{~d}$ of sample collection and analyzed within $40 \mathrm{~d}$ of extraction.

The contractual holding times, which differ from the technical holding times, state that extraction of soil/sediment samples are to be extracted within $10 \mathrm{~d}$ of validated time of sample receipt (VTSR). Also, contractually soil sample extracts must be analyzed within $40 \mathrm{~d}$ of sample extraction. However, the contractual delivery due date is either $14 \mathrm{~d}$ or $35 \mathrm{~d}$ after receipt in the laboratory of the last sample in the SDG, depending on the contract.

[For data generated through the Low Concentration SOW: The contractual holding times state that the extraction of all samples must be started within $5 \mathrm{~d}$ of the VTSR, and the extracts must be analyzed within $40 \mathrm{~d}$ of VTSR. However, the contractual delivery due date is $14 \mathrm{~d}$ after receipt in the laboratory of the last sample in the SDG.]

\section{Evaluation}

Technical holding times for sample extraction are established by comparing the sample collection date on the EPA Sample Traffic Report with the dates of extraction on Form I PEST (or equivalent) and the sample extraction sheets. To determine if the samples were analyzed within the holding time after extraction, compare the dates of extraction on the sample extraction sheets with the dates of analysis on Form I PEST (or equivalent).

Verify that the traffic report indicates that the samples were received intact and iced. If the samples were not iced or there were any problems with the samples upon receipt, then discrepancies in the sample condition could effect the data.

\section{E. Action}

1. If technical holding times are exceeded, qualify all detected compound results as estimated " $\mathrm{J"}$ and sample quantitation limits as estimated "UJ," and document in the data review narrative that holding times were exceeded.

2. If technical holding times are grossly exceeded, either on the first analysis or upon reanalysis the reviewer must use professional judgement to determine the reliability of the data and the effect of additional storage on the sample results. The reviewer may determine that detected compound results or the associated quantitation limits are approximates and should be qualified with "J" or "UJ," respectively. The reviewer may determine that nondetected target compound data are unusable, "R."

3. Due to limited information concerning holding times for soil samples, it is left to the discretion of the data reviewed to apply water holding time criteria to soil samples. Professional judgement is required to evaluate holding times for soil samples. 
4. Whenever possible the reviewer should comment on the effect of exceeding the holding time on the resulting data in the data review narrative.

5. When contractual and/or technical holding times are exceeded, this should be noted as an action item for the analytical coordinator.

6. The reviewer should also be aware of the scenario in which the laboratory has exceeded the technical holding times but met contractual holding times. In this case, the data reviewer should notify the analytical coordinator that shipment delays have occurred so that the field problem can be corrected. The reviewer may pass this information on to the laboratory's project manager but should explain that contractually the laboratory met the requirements.

\subsection{GC/ECD INSTRUMENT PERFORMANCE CHECK}

\section{A. Review Items}

Form VI PEST-4, Form VII PEST-1, Form VIII PEST (or equivalents), chromatograms, and data system printouts.

\section{B. Objective}

Performance checks on the GC/ECD system are performed to ensure adequate resolution and instrument sensitivity. These criteria are not sample specific. Conformance is determined using standard materials, therefore, these criteria should be met in all circumstances.

\section{Criteria}

\section{Resolution Check Mixture}

a. The Resolution Check Mixture must be analyzed at the beginning of every initial calibration sequence, on each GC column and instrument used for analysis. The Resolution Check Mixture contains the following pesticides and surrogates:

gamma-Chlordane
Endosulfan I
4,4'-DDE
Dieldrin
Endosulfan sulfate

\section{Endrin ketone} Methoxychlor Tetrachloro-m-sylene Decachlorobiphenyl

b. The depth of the valley between two adjacent peaks in the Resolution Check Mixture, must be greater than or equal to $60.0 \%$ of the height of the shorter peak.

\section{PEMs}

a. The PEM must be analyzed at the beginning (following the resolution check mixture) and at the end of the initial calibration sequence. The PEM must also be analyze at the beginning of every other $12-\mathrm{h}$ analytical period. The PEM contains the following pesticides and surrogates: 


$\begin{array}{ll}\text { gamma-BHC } & \text { Endrin } \\ \text { alpha -BHC } & \text { Methoxychlor } \\ \text { 4,4'-DDT } & \text { Tetrachloro-m-xylene } \\ \text { beta-BHC } & \text { Decachlorobiphenyl }\end{array}$

b. The resolution of adjacent peaks for the PEM injections in each calibration (initial and continuing) must be $100 \%$ for both GC columns.

c. The absolute RTs of each of the single component pesticides and surrogates in all PEM analyses must be within the specific RT windows centered around the mean RTs determined from the three-point initial calibration using the Individual Standard Mixtures. A list of the RT windows is included in Appendix B.

For example, for a given pesticide the mean RT is first determined from the initial calibration and found to be $\mathbf{1 2 . 6 9} \mathrm{min}$. The RT window for this pesticide is \pm 0.05 min. Therefore, the calculated RT window would range from 12.64 to $12.74 \mathrm{~min}$.

d. The relative percent difference (RPD) between the calculated amount and the true amount for each of the single component pesticides and surrogates in the PEM analyses must be less than or equal to $25.0 \%$.

e. The percent breakdown is the amount of decomposition that 4,4'-DDT and Endrin undergo when analyzed on the GC column. For Endrin, the percent breakdown is determined by the presence of Endrin aldehyde and/or Endrin ketone in the GC chromatogram. For 4,4'-DDT, the percent breakdown is determined from the presence of $4,4^{\prime}-\mathrm{DDD}$ and/or $4,4^{\prime}-\mathrm{DDE}$ in the GC chromatogram. The equations used to verify these calculations are provided in Appendix B.

i. The percent breakdown for both 4,4'-DDT and Endrin in each PEM must be less than or equal to $20.0 \%$ for both GC columns.

ii. The combined percent breakdown for 4,4'- DDT and Endrin in each PEM must be less than or equal to $30.0 \%$ for both GC columns.

\section{Evaluation}

1. Resolution Check Mixture

a. Verify from the Form VIII PEST (or equivalent) that the resolution check mixture was analyzed at the beginning of the initial calibration sequence on each GC column and instrument used for analysis.

b. Check the data and Form VI PEST-1 to verify that the resolution criteria between two adjacent peaks for the required compounds is less than or equal to $60 \%$ using equations found in Appendix B.

\section{PEM}

a. Verify from the Form VIII PEST (or equivalent) that the PEM was analyze at the proper frequency and position sequence. 
b. Check the PEM data from the initial and continuing calibrations to verify than the resolution between adjacent peaks is $100 \%$ on both GC columns.

c. Check the PEM data from the initial and continuing calibrations and Form VII PEST-1 solvent vent that the absolute RTs for the pesticides in each analysis are within the calculated RT windows based on the mean RT from the three-point initial calibration using equations and examples found in Appendix B.

d. Verify that the RPD between the calculated amount and the true amount for each of the pesticides and surrogates is less than or equal to $25.0 \%$.

e. Verify that the individual breakdowns for 4,4-DDT and Endrin are less than or equal to $20.0 \%$ and that the combined breakdown is less that or equal to $30.0 \%$.

\section{E. Action}

1. Resolution Check Mixture: If resolution criteria are not met, the quantitative results may not be accurate due to inadequate resolution. Detected target compounds that were not adequately resolved should be qualified with "J." Qualitative identifications may also be questionable if coelution exists. Nondetects with RTs in the region of coelution may not be valid depending on the extent of the problem. Professional judgement should be used to determine the need to qualify data as unusable, "R."

2. PEM RTs: RT windows are used in qualitative identification. If the RTs of the pesticides in the PEM do not fall within the RT windows, the associated sample results should be carefully evaluated. All samples injected after the last in-control standard are potentially effected, It should be noted for analytical coordinator action if the PEM RT criteria are grossly exceeded.

a. For the effected samples, check to see if the sample chromatograms contain any peaks that are close to the expected RT window of the pesticide of interest. If no peaks are present either within or close to the RT window of the deviant target pesticide compound then there is usually no effect on the data (i.e., nondetected values can be considered valid). Sample data that are potentially effected by standards not meeting the RT windows should be noted in the data review narrative.

b. If the effected sample chromatograms contain peaks which may be of concern (i.e., above the CRQL and either close to or within the expected RT window of the analyte of interest) then the reviewer should determine the extent of the effect on the data and may choose to qualify detected target compounds " $\mathrm{NJ}$ " and nondetected target compounds "UJ." In some cases, additional effort by the reviewer may be necessary to determine if sample peaks represent the compounds of interest, for example:

i. The reviewer can examine the data package for the presence of three or more standards containing the pesticide of interest that were run within a $72-\mathrm{h}$ period during which the sample was analyzed.

ii. If three or more such standards are present, the mean and standard deviation of the RT window can be re-evaluated. 
iii. If all standards and MSs fall within the revised window, the valid positive or negative sample results can be determined using this window.

iv. The narrative should identify the additional efforts iamin by the reviewer and the resultant impact on data usability. In addition, the support documentation should contain all calculations and comparisons generated by the reviewer.

c. If the reviewer cannot do anything with the data to resolve the problem of concern all positive results and quantitation limits should be qualified "R."

3. PEM Resolution: If PEM resolution criteria are not met then the quantitative results may not be accurate due to inadequate resolution. Positive sample results for compounds that were not adequately resolved should be qualified with "J." Qualitative identifications may be questionable if coelution exists. Nondetected target compounds that elute in the region of coelution may not be valid depending on the extent of the coelution problem. Professional judgement should be used to qualify data as unusable "R."

4. If RPD criteria are not met, qualify all associated positive results generated during the analytical sequence with " $\mathrm{J"}$ and the sample quantitation limits for nondetected target compounds with "UJ."

\section{4,4'-DDT/Endrin Breakdown:}

a. If $4,4^{\prime}-\mathrm{DDT}$ breakdown is greater than $20.0 \%$ :

i. Qualify all positive results for DDT with "J." If DDT was not detected, but DDD and DDE are detected, then qualify the quantitation limit for DDT as unusable, "R."

ii. Qualify positive results for DDD, and/or DDE as presumptively present at an approximated quantity "NJ."

b. If Endrin breakdown is greater than $20.0 \%$ :

i. Qualify ail positive results for Endrin with "J." If Endrin was not detected but Endrin aldehyde and Endrin ketone are detected, then qualify the quantitation limit for Endrin as unusable "R."

ii. Qualify positive results for Endrin ketone as presumptively present at an approximated quantity "NJ."

c. If The combined $4,4^{\prime}-$ DDT and Endrin breakdown is greater than $30.0 \%$ :

i. Qualify all positive results for DDT and Endrin with "J." If Endrin was not detected, but Endrin aldehyde and Endrin ketone are detected, then qualify the quantitation limit for Endrin as unusable, "R." If DDT was not detected, but DDD and DDE are detected, then qualify the quantitation limit for DDT as unusable, "R." 
ii. Qualify positive results for Endrin ketone as presumptively present at an approximated quantity, "NJ." Qualify positive results for DDD and/or DDE as presumptively present at an approximated quantity, "NJ."

6. Potential effects on the sample data resulting from the initial calibration problems should be noted in the data review narrative.

\subsection{INITAL CALIBRATION}

\section{A. Reviow Items}

Form VI PEST-1, 2, 3, and 4 (or equivalent), and Form VII PEST-1 (or equivalent), Form VIII PEST (or equivalent) chromatograms, and data system printouts.

\section{B. Objective}

Compliance requirements for satisfactory initial calibration are established to ensure that the instrument is capable of producing acceptable qualitative and quantitative data for pesticide and Aroclor target compounds. Initial calibration demonstrates that the instrument is capable of acceptable performance at the beginning of the analytical sequence and of producing a linear calibration curve.

\section{Criteria}

\section{Individual Standard Mixtures}

a. Individual Standard Mixtures A and B (containing all of the single component pesticides and surrogates) must be analyzed at low, midpoint, and high levels during the initial calibration on each GC column and instrument used for analysis.

b. The resolution between any two adjacent peaks in the midpoint concentration of Individual Standard Mixtures $A$ and $B$ in the initial calibration must be greater than or equal to $90.0 \%$ on both columns.

c. The absolute RTs of (Ach of the single component pesticides and surrogates are determined from three-point initial calibration using the Individual Standard Mixtures. A list of the RT windows is included in Appendix A and an example for calculating RT window is given in Sect. II.C.2.c and in Appendix B.

d. At least one chromatogram from each of the Individual Standard Mixtures A and B must yield peaks that give recorder deflections between 50 to $100 \%$ of full scale.

e. The concentrations of the low, medium, and high level standards containing all of the single component pesticides and surrogates (Individual Standard Mixtures A and B) must meet the following criteria on both GC columns.

The low point corresponds to the CRQL for each analyte. The midpoint concentration must be four times the low point. The high point must be at least 16 times the low point, but a higher concentration may be chosen. 
f. The percent relative standard deviation (\%RSD) of the calibration factors for each of the single component pesticides and surrogates in the initial calibration on both columns for Individual Standard Mixtures A and B must be less than or equal to $20.0 \%$, except as noted below. For the two surrogates, the \%RSD must be less than or equal to $30.0 \%$. Up to two single component target pesticides (other than the surrogates) per column may exceed the $20.0 \%$ limit but the \%RSD must be less than or equal to $30.0 \%$.

Note: Either peak area or peak height may be used to calculate the calibration factors that are, in turn, used to calculate \%RSD. However, the type of peak measurement used to calculate each calibration factor for a given compound must be consistent. For example, if peak area is used to calculate the low point calibration factor for Endrin, then the mid and high point calibration factors for, Endrin must also be calculated using peak area.

\section{Multicomponent Target Compounds}

a. The multicomponent target compounds (the 7 Aroclors and toxaphene) must each be analyzed separately at a single concentration level during the initial calibration sequence. The analysis of the multicomponent target compounds must also contain the pesticide surrogates.

b. For each multicomponent analyte, the RTs are determined for three to five peaks. A RT window of $\pm 0.07 \mathrm{~min}$. is used to determine RT windows for all multicomponent analyte peaks.

c. Calibration factor data must be determined for each peak selected from the multicomponent analytes.

\section{Evaluation}

1. Individual Standard Mixtures

a. Verify from the Form VIII PEST (or equivalent) that the Individual Standard Mixtures A and B were analyzed at the proper frequency on each GC column and instrument used for analysis. Check the raw data (chromatograms and data system printouts) for each standard to verify that each of the standards was analyzed at the required concentration levels.

b. Check the raw data and determine that the midpoint standard's concentration is four times the concentration of the low point standard's concentration and verify that resolution is greater than $90 \%$.

c. Check the Individual Standard Mixtures A and B data and Form VI PEST-1 (or equivalent) and review the calculated RT windows for calculation and transcription errors.

d. Check the Individual Standard Mixtures A and B data and Form VI PEST-2 (or equivalent) to verify that the \%RSD for the calibration factors in each of the single component pesticides and surrogates in the initial calibration analyses on both 
columns are in compliance with the criteria in Sect. III.C. Check and recalculate the calibration factors and \%RSD for one or more pesticides, verify that the recalculated values agree with the reported values. If errors are detected, more comprehensive recalculation should be performed.

\section{Multicomponent Target Compounds}

a. Verify from the Form VIII PEST (or equivalent) that each of the multicomponent target compounds were analyzed at the required frequency. Check the raw data for the standards to verify that the multicomponent analytes were analyzed at the required concentration.

b. Check the data for the multicomponent target compounds and Form VI PEST-3 (or equivalent) to verify that at least three peaks were used for calibration and that RT and calibration factor data are available for each peak.

\section{E. Action}

1. If the initial calibration sequence was not followed as required, then professional judgement must be used to evaluate the effect of the noncompliance on the sample data. If the requirements for the initial calibration sequence were not met, then this should be noted for analytical coordinator action. If the noncompliance has a potential effect on the data, then the data should be qualified according to the professional judgement of the reviewer and this should be noted in the data review narrative.

2. If resolution criteria are not met, then the quantitative results may not be accurate due to peak overlap and lack of adequate resolution. Positive sample results for compounds that were not adequately resolved should be qualified with "J." Qualitative identifications may be questionable if coelution exists. Nondetected target compounds that elute in the region of coelution may not be valid depending on the extent of the coelution problem. Professional judgement should be used to qualify data as unusable, "R."

3. If the \%RSD linearity criteria are not met for the compound(s) being quantified, qualify all associated positive quantitative results with " $\mathrm{J"}$ and the sample quantitation limits for nondetected target compounds with "UJ."

4. Potential effects on the sample data due to problems with calibration should be noted in the data review narrative. If the data reviewer has knowledge that the laboratory has repeatedly failed to comply with the requirements for frequency, linearity, RT, or resolution, the data reviewer should notify the analytical coordinator.

\subsection{CONTINUING CALIBRATION}

\section{A. Review Items}

Form VII PEST-1 and PEST-2 (or equivalent), Form VIII PEST (or equivalent), chromatograms, and data system printout. 


\section{B. Objective}

Compliance requirements for satisfactory instrument calibration are established to ensure that the instrument is capable of producing acceptable qualitative and quantitative data. Continuing calibration checks and documents satisfactory performance of the instrument over specific time period during sample analysis. To verify the calibration and evaluate instrument performance, continuing calibration is performed, consisting of the analyses of instrument blanks, the PEM, and the midpoint concentration of Individual Standard Mixtures A and B.

\section{Criteria}

1. An instrument blank and the PEM must bracket one end of a 12-h period during which samples are analyzed and a second instrument blank and the midpoint concentration of Individual Standard Mixtures A and B must bracket the other end of the 12-h period.

2. The resolution between any two adjacent peaks in the midpoint concentration of Individual Standard Mixtures A and B must be greater than or equal to $90.0 \%$.

3. The ab iute RT for each single component pesticide and surrogate in the midpoint concentration of Individual Standard Mixtures A and B must be within the RT windows determined from the initial calibration.

4. The RPD between the calculated amount and the true amount for each of the pesticide and surrogates in the midpoint concentration of the Individual Standard Mixture A and B must not exceed $25.0 \%$.

\section{Evaluation}

1. Check the Form VIII PEST (or equivalent) to verify that the instrument blanks, PEMs, and Individual Standard Mixtures were analyzed in the proper sequence and that no more than $12 \mathrm{~h}$ had elapsed between continuing calibration brackets in an ongoing analytical sequence.

2. Check the data for the midpoint concentration of Individual Standard Mixtures $A$ and $B$ to verify that the resolution between any two adjacent peaks is greater than or equal to $90.0 \%$.

3. Check the data for each of the single component pesticides and surrogates in the midpoint concentration of Individual Standard Mixtures A and B and Form VII PEST-2 (or equivalent) to verify that the absolute RTs are within the appropriate RT window.

4. Check the data from the midpoint concentration of Individual Standard Mixtures A and $B$ and Form VII PEST-2 (or equivalent) to verify that the RPD between the calculated amount and the true amount for each of the pesticides and surrogates is less than or equal to $25 \%$.

\section{E. Action}

1. If the continuing calibration sequence was not followed as required, then professional judgement must be used to evaluate the effect of the noncompliance on the sample data. 
If the requirements for the continuing calibration sequence were not met, then this should be noted for analytical coordinator action. If the noncompliance has a potential effect on the data, then the data should be qualified according to the professional judgement of the reviewer and this should be noted in the data review narrative.

2. If resolution criteria are not met, then the quantitative results may not be accurate due to inadequate resolution. Positive sample results for compounds that were not adequately resolved should be qualified "J." Qualitative identifications may be questionable if coelution exists. Nondetected target compounds that elute in the region of coelution may not be valid depending on the extent of the coelution problem. Professional judgement should be used to qualify data as unusable, "R."

3. RT windows are used in qualitative identification. If the standards do not fall within the RT windows, the associated sample results should be carefully evaluated. All samples injected after the last in-control standard are potentially effected.

a. For the effected samples, check to see if the sample chromatograms contain any peaks that are close to the expected RT window of the pesticide of interest. If no peaks are present either within or close to the RT window of the deviant large pesticide compound, then nondetected values can be considered valid. Sample data that are potentially effected by the standards not meeting the RT windows should be noted in the data review narrative. If the RT window criteria are grossly exceed, then this should be noted for analytical coordinator action.

b. If the effected sample chromatograms contain peaks that may be of concern, (i.e., above the CRQL and either close to or within the expected RT window of the pesticide of interest), then the reviewer should follow the guidelines provided in Sect. III.E. 3 to determine the extent of the effect on the data.

4. If the RPD is greater than $25 \%$ for the compound(s) being quantified, qualify all associated positive quantitative results with "J" and the sample quantitation limits for nondetects with "UJ."

5. Potential effects on the sample data due to problems with calibration should be noted in the data review narrative. If the data reviewer has knowledge that the laboratory has repeatedly failed to comply with the requirements for frequency, linearity, RT, resolution, or DDT/endrin breakdown, the data reviewer should notify the analytical coordinator.

\subsection{BLANKS}

\section{A. Review Items}

Form I PEST (or equivalent), Form IV PEST (or equivalent), chromatograms, and data system printouts.

\section{B. Objective}

The purpose of laboratory (or field) blank analyses is to determine the existence and magnitude of contamination problems resulting from laboratory (or field) activities. The 
criteria for evaluation of laboratory blanks apply to any blank associated with the samples (e.g., method blanks, instrument blanks, and sulfur cleanup blanks). If problems with any blank exist all associated data must be carefully evaluated to determine whether or not there is an inherent variability in the data, or if the problem is an isolated occurrence not effecting other data.

\section{Criteria}

1. No contaminants should be present in the blanks.

2. Frequency:

a. Method Blanks - A method blank analysis must be performed for each $\mathbf{2 0}$ samples of similar matrix in each SDG or whenever a sample extraction procedure is performed.

b. Instrument Blanks - An acceptable instrument blank must be run at least once every $12 \mathrm{~h}$ and immediately before the analysis of either the PEM or Individual Standard Mixtures $\mathrm{A}$ and $\mathrm{B}$, depending on the place in the analysis sequence.

c. Sulfur Cleanup Blanks - A sulfur cleanup blank must be analyzed whenever part of a set of samples extracted together requires sulfur cleanup. If the entire set of samples associated with a method blank requires sulfur cleanup then the method blank also serves the purpose of a sulfur blank, and no separate sulfur blank is required.

\section{Evaluation}

1. Review the results of all associated blanks, Form I PEST (or equivalent) and Form IV PEST (or equivalent), and raw data (chromatograms and data system printouts) to evaluate the presence of target compound list pesticides.

2. Verify that method blank analyses have been reported per SDG, per matrix, per concentration level, for each GC system used to analyze samples, and for each extraction batch.

3. Verify that the method blank analyses do not contain any target pesticide or Aroclor/toxaphene at greater than its CRQL.

4. For the surrogates in each method blank, verify that the observed RTs are within the appropriate RT windows calculated from the initial calibration.

5. Verify that the instrument blank analysis has been performed every $12 \mathrm{~h}$ as part of the continuing calibration and following a sample analysis that contains an analyte(s) at high concentration(s), and that the instrument blanks do not contain any target analytes above one-half the CRQL assuming that the material in the instrument resulted from the extraction of a $1 \mathrm{~L}$ water sample.

6. Verify that the sulfur cleanup blanks were analyzed at the required frequency, and that they do not contain any target compound above the CRQL assuming that the material 
in the instrument resulted from the extraction of a $1 \mathrm{~L}$ water sample. If a separate sulfur cleanup blank was prepared, one version of Form IV PEST (or equivalent) should be completed associating all the samples with the method blank, and a second version of Form IV PEST (or equivalent) should be completed listing only those samples associated with the separate sulfur cleanup blank.

7. Is all pertinent information supplied in the header? (Lab name, sample ID, matrix, extraction method, extraction and analysis dates, instrument IDs, column IDs)

8. Are sample, MS, and MSD associated with this method blank included on this form (CLP Form IV PEST)?

9. Are both quantitation and confirmation dates of analysis and GC information supplied?

10. Are GC columns identified by their stationary phases? Mixed phases cannot be entered as "mixed."

\section{E. Action}

If the appropriate blanks were not analyzed with the frequency described in Criteria 3, 4 , and 5 , then the data reviewer should use professional judgement to determine if the associated sample data should be qualified. The reviewer may need to obtain additional information from the laboratory. The situation should be brought to the attention of the analytical coordinator.

Action in the case of unsuitable blank results depends on the circumstances and the origin of the blank. Detected compound results should be reported unless the concentration of the compound In the sample is less than or equal to 5 times $(5 x)$ the amount in the blank. In instances where more than one blank is associated with a given sample, qualification should be based upon a comparison with the associated blank having the highest concentration of a contaminant. The results must not be corrected by subtracting the blank value.

Specific actions are as follows:

1. If a target pesticide or Aroclor/toxaphene is found in the blank but not found in the sample(s), no qualification is required. If the contaminant(s) is found at level(s) significantly greater than the CRQL then this should be noted in the data review narrative.

2. Any pesticide or Aroclor/toxaphene detected in the sample that was also detected in any associated blank is qualified if the sample concentration is less than five times (5x) the blank concentration. The quantitation limit may also be elevated. Typically, the sample CRQL is elevated to the concentration found in the sample. The reviewer should use professional judgement to determine if further elevation of the CRQL is required

The reviewer should note that analyte concentrations calculated for method blanks may not involve the same weights volumes or dilution factors as the associated samples. These factors must be taken into consideration when applying the " $5 \mathrm{x}$ " criteria, such that a comparison of the total amount of contamination is actually made. 
Additionally, there may be instances when little or no contamination was present in the associated blanks, but qualification of the sample was deemed necessary. Contamination introduced through dilution is one example. Although it is not always possible to determine, instances of this occurring can be detected when contaminants are found in the diluted sample result, but absent in the undiluted sample result. Since both results are not routinely reported, it may be impossible to verify this source of contamination. However, if the reviewer determines that the contamination is from a source other than the sample, he/she should qualify the data. In this case, the " $5 \mathrm{X}$ " rule does not apply; the sample value should be qualified as a nondetected target compound, "U."

3. If gross contamination exists (i.e., saturated peaks), all affected compounds in the associated samples should be qualified as unusable, "R," due to interference. This should be noted in the data review narrative if the contamination is suspected of having an effect on the sample results.

4. If inordinate amounts of other target pesticides or Aroclors/toxaphene are found at low levels in the blanks(s), it may be indicative of problems at the laboratory and should be noted in the data review narrative.

5. If an instrument blank was not analyzed following a sample analysis which contained an analyte(s) at high concentration(s), sample analysis results after the high concentration sample must be evaluated for carryover. Professional judgement should be used to determine if instrument cross-contamination has effected any positive compound identification(s), and if so, detected compound results should be qualified. If instrument cross-contamination is suggested, then this should be noted in the data review narrative.

The following are examples of applying the blank qualification guidelines. Certain circumstances may warrant deviations from these guidelines.

Example 1: Sample result is greater than the CRQL, but is less than the $5 x$ multiple of the blank result.

\begin{tabular}{ll} 
& $5 \mathrm{XX}$ \\
\cline { 2 - 2 } Blank Result & 1.0 \\
CRQL & 0.5 \\
Sample Result & 4.0 \\
Qualified Sample Result & $4.0 \mathrm{U}$
\end{tabular}

In this case, sample results less than 5.0 (or $5 \times 1.0$ ) would be qualified as nondetected target compounds.

Example 2: Sample result is less than the CRQL , and is also less than the 5x multiple of the blank result.

$\begin{array}{ll} & \frac{5 \mathrm{X}}{1.0} \\ \text { Blank Result } & 0.5 \\ \text { CRQL } & 0.4 \mathrm{~J} \\ \text { Sample Result } & 0.5 \mathrm{U}\end{array}$


Example 3: Sample result is greater than the 5x multiple of the blank result

$\begin{array}{lc} & \underline{5 X} \\ \text { Blank Result } & 1.0 \\ \text { CRQL } & 0.5 \\ \text { Sample Result } & 10.0 \\ \text { Qualified Sample Result } & 10.0\end{array}$

In this case, the sample result exceeded the adjusted blank result $(5 \times 1.0)$ and the sample result is not qualified.

\subsection{SURROGATE SPIKES}

\section{A. Review Items}

Form II PEST (or equivalent), Form VII PEST (or equivalent), chromatograms, and data system printouts.

\section{B. Objective}

Laboratory performance on individual samples is established by means of spiking samples before extraction and analysis to determine surrogate spike recoveries. All samples are spiked with surrogate compounds before sample extraction. The evaluation of the recovery results of these surrogate spikes is not necessarily straightforward. The sample itself may produce effects due to such factors as interferences and high concentrations of target and/or nontarget compounds. Since the effects of the sample matrix are frequently outside the control of the laboratory and may present relatively unique problems, the evaluation and review of data based on specific sample results is frequently subjective and demands analytical experience and professional judgement. Accordingly, this section consists primarily of guidelines, in some cases with several optional approaches suggested.

\section{Criteria}

1. Two surrogate spikes, tetrachloro-m-xylene and decachlorobiphenyl, are added to all samples, Individual Mixtures, PEMs, blanks, and MSs to measure their recovery in saniple and blank matrices.

2. The advisory limits for recovery of the surrogates TCMX and DCB are 60 to $150 \%$ for soil samples.

3. The RTs of both the surrogates in the PEM, Individual Standard Mixtures, and samples must be within the calculated RT windows. TCMX must be within \pm 0.05 min., and DCB must be within $\pm 0.10 \mathrm{~min}$. of the mean RT determined from the initial calibration.

D. Evaluation

1. Check raw data (e.g., chromatograms and data system printouts) to verify that the recoveries on Form II PEST (or equivalent) are accurate and within the advisory limits, 
and that the RTs on Form VIII PEST (or equivalent) are accurate and within the RT limits.

2. Check that the surrogate spike recoveries were calculated correctly and are free from transcription errors.

3. If surrogate spike recoveries are not within limits, check the raw data for possible interferences which may have effected surrogate recoveries.

4. If RT limits were not met, check the raw data for possible misidentification of GC peaks. Nonrecovery of surrogates may be due to shifts in RT.

5. If low surrogate recoveries are observed, the reviewer should investigate whether the low recoveries were a result of sample dilution.

6. In the special case of a blank analysis with surrogates out of specification, the reviewer must give special consideration to the validity of associated sample data. The basic concern is whether the blank problems represent an isolated problem with the blank alone, or whether there is a fundamental problem with the analytical process. For example, if one or more samples in the batch show acceptable surrogate recoveries. the reviewer may choose to consider the blank problem to be an isolated occurrence.

7. Are sample, blank, MS, and duplicate recoveries included on this form?

8. Are surrogate recoveries that are outside the QC limits flagged with an asterisk (*) under the "\#" symbol?

9. Were surrogates that were diluted out flagged with a "D" under the "\#" symbol?

E. Action

1. If surrogate spike recoveries are outsold of advisory limits, the following guidance is suggested. Professional judgement must be used in applying these criteria.

a. If low recoveries (i.e., between 10 to $60 \%$ ) are obtained, this may be an indication of a low bias in sample results and associated detected compound data should be qualified "J" and quantitation limits "UJ."

b. If high recoveries (i.e., greater than $150 \%$ ) are obtained, this may be an indication of a high bias due to coeluting interferences. Qualify associated detected compound data with "J"; nondetected analytes do not require qualification.

c. If either pesticide surrogate recovery is reported as between 0 to $10 \%$, the reviewer should examine the sample chromatogram to assess the qualitative validity of the analysis. If low surrogate recoveries are found to be due to sample dilution, then professional judgement should be used to determine if the resolute data should be qualified. If sample dilution is not a factor, then detected target compounds may be qualified "J" and nondetected target compound results should be qualified unusable, "R." 
d. If zero pesticide surrogate recovery is reported, the reviewer should examine the sample chromatogram to determine if the surrogate may be present but slightly outside its RT window. If this is the case in addition to assessing surrogate recovery for quantitative bias, the overriding consideration is to investigate the qualitative validity of the analysis. If the surrogate is not present qualify all nondetected target compounds as unusable, "R."

2. If surrogate RTs in PEMs, individual standards, and samples are outside of the RT limits, qualification of the data is left up to the professional judgement of the reviewer.

3. Extreme or repeated analytical problems with surrogate recoveries should the noted for analytical coordinator action.

4. Potential effects of the data resulting from surrogate recoveries not meeting the advisory limits should be noted in the data review narrative.

\subsection{MATRIX SPIKES/MATRXX SPIKE DUPLICATES}

\section{A. Review Items}

Form III PEST-1 and PEST-2, chromatograms, and data system printouts.

\section{B. Objective}

Data for MS and MSD are generated to determine long-term precision and accuracy of the analytical method on various matrices. These data alone cannot be used to evaluate the precision and accuracy of individual samples. However, when exercising professional judgement, MS/MSD data should be used in conjunction with information on other deficiencies.

\section{Criteria}

1. MS and MSD samples are analyzed at a frequency of al least one MS and MSD per 20 samples of each matrix.

2. MS recoveries should be within the advisory limits provided on Form III PEST-1 and PEST-2 and in Appendix A.

3. RPD between MS and MSD recoveries must be within the advisory limits provided on Form III PEST-1 and PEST-2 and in Appendix A.

D. Evaluation

1. Verify that MS and MSD samples were analyzed at the required frequency and that results are provided for each sample matrix.

2. Inspect results for the MS MSD Recovery on Form III PEST-1 and PEST-2 and verify that the results for recovery and RPD are within the advisory limits. 
3. Verify transcriptions from raw data and verify calculations.

4. Check that the MS recoveries and RPD were calculated correctly.

5. Compare \%RSD results of nonspiked compounds between the original result, MS, and MSD.

6. Are the correct concentrations of spiking compounds used?

7. Are percent recoveries and RPDs that are outside the QC limits flagged with an asterisk?

8. Check some percent recoveries (MS and MSD) and RPDs for calculation errors.

9. If 4 or more of the $12 \%$ recoveries are outside the $\mathrm{QC}$ limits, comment on this because the matrix should have been clean and extreme recovery values should not be attributed to it.

10. If both MS and MSD recoveries grossly exceeded QC limits for a spiking compound, comment on spiking solution.

E. Action

1. No action is taken on MS/MSD data alone. However, using informed professional judgement the data reviewer may use the MS and MSD results in conjunction with other QC criteria and determine the need for some qualification of the data.

2. The data reviewer should first try to determine to what extent the results of the MS/MSD affect the associated sample data. This determination should be made with regard to the MS/MSD sample itself, as well as specific analytes for all samples associated with the MS/MSD.

3. In those instances where it can be determined that the results of the MS/MSD affect only the sample spiked, then qualification should be limited to this sample alone. However, it may be determined through the MS/MSD results that a laboratory is having a systematic problem in the analysis of one or more analytes, which affects all associated samples. For example, if the recoveries for MS and MSD are consistently low for soil samples, this could be indicative of a systematic problem in the laboratory and recoveries should be examined in all associated samples.

4. The reviewer must use professional judgement to determine the need for qualification of positive results of nonspiked compounds.

Note: If a field blank was used for the MS/MSD, a statement to that effect must be included for the analytical coordinator. 


\subsection{LABORATORY CONTROL SAMPLES}

\section{A Review Items}

Form I (or equivalent), Form III (or equivalent), LCS chromatograms, and data system printouts.

\section{B. Objective}

Data for LCS are generated to provide information on the accuracy of the analytical method and the laboratory performance.

\section{Criteria}

1. LCSs are analyzed at a frequency of once per SDG.

2. The LCS contains the following pesticides: gamma-BHC, heptachlor epoxide, dieldrin, 4,4-DDE, endrin, endosulfan sulfate, and gamma-chlordane, in addition to the two required surrogates.

3. The percent recoveries for the LCS compounds must be within QC limits provided on Form III (or equivalent). The LCS must meet the recovery criteria for the sample data to be acceptable.

4. The criteria for surrogate recovery and target compound identification also apply.

D. Evaluation

1. Verify that LCS samples were analyzed at the required frequency.

2. Verify that the LCS recoveries reported in Form III (or equivalent) are within the advisory limits.

3. Check that the LCS recoveries were calculated correctly.

4. Verify transcriptions from raw data to Forms I and III (or equivalent).

\section{E. Action}

If the LCS criteria are not met, then the laboratory performance and method accuracy are in question. Professional judgement should be used to determine if the data should be qualified or rejected. The following guidance is suggested for qualifying sample data for which the associated LCS does not meet the required criteria.

1. Action on the LCS recovery should be based on both the number of compounds that are outside of the recovery criteria and the magnitude of the noncompliance

2. If the LCS recoveries criteria are not met, then the LCS results should be used to qualify sample data for the specific compounds that are included in the LCS solution. If the LCS recovery is out on the high end, detected target compounds may be qualified "J." 
If the LCS recovery is out on the low end, detected target compounds may be qualified "J" and nondetects may be qualified unusable, "R." Professional judgement should be used to qualify data for compounds other than those compounds that are included in the LCS. Professional judgement to qualify non-LCS compounds should take into account the compound class, compound recovery efficiency, analytical problems associated with each compound, and comparability in performance of the LCS compound to the non-LCS compound.

3. If more than half of the compounds in the LCS are not within required advisory recovery criteria, then all of the associated detected target compounds should be qualified " $\mathrm{J}$ " and associated nondetected compounds should be qualified unusable.

4. It should te noted for analytical coordinator action if a laboratory fails to analyze a LCS with each SDG, or if the reviewer has knowledge that a laboratory consistently fails to generate acceptable LCS recoveries.

\subsection{PESTICIDE CLEANUP CHECKS}

\section{A. Review Items}

Form IX PEST-1 and -2 (or equivalent), chromatograms, and data system printouts.

\section{B. Objective}

Pesticide cleanup procedures are utilized to remove matrix interferences from sample extracts before analysis. The use of the Florisil cartridge cleanup procedure significantly reduces matrix interferences caused by polar compounds. GPC is used to remove high molecular weight contaminants that can interfere with the analysis of target analytes. Pesticide cleanup procedures are checked by spiking the cleanup columns and cartridges, and verifying the recovery of pesticides, through the cleanup procedure.

\section{Criteria}

\section{Forisil Cartridge Cleanup}

a. Florisil cartridge must be used for the cleanup of all sample extracts.

b. Every lot number of Florisil cartridges used for sample cleanup must be checked by spiking with 2,4,5-trichlorophenol and the midpoint concentration of Individual Standard Mixture A.

c. The lot of Florisil cartridges is acceptable if the recoveries for all of the pesticides and surrogates in Individual Standard Mixture $A$ are within 80 to $120 \%$, if the recovery of 2,4,5-trichlorophenol is less than $5 \%$, and if no peaks interfering with the target analytes are detected. 


\section{GPC}

a. GPC is used for the cleanup of all soil sample extracts.

b. At least once every $7 \mathrm{~d}$, the calibration of the GPC unit must be checked by spiking with two check mixtures: the matrix spiking solution and a mixture of $0.2 \mathrm{ug} / \mathrm{mL}$ Aroclors 1016 and 1260 . The matrix spiking solution compounds for the GPC Check are listed in Appendix B.

c. The GPC calibration is acceptable if the recovery of the pesticides in the matrix spiking solution are within 80 to $110 \%$, and the Aroclor patterns should match those generated for previously run standards.

d. A GPC blank must be analyzed after each GPC calibration and is acceptable if the blank does not exceed one-half the CRQL for any target analytes.

D. Evaluation

1. Florisil Cartridge (Check)

Check the data from the Florisil cartridge solution analyses and the Form IX PEST-1 (or equivalent) and recalculate some of the percent recoveries to verify that the percent recoveries of the pesticides and surrogates in Individual Standard Mixture A are within 80 to $120 \%$, the recovery of 2,4,5-trichlorophenol is less than $5 \%$, and no interfering peaks are present. Compare the raw data to the reported results and verify that no calculation or transcription errors have occurred.

2. GPC

Check the data from the GPC calibration check analyses and the Form IX PEST-2 and recalculate some of the percent recoveries to verify that the percent recoveries of the pesticides in the MS solution are within 80 to $110 \%$ and that the Aroclor patterns are similar to those of previous standards. Check to make sure that no transcription errors have occurred.

\section{E. Action}

1. If Florisil Cartridge Check criteria are not met, the raw data should be examined for the presence of polar interferences and professional judgement should be used in qualifying the data. If a laboratory chooses to analyze samples under an unacceptable Florisil Cartridge Check, then the analytical coordlinator should be notified.

2. If Tel Permeation Criteria are not met, the raw data should be examined for the presence of high molecular weight contaminants and professional judgement should be used in qualifying the data. If a laboratory chooses to analyze samples under unacceptable Gel Permeation Criteria, then the analytical coordinator should be notified.

3. If zero recovery was obtained for the pesticide compounds and surrogates during either check, then the nondetected target compounds may be suspect and the data may be qualified unusable "R." 
4. If high recoveries (i.e., greater than 120\%) were obtained for the pesticides and surrogates during either check, use professional judgement to qualify detected target compounds. Nondetected target compounds do not require qualification.

5. Potential effects on the sample data resulting from the pesticide cleanup analyses not yielding acceptable results should be noted in the data review narrative.

\subsection{TARGET COMPOUND IDENTIFICATION}

\section{A. Review Items}

Form I PEST (or equivalent), Form X PEST-1 and PEST-2 (or equivalent), chromatograms, and data system printouts.

\section{B. Objective}

Qualitative criteria for compound identification have been established to minimize the number of false positive (reporting a compound present when it is not) and false negatives (not reporting a compound that is present).

\section{Criteria}

1. The RTs of both of the surrogates, MS, and reported compounds in each sample must be within the calculated RT windows on both columns TCMX must be within +0.05 min. of the mean RT determined from the initial calibration and DCB must be within 0.10 min. of the mean RT.

2. GC/MS confirmation is required if the concentration of a compound exceeds $10 \mathrm{ng} / \mu \mathrm{L}$ in the final sample extract pesticides that are confirmed by GC/MS should be identified with a " $\mathrm{C}$ " in the $\mathrm{Q}$ column on Form I PEST (or equivalent).

3. When no analytes are identified in a sample the chromatograms from the analyses of the sample extract must use the same scaling factor as was used for the low point standard of the initial calibration associated with those analyses.

4. Chromatograms must display single component pesticides detected and the largest peak of any multicomponent analyte detected in the sample at less than full scale.

5. If an extract must be diluted, chromatograms must display single component pesticides between 10 to $100 \%$ of full scale and multicomponent analytes between 25 to $100 \%$ of full scale.

6. For any sample, the baseline of the chromatogram must rerun to below $50 \%$ of full scale before the elution time of alpha-BHC and also return to below $25 \%$ of full scale after the elution time of alpha-BHC and before the elution time of decachlorobiphenyl.

7. If a chromatogram is replotted electronically to meet these requirements, the scaling factor used must be displayed on the chromatogram, and both the initial chromatogram and the replotted chromatogram must be submitted in the data package. 


\section{Evaluation}

1. Review Form I PEST (or equivalent), the associated raw data (chromatograms and data system printouts), and Form X PEST-1 and PEST-2 (or equivalent). Confirm reported detected analytes by comparing the sample chromatograms to the tabulated results and verifying peak measurements and RTs. Confirm reported nondetected analytes by a review of the sample chromatograms. Check the associated blank data for potential interferences (to evaluate sample data for false positives) and check the calibration data for adequate RT windows (to evaluate sample data for false positives and false negatives).

2. For multicomponent target compounds (toxaphene and Aroclors), the RTs and relative peak height ratios of major component peaks should be compared against the appropriate standard chromatograms.

3. Verify that GC/MS confirmation was performed for pesticide concentrations in the final sample extract which exceeded $10 \mathrm{ng} / \mu \mathrm{L}$.

4. Is all pertinent information supplied in the header? (Lab name, sample \#, matrix, sample ID, volume, extraction and analysis dates, date of receipt, dilution factor, GPC cleanup)

5. Does "Date Received" match the verified date of sample receipt on traffic report?

6. Were contractual holding times met for extraction and analysis for both AESG and CLP SOW requirements?

AESG requirement: Extraction must begin within $7 \mathrm{~d}$ of sample collection, and analysis within $\mathbf{4 0} \mathrm{d}$ of sample extraction. (Contractual)

Continuous liquid/liquid extractions must begin within $5 \mathrm{~d}$ of VTSR as noted in the traffic report. Separatory extractions must be completed within $10 \mathrm{~d}$ VTSR.

7. Values less than CRQL are to be reported and flagged as estimated, "J."

8. Are the chromatograms (quantitation and confirmation) that are applicable to information on Form I provided?

9. Second column confirmation is required for $3 / 90$ even when the quantitation analysis shows no target compounds.

10. Are the chromatograms labeled with the following?

Sample identification

Volume injected in microliters (ul)

Date and time of injection

GC column stationary phase

GC instrument identification 
11. Are positively identified compounds labeled with names of the compounds, either directly out from the peak, or on the printout of RT information?

12. If GPC cleanup was performed (see Form I), are ultraviolet (UV) traces provided in the data package?

Note: GPC is not required for water samples.

13. If not confirmed by GC/MS, samples, blanks, spikes and duplicates must be analyzed on two different GC columns.

14. Check for resolution problems between the following pairs of compounds.

DB-608 or equivalent column:

DDE and dieldrin, methoxychlor and endrin ketone, and endosulfan I and gamma-chlordane.

DB-1701 or equivalent column:

Endosulfan I and gamma-chlordane and methoxychlor and endosulfan sulfate.

15. Examine chromatograms for compliancy peaks and multicomponent fingerprints.

16. Autosample injection volumes must be at least $1 \mathrm{ul}$; manual injection volumes must be at least 2 ul. The same injection volume must be used for all samples standards, spikes, and blanks.

17. Calculate concentrations from information supplied on data printout and against manual worksheets provided for at least two compounds for both the quantitation and confirmation columns.

18. Check the calibration factors used.

\section{E. Action}

1. If the qualitative criteria for both columns were not met, all target compounds that are reported detected should be considered nondetected. The reviewer may need to use the qualifiers that are specific to pesticides. The reviewer should use professional judgement to assign an appropriate quantitation limit using the following guidance:

a. If the misidentified peak was sufficiently outside the target pesticide RT window, then the reported values may be a false positive and should be replaced with the sample CRQL value.

b. If the misidentified peak poses an interference with potential detection of a target peak, then the reported value should be considered and qualified as unusable, "R."

2. If the data reviewer identifies a peak in both GC column analyses that falls within the appropriate RT windows, but was reported as a nondetect, then the compound may be 
a false negative. Professional judgement should be used to decide if the compound should be included. All conclusions made regarding target compound identification should be included in the data review narrative.

3. If multicomponent target compounds exhibit marginal pattern-matching quality, professional judgement should be used to establish whether the differences are due to environmental "weathering" (i.e., degradation of the earlier eluting peaks relative to the later eluting peaks). If the presence of a multicomponent pesticide is strongly suggested, results should be qualified as presumptively present $(\mathrm{N})$.

If an observed pattern closely matches more than one Aroclor, professional judgement should be used to decide whether the neighboring Aroclor is a better match, or if multiple Aroclors are present.

4. If GC/MS confirmation was required but not performed, the reviewer should report this for analytical coordinator action.

\subsection{COMPOUND QUANTITATION AND REPORTED CONTRACT REQUIRED QUANTITATION LIMITS}

\section{A. Review Items}

Form I PEST (or equivalent), Form X PEST-1 and PEST-2 (or equivalent), sample preparation log sheets, chromatograms, case narrative, and data system printouts.

\section{B. Objective}

The objective is to ensure that the reported quantitative results and CRQLs are accurate.

\section{Criteria}

Compound quantitation, as well as the adjustment of the CRQL, must be calculated according to the equations provided in Appendix A (also found in Sect. D/PEST of the Statement of Work).

\section{Evaluation}

1. Raw data should be examined to verify the correct calculation of all sample results reported by the laboratory. Data system printouts, chromatograms, and sample preparation log sheets should be compared to the reported positive sample results and quantitation limits. Verify that the sample values are reported correctly.

2. Verify that the CRQLs have been adjusted to reflect all sample dilutions, concentrations, splits, clean-up activities, and dry weight factors that are not accounted for by the method. 


\section{E. Action}

1. Quantitation limits effected by large, off-scale peaks should be qualified as unusable, "R." If the interference is on-scale, the reviewer can provide an approximated quantitation limit "UJ" for each effected compound.

Note: Single-peak pesticide results are checked for rough agreement between quantitative results obtained on the two GC columns. The potential for coelution should be considered and the reviewer should use professional judgement to decide whether a much larger concentration obtained on one column versus the other indicates the presence of an interfering compound. If an interfering compound is indicated, professional judgement must be used to determine how best to report, and if necessary, qualify the data. Contractually the lower of the two values is reported.

2. If there are any discrepancies found, the laboratory may be contacted by the designated representative to obtain additional information that could resolve any differences. If a discrepancy remains unresolved, the reviewer must decide which value is the best value. Under these circumstances, the reviewer may determine if qualification of the data is warranted. A description of the reasons for data qualification and the qualification that is applied to the data should be documented in the data review narrative.

\subsection{SYSTEM PERFORMANCE}

\section{A. Review Items}

Form III, and chromatograms

\section{B. Objective}

During the following Instrument Performance QC checks (e.g., blanks and calibration), changes may occur in the system that degrade the quality of the data.

While this degradation would not be directly shown by $\mathrm{QC}$ checks until the next required series of analytical QC runs, a thorough review of the ongoing data acquisition can yield indicators of instrument performance.

\section{Criteria}

There are no specific criteria for system performance. Professional judgement should be used to assess the system performance.

\section{Evaluation}

Abrupt, discrete shifts in the chromatogram baseline may indicate a change in the instrument's sensitivity or the zero setting. A baseline shift could indicate a decrease in sensitivity in the instrument or an increase in the instrument zero, possibly causing target compounds at or near the detection limit to be nondetects. A baseline "rise" could indicate problems such as a change in the instrument zero, a leak, or degradation of the column. 
Poor chromatographic performance affects both qualitative and quantitative results. Indications of substandard performance include the following:

high background levels, excessive baseline rise at elevated temperature, extraneous peaks, and peak tailing or peak splitting that may result in inaccurate quantitation.

\section{E Action}

Professional judgement must be used to qualify the data if it is determined that system performance has degraded during sample analyses. Any degradation of system performance which significantly affected the data should be documented for action.

\subsection{OVERALL ASSESSMENT}

\section{A Review Items}

Entire data package, data review results, (if available) Quality Assurance Project Plan (QAPjP), Sampling and Analysis Plan (SAP), and field QC.

\section{B. Objective}

The overall assessment of a data package is a brief narrative in which the data reviewer expresses concerns and comments on the quality and, if possible, the useability of the data.

A secondary stage of validation will occur once the initial validation for a discrete sampling event has been completed, and the sample result database has been generated for each parameter analyzed for. Individual field blanks will be associated with the corresponding samples in the database and data qualifiers assigned using the criteria listed below.

\section{Criteria}

Assess the overall quality of the data.

Review all available materials to assess the overall quality of the data, keeping in mind the additive nature of analytical problems.

Soil duplicates/splits are collected and homogenized before being split. Field duplicates for water samples will be collected simultaneously. Field duplicates are used to assess the representativeness of the sampling procedure. Field duplicates will be examined for precision. RPD will be calculated using the following formula:

$$
R P D=[|S-D| /|S+D / 2|] * 100
$$

Where: $\mathbf{S}=$ First Sample Value(Original), and

$$
\text { D = Second Sample Value (Duplicate). }
$$




\section{Evaluation}

1. Evaluate any technical problems which have not been previously addressed.

2. Review all available materials to assess the overall quality of the data, keeping in mind the additive nature of analytical problems.

3. If appropriate information is available, the reviewer may assess the useability of the data to assist the data user in avoiding inappropriate use of the data. Review all available information, including the QAPjP (specifically the Data Quality Objectives), SAP, and communication with data user that concerns the intended use and desired quality, of the data.

4. Blind field duplicates will be examined for precision by calculating the RPD as above; however, sample data will not be flagged for duplicate results falling outside of the QC limits listed below. As with the field blanks, field duplicate results will be evaluated using the sample result database, rather than at the primary data validation stage.

5. A control limit of $\pm 70 \%$ for soil for the RPD shall be used for sample values greater than 5X the CRQL.

6. A control limit of $\pm 4 X$ the $C R Q L$ for soil shall be used for sample values less than $5 X$ the CRQL.

\section{E. Action}

1. Use professional judgement to determine if there is any need to qualify data which were not qualified based on the QC criteria previously discussed.

2. Write a brief narrative to give the user an indication of the analytical limitations of the data. Any inconsistency of that data with the SDG narrative should be noted for analytical coordinator action. If sufficient information on the intended use and required quality of the data are a available, the reviewer should include his/her assessment of the useability of the data within the given context.

3. No action is taken on the basis of blind field duplicate results. Results which fall outside the above criteria will be noted in the data validation summary. Using informed professional judgement, the data validator may use these results in conjunction with other QC criteria to determine the need for further qualification of the data. 


\section{DATA VALIDATION OF CHLORINATED HERBICIDES IN SOIL SAMPLES}

\subsection{METHOD SUMMARY}

Chlorinated herbicide concentrations are determined according to EPA Method 8150, through a process involving sample extraction, esterification, and gas chromatography. Spiked samples are used to verify the applicability of the chosen extraction technique to each new sample type. The esters are hydrolyzed with potassium hydroxide, and extraneous organic material is removed by a solvent wash. After acidification, the acids are extracted with solvent and converted to their methyl esters using diazomethane as the derivatizing agent. After excess reagent is removed, the esters are determined by gas chromatography employing an $\mathrm{ECD}$, microcoulometric detector, or electrolytic conductivity detector. Second column confirmation will he performed when there are compounds identified above the reporting limits. The results are reported as the acid equivalents.

\subsection{LEVEIL D DELIVERABLES:}

The following information should be included in the data package. This information should be accompanied by all raw data, including chromatograms and control charts.

QC Summary Package:

Form II or surrogate recoveries

Form III or MS/MSD recoveries

Form IV or Method Blank Summary

Form III or LCS

Internal COC Forms

Sample Data:

Form I or Sample Analysis Results

Standards Data:

Form VI or Initial Calibration Data

Form VII or Calibration Verification Data

Form VIII or Herbicide Analytical Sequence

Form X for Positively Identified Compounds

Raw QC Data:

Blank Data

MS Data

MSD Data 


\subsection{TECHNICAL HOLDWNG TMMES}

\section{A. Review Items}

Form I and chain-of-custody (COC) form.

\section{B. Objective}

The objective is to ascertain the validity of results based on the holding time of the sample from time of collection to time of sample extraction and analysis.

\section{Criteria}

Soil samples should be collected in amber glass containers and tightly sealed with a Teflon-lined cap. Samples should be preserved by cooling to a temperature of $4^{\circ} \mathrm{C} \pm 2^{\circ} \mathrm{C}$. All samples must be extracted within $14 \mathrm{~d}$ of collection, analyzed within $40 \mathrm{~d}$ of extraction, and must be stored at $4^{\circ} \mathrm{C} \pm 2^{\circ} \mathrm{C}$, away from light.

\section{Evaluation}

Technical holding times are established by comparing the sampling date and time on the COC form with date and time of extraction on Form I. To determine if the samples were analyzed within the holding time after extraction, compare the date and time on the sample extraction sheet and those on Form I.

\section{E. Action}

If technical holding times are exceeded, qualify all positive results as estimated "J" and samples at the quantitation limit as estimated "UJ." Document in the data review narrative that holding times were exceeded. If holding times are grossly exceeded (greater than two times the defined holding time), the reviewer must use professional judgement to determine the reliability of the data and the effects of additional storage on the sample results. The reviewer may determine that nondetect data are unusable "R."

If deficiencies in the COC documentation are noted, they should be reported in the DVR as previously outlined. Note that a problem could arise if any of the affected data are to be used in litigation.

Any noted deficiencies which do (or could) affect the data on a chemical basis can be considered "major" deficiencies. As an example, general requirement deficiencies which prevent the reviewer from determining the date of sample collection, date of extraction, or date of analysis, and preclude determination of technical holding time, would be considered major. The inability of a reviewer to determine the date or time of sample analysis due to general requirements deficiencies will prevent the linking of the sample with a specific calibration, method blank, or other QC measures. Upon discovery of a "major" general requirements deficiency, if time permits, the data package review should be discontinued, and the laboratory should be immediately contacted. Data review should not continue until the "major" deficiency has been resolved by the laboratory. 


\subsection{INSTRUMENT CALIBRATION AND CALIBRATION VERIFICATION}

\section{A. Reviow Items}

Form VI, Form VII, analytical sequence and RT windows, chromatograms, and quantitation reports.

\section{B. Objective}

Instrument performance and calibration verification criteria are established to ensure that adequate chromatographic resolution and instrument sensitivity are achieved by the chromatographic system. Initial calibration consists of five standards.

Initial calibration verification (ICV) ensures that the instrument is capable of producing accurate analytical results at the start of the sample measurement run. Continuing calibration verification (CCV) ensures that the initial calibration remains valid throughout the sample measurement run. These criteria are not sample-specific. Conformance is determined using standard materials; therefore, these criteria should be met in all circumstances.

\section{Criteria}

RT windows are used in qualitative identification. Three injections are made of all single component standard mixtures and multiresponse products throughout the course of a $72-\mathrm{h}$ period. RT windows for each compound of interest are set at \pm 0.08 of the compoundspecific mean RT; however, the experience of the analyst is weighed heavily in the interpretation of chromatograms. Daily adjustment of RT windows is based on daily RT for each compound in the standard. If the standards do not fall within the RT windows, the associated sample results should be carefully evaluated. All samples injected after the last incontrol standard are potentially affected.

Appropriate standard concentrations must be used for the initial calibration so that the project required quantitation limits for target compounds listed in Table 6.7 of the Project Plan for the Background Soil Characterization Project at the Oak Ridge Reservation, Oak Ridge, Tennessee (Energy Systems 1992), are bracketed by the initial calibration linear range.

If all standards and MSs fall within the revised window, the valid positive or negative sample results can be determined using this window.

The narrative should identify the additional efforts taken by the reviewer and the resultant impact on the data usability. In addition, the support documentation should contain all calculations and comparisons generated by the reviewer.

The laboratory must use the external calibration procedure for quantitation.

If calibration factors are used for sample quantitation:

For initial calibration, all \%RSD must be less than or equal to $20 \%$.

Check the raw data to verify the reported \%RSD values are correct, using the following formula: 
Calculation of \%RSD: $\quad \%$ RSD $=\frac{\text { Standard Deviation }}{\text { Mean }} * 100$

For continuing calibration, all percent differences (\%D) must be less than $15 \%$. formula.

Check the raw data to verify the reported $\% \mathrm{D}$ values are correct, using the following

$$
\begin{aligned}
\% D & =[(\mathrm{R} 1-\mathrm{R} 2) / \mathrm{R} 1] * 100 \\
\text { Where: } & \mathbf{R} 1=\text { Calibration factor from first analysis } \\
\mathbf{R} 2 & =\text { Calibration factor from succeeding analysis }
\end{aligned}
$$

If the \%RSD of the calibration factor is less than $20 \%$ over the working range, linearity through the origin can be assumed, and the average calibration factor can be used in place of a calibration curve.

$$
\text { Calibration factor }=\frac{\text { Total area of peak }}{\text { Mass injected (ng) }}
$$

If linear regreasion is ued for sample quantitation:

Verification of the calibration curve is required, and the correlation coefficient $\left(r^{2}\right)$ must be greater than or equal to 0.990 .

In the primary analysis, all standards are analyzed at the beginning of the $72-\mathrm{h}$ period, followed by the proper sample/standard sequence. Confirmation analysis requires a midlevel standard at the beginning of the $72-\mathrm{h}$ period. The midlevel standard must be repeated after every 10 samples.

Verify that all standards were analyzed in the daily analytical run.

\section{Evaluation}

Review appropriate records to ensure that instrument performance criteria were met, and the proper number of calibrations were performed in the proper time frame.

\section{E. Action}

If the proper type and number of standards have not been analyzed, data may be affected. The data reviewer must use professional judgement to determine severity of the effect and qualify the data accordingly.

If the criteria for initial calibration are not met, use professional judgement when necessary to evaluate data reliability, otherwise qualify all associated quantitative results as estimated "J." If the criteria for continuing calibration are not met in the primary analysis, qualify all associated quantitative results as estimated "J." If the criteria for continuing calibration are not met in the confirmation analysis, use professional judgement as to data reliability. 
If the affected sample chromatograms contain peaks which may be of concern [i.e., above the contract required quantitation limit (CRQL) and either close to or within the expected RT window of the herbicide of interest], and if no additional effort is warranted by the reviewer, qualify all positive results and quantitation limits as unusable "R." The narrative should emphasize the possibility of either false negatives or false positives, as appropriate.

For the affected samples, check to see if chromatograms contain any peaks within an expanded window surrounding the expected RT window of the herbicide of interest. If no peaks are present either within or close to the RT window of the deviant target herbicide, there is usually no effect on the data. Nondetected values can be considered valid.

If the affected sample chromatograms contain peaks which may be of concern (i.e., above the CRQL and either close to or within the expected RT window of the herbicide of interest), then in some cases, additional effort is warranted by the reviewer (e.g., if the data are needed on a priority basis and if the peak(s) present might represent a level of concern for that particular herbicide). In these situations, the reviewer may undertake the following additional efforts to determine a usable RT window for the affected samples.

The reviewer should examine the data package for the presence of three or more standards containing the herbicide of interest that were run within a daily analytical sequence during which the sample was analyzed.

If three or more such standards are present, the mean and standard deviation of the RT window can be re-evaluated.

\subsection{BLANKS}

\section{A. Review Items}

Forms I and IV and raw data (chromatograms, reconstructed ion chromatograms (RIC), quantitation reports, and data system printouts).

\section{B. Objective}

The objective of blank analyses is to determine the existence and magnitude of contamination problems resulting from laboratory performance. The criteria for evaluation of blanks apply to any blank associated with samples (e.g., method blanks). If problems with any blank exist, all associated data must be carefully evaluated to determine whether or not there is inherent variability in the data, or if the problem is an isolated occurrence not affecting other data.

\section{Criteria}

No contaminants should be present in blanks. Blanks should be carried through the entire sample preparation and analysis process. Blanks will be analyzed for every sample set, for each matrix type, or once in every batch of samples (up to 20 samples), whichever is more frequent. 


\section{Evaluation}

Review the results of all associated blanks, Form Is, and raw data, and verify that the results were accurately reported. Ensure that the proper number of blanks was analyzed, at the proper frequency.

Verify that the all blank analyses contain less than the CRQL of the analyte or interfering peak.

Verify that method blank analyses have been reported per matrix, per concentration level, to analyze samples, and for each extraction batch.

Verify that an instrument blank analysis has been performed following a sample analysis which contains analytes at high concentration(s).

\section{E. Action}

Action in the case of unsuitable blank results depends on the circumstances and origin of the blank. No positive sample results should be reported unless the concentration of the compound in the sample exceeds 5 times (5X) the amount in any blank for that compound. In instances where more than one blank is associated with a given sample, qualification should be based upon a comparison with the associated blank having the highest concentration of a contaminant. The results must not be corrected by subtracting any blank value.

If a compound is found in a blank but not found in the sample, no action is taken.

If a compound is found in a blank and the associated sample, the following $5 \mathrm{X}$ rule applies:

- When the concentration of that compound is greater than or equal to the CRQL but less than five times the highest concentration found in any blank, consider the result as a nondetect and report it with a " $U$ " qualifier.

- When the concentration of that compound is less than the CRQL and less than five times the highest concentration found in any blank, report the result and the CRQL with a "Un" qualifier.

- When the concentration of the compound is greater than or equal to five times the highest concentration found in any blank, consider the result as positive, and no qualifier is required.

Sample analytes not detected or detected at levels less than CRQL are reported as the CRQL with a "U" qualifier.

The following are examples of applying the blank qualification guidelines. Certain circumstances may warrant deviations from these guidelines. 
- If gross contamination exists (i.e., saturated peaks), all compounds affected should be qualified as unusable " $R$," due to interferences, in all samples affected.

- If incrdinate amounts of other organic compounds are found at low levels in the blanks, it may be indicative of a problem at the laboratory and should be noted in the data review comments.

\subsection{SURROGATE RECOVERY}

\section{A. Review Items}

Form II, chromatograms, and quantitation reports.

\section{B. Objective}

Laboratory performance of individual samples is established by means of spiking activities. All samples are spiked with the surrogate compound 2,4dichlorophenylmethylacetate before sample preparation. The results of this spike must be carefully evaluated as the sample itself may produce, effects due to such factors as interferences and high concentrations of analytes. Because the effects of the sample matrix are frequently outside the control of the laboratory and may present relatively unique problems, the evaluation and review of data based on specific sample results is frequently subjective and demands analytical experience and professional judgement.

\section{Criteria}

The surrogate recovery limits for sample and blank recoveries are 50 to $150 \% \mathrm{R}$ (internal laboratory recovery limits).

\section{Evaluation}

Check raw data (e.g., chromatograms and quantitation lists) to verify the recoveries on the Surrogate Recovery Form II.

If recoveries are not within limits, check raw data for possible interferences which may have affected surrogate recoveries.

Check the surrogate recovery form to determine if the laboratory has failed to perform satisfactorily if surrogate recoveries are out of specification with no evidence or reinjection or re-extraction.

Verify that no blanks have surrogates outside the criteria.

If there are two or more analyses for a particular fraction, the reviewer must determine which are the best data to report. Considerations should include surrogate recovery, technical 
holding times, and comparison of the values of the Appendix $\mathrm{IX}^{4}$ (SW-846 target compounds) compounds reported in each fraction.

Verify transcriptions from raw data and verify calculations.

Calculation for percent recovery:

$$
\% \text { Recovery }=\frac{\text { Concentration (or amount) found }}{\text { Concentration (or amount) spiked }} * 100
$$

\section{E. Action}

If any surrogate recovery is out of specification but greater than $10 \%$ recoven', qualify positive results as estimated "J" and qualify negative results with the CRQL as estimated "UJ."

If any surrogate shows less than $10 \%$ recovery, qualify positive results as estimated "J" and nondetects as unusable "R."

If any blank has surrogates out of specification, qualify results using professional judgement.

If zero recovery is reported, the reviewer should examine the sample chromatograms and to determine if the surrogate may be present but slightly outside its RT window. If this is the case, in addition to assessing surrogate recovery for quantitative bias, the overriding consideration is to investigate qualitative validity of the analysis.

If the surrogate is not present, qualify positive results as estimated "J" and nondetects as unusable "R."

\subsection{MATRXX SPIKEMATRIX SPIKE DUPLICATE (MSMSD)}

\section{A Review Items}

Form III, chromatograms, and quantitation reports.

\section{B. Objective}

These data are generated to determined the precision and accuracy of the analytical method. These data alone cannot be used to evaluate the precision and accuracy of individual samples.

${ }^{4}$ Refers to Federal Register, Volume 52, No. 131, July 9, 1987. 
C. Criteria

\begin{tabular}{lll} 
MS COMPOUND & \% RECOVERY & RPD $^{\text {b }}$ \\
\cline { 2 - 3 } $2,4-\mathrm{D}$ & $50-89$ & 50 \\
$2,4,5-\mathrm{TP}$ (Silvex) & $63-103$ & 50 \\
$2,4,5-\mathrm{T}$ & $57-103$ & 50
\end{tabular}

"Control limits are calculated from Mean Recovery (\%R) and Standard Deviation (s) data provided in Table 3 of SW-846 Method 8150 Revision 1, December 1987. Method Control Limits were calculated as $\% R+/-3$ s for each concentration (two to three sets of matrix/concentration results were provided for each compound).

Laboratory Lower Control Limit $=$ Lowest $\% \mathrm{R}$ of three Method-specified Control Limits.

Laboratory Upper Control Limit $=$ Highest $\% \mathrm{R}$ of three Method-specified Higher Control limits.

'Internal laboratory limit.

D. Evaluation

Inspect results for the MS/MSD percent recovery (\%R) and RPD.

Verify transcriptions from raw data and verify calculations.

Calculation for percent recovery:

$\%$ Recovery $=$ Concentration (or amount) found - Sample Result $* 100$ Concentration (or amount) spiked

Calculation for RPD: $\quad R P D=\frac{[M S R-M S D R] * 100}{(1 / 2)(M S R+M S D R)}$

Where: RPD = Relative Percent Difference

MSDR = Matrix Spike Duplicate Recovery

MSR = Matrix Spike Recovery

\section{E. Action}

No action is taken on MS/MSD data alone. However, using informed professional judgement, the data reviewer may use the MS and duplicate results in conjunction with other QC criteria and determine the need for some qualifications of the data.

The data reviewer should first try to determine to what extent the results of the MS/MSD affect the associated data. This determination should be made with regard to the MS/MSD sample itself as well as specific analytes for all samples associated with the MS/MSD. 
In those instances where it can be determined that the results of the MS/MSD affect only the sample spiked, then qualifications should be limited to this sample alone. However, it may be determined through the MS/MSD results that a laboratory is having a systematic problem in the analysis of one or more analytes, which affects all associated samples.

\subsection{LABORATORY CONTROL SAMPLES}

\section{A. Review Items}

Form III, surrogate compounds plotted on separate control charts, quantitation reports and chromatograms.

\section{B. Objective}

Data for LCSs are generated to provide information on the accuracy of the analytical method and the laboratory performance.

\section{Criteria}

LCSs are analyzed at a frequency of once per 20 samples per SDG. The LCS must be prepared and analyzed concurrently with the samples in the SDG.

LCS percent recoveries must be within the limits established by the laboratory. If this information is not available, the recoveries outlined in the method are to be used. The LCS must meet the recovery criteria for the sample data to be accepted.

The criteria for surrogate recovery also apply.

\section{Evaluation}

Ensure that each sample is analyzed in a batch in which a LCS has been performed. Any LCS exceeding QC limits set by the laboratory for a given sample matrix shall require all data from the associated batch of samples to be closely inspected.

If no analytical problems are found, data analyzed with the out-of-control point shall be discussed.

If problems are found in the analytical data, ensure that samples associated with the batch were reanalyzed and data from the analysis reported.

If holding times are exceeded in the reanalysis, both sets of data shall be presented.

\section{E. Action}

If the LCS criteria are not met, then the laboratory performance and method accuracy are in question. Professional judgement should be used to determine if the data should be qualified or rejected. 
The following guidance is suggested for qualifying sample data for which the associated LCS does not meet the required criteria.

Action on the LCS recovery should be based on both the number of compounds that are outside of the recovery criteria and the extent to which it was outside of the criteria.

If the LCS recovery criteria are not met, then the LCS results should be used to qualify sample data for the specific compounds that are included in the LCS solution. Professional judgement should be used to qualify data for compounds other than those compounds that are included in the LCS. Professional judgement to qualify non-LCS compounds should take into account the compound class, compound recovery efficiency, analytical problems associated with each compound, and comparability in performance of the LCS compound to the non-LCS compound.

Action on noncompliant surrogate recovery should follow the procedures provided in the appropriate sections of this guideline. Professional judgement should be used to evaluate the impact that noncompliance for surrogate recovery performance in the LCS has on the associated sample data. follows:

If the LCS results are below internal laboratory limits, the data shall be qualified as

- Qualify nondetects for samples associated with the LCS as estimated "UJ."

- Qualify positive results for samples associated with the LCS as estimated "J." follows:

If the LCS results are above internal laboratory limits, the data shall be qualified as

- Nondetects for samples associated with the LCS will not be qualified.

- Qualify positive results for samples associated with the LCS as estimated "J."

If the LCS results are below internal laboratory limits and if MS/MSD results are below the QC limits, the data shall be qualified as follows:

- Qualify nondetects for samples associated with the LCS as estimated "UJ."

- Qualify positive results for samples associated with the LCS as estimated "J."

If the LCS results are above internal laboratory limits and if MS/MSD results are above the QC limits, the data shall be qualified as follows:

- Nondetects for samples associated with the LCS will not be qualified.

- Qualify positive results for samples associated with the LCS as estimated "J." 


\subsection{COMPOUND IDENTIFICATION}

\section{A. Review Items}

Forms I, VI and VI, chromatograms, RT check and quantitation reports.

\section{B. Objective}

Qualitative criteria for compound identification have been established to minimize the number of erroneous identifications of compounds. Erroneous identification can either be a false positive (reporting a compound present when it is not) or a false negative (not reporting a compound that is present).

\section{Criteria}

RTs of reported compounds must fall within the calculated RT windows for the chromatographic column.

\section{Evaluation}

Review Form I, the associated raw data chromatograms and data systems printouts. Confirm reported positive detects, using appropriate RTs and RT windows, and verify that the compounds listed as "nondetected" are correct.

For multipeak herbicides, the RTs and relative peak height ratios of major component peaks should be compared against the appropriate standard chromatograms.

\section{E. Action}

All chromatograms that have peaks within the RT window but not reported, and those cases in which the compound is outside of the RT window and reported, should be reviewed if time permits. When these cases arise, the reviewer should contact the laboratory for the judgement used by the analyst in reporting the data. The reviewer should qualify the data using professional judgement, basing the qualification on the analyst's reasoning.

If the affected sample chromatograms contain peaks which may be of concern (i.e., above the CRQL and either close to or within the expected RT window of the herbicide of interest) and if the laboratory's explanation for the manner which the peak was reported is not acceptable to the reviewer, qualify all positive results and quantitation limits as unusable "R." The narrative should emphasize the possibility of either false negatives or false positives, as appropriate. 


\subsection{COMPOUND QUANTITATION AND REPORTED CONTRACT REQUIRED QUANTITATION LIMTIS}

\section{A. Review Items}

Form I, sample preparation log sheets, case narrative and quantitation reports.

\section{B. Objective}

The objective is to ensure that the reported quantitation results and CRQLs are accurate.

\section{Criteria}

Compound quantitation, as well as the adjustment of the CRQL, must be calculated according to the appropriate SOP.

\section{Evaluation}

Verify that the method quantitation limits reported by the laboratory are less than or equal to the corresponding project required quantitation limits listed in Table 6.7 of the Project Plan for the Background Soil Characterization Project at the Oak Ridge Reservation, Oak Ridge, Tennessee (Energy Systems 1992). If sample dilution is necessary due to elevated target compound concentrations, or if interference related to the sample matrix is observed, method quantitation limits reported by the laboratory may exceed the required limits.

Raw data should be examined to verify the correct calculation of all sample results reported by the laboratory. Check that the correct final volume of the sample extract was $10.0 \mathrm{~mL}$ for this analysis. Quantitation reports, chromatograms, and sample preparation log sheets should be compared to the reported positive sample results and quantitation limits.

Check a few of the detected compounds for the correct quantification.

$$
\text { Calculation of concentration: } \quad n g / g=\frac{(A x)(A)(V t)(D)}{(A s)(V i)(W)}
$$

Where: $A x=$ Response for the analyte in the sample, units may be in area counts or peak height.

As $=$ Response for the external standard, units same as for Ax.

$\mathrm{D}=$ Dilution factor, if the dilution was made on the sample before analysis. If no dilution was made, $D=1$, dimensionless.

$A=$ Amount of standard injected (ng).

$\mathrm{Vt}=$ Volume of total extract (uL).

$\mathrm{Vi}=$ Volume of extract injected (uL).

$\mathrm{W}=$ Weight of sample extracted (g). The wet weight or dry weight may be used, depending upon the specific application of the data.

Verify that the CRQLs have been adjusted to reflect all sample dilutions, concentrations, splits, clean-up activities, and dry-weight factors that are not accounted for by the method. 


\section{E. Action}

If the method quantitation limits reported by the laboratory exceed corresponding project required detection limits, and no sample dilutions were necessary or matrix related interference observed, professional judgement should be used to assess the validity of the elevated sample results. The problem should be noted in the validation report and brought to the attention of the validation project manager so that appropriate corrective action may be initiated.

Quantitation limits affected by large, off-scale peaks should be qualified as unusable "R." If the interference is on-scale, the reviewer can provide an estimated quantitation limit "UJ" for each affected compound.

Note: Simple-peak herbicides results can be checked for rough agreement between quantitative results obtained of the two GC columns. The reviewer should use professional judgement to decide whether a much larger concentration obtained on one column versus the other indicated the presence of an interfering compound. If an interfering compound is indicated, the lower of the two values should be reported and qualified as presumptively present at an estimated quantity "NJ." This necessitates a determination of an estimated concentration on the confirmation column. The narrative should indicate that the presence of interferences has obscured the attempt at a second column confirmation.

\subsection{SYSTEM PERFORMANCE}

\section{A. Review Items}

Form III, and chromatograms

\section{B. Objective}

During the following Instrument Performance QC checks (e.g., blanks, tuning, calibration), changes may occur in the system that degrade the quality of the data.

While this degradation would not be directly shown by QC checks until the next required series of analytical QC runs, a thorough review of the ongoing data acquisition can yield indicators of instrument performance.

\section{Criteria}

There are no specific criteria for system performance. Professional judgement should be used to assess the system performance.

\section{Evaluation}

Abrupt, discrete shifts in the RIC baseline may indicate a change in the instrument's sensitivity or the zero setting. A baseline shift could indicate a decrease in sensitivity in the instrument or an increase in the instrument zero, possibly causing target compounds at or near the detection limit to be nondetects. A baseline "rise" could indicate problems such as a change in the instrument zero, a leak, or degradation of the column. 
Poor chromatographic performance affects both qualitative and quantitative results. Indications of substandard performance include the following:

- high RIC background levels, or excessive baseline rise at elevated temperature and extraneous peaks and

- peak tailing or peak splitting that may result in inaccurate quantitation.

\section{E. Action}

Professional judgement must be used to qualify the data if it is determined that system performance has degraded during sample analyses. Any degradation of system performance which significantly affected the data should be documente 1 for action.

\subsection{OVERALL ASSESSMENT OF DATA FOR A CASE}

\section{A. Review Items}

Entire data package, data review results, QAPjP, and SAP.

\section{B. Objective}

The overall assessment of a data package is a brief narrative in which the data reviewer expresses concerns and comments on the quality and, if possible, the usability of the data.

\section{Criteria}

Assess the overall quality of the data.

\section{Evaluation}

Evaluate any technical problems which have not been previously addressed.

Review all available materials to assess the overall quality of the data, keeping in mind the additive nature of analytical problems.

If appropriate information is available, the reviewer may assess the usability of the data to assist the data user in avoiding inappropriate use of the data. Review all available information [e.g., QAPjP (specifically the Data Quality Objectives), SOP, communication with data user or sampler concerning the intended use and desired quality of this data].

\section{E. Action}

Use professional judgement in qualifying data which were not qualified based on the QC criteria previously discussed. Write a brief narrative which gives the user an indication of the analytical limitations of the data and the consistency of that data with the laboratory certification statement. If sufficient information on the intended use and required quality of the data are available, the reviewer should include his/her assessment of the usability of the data within the given contract. 


\section{DATA VALIDATION OF POLYNUCLEAR AROMATIC HYDROCARBONS IN SOIL SAMPLES}

\subsection{METHOD SUMMARY}

PAHs are determined according to EPA SW-846 Method 8310 . Method 8310 provides high performance liquid chromatography (HPLC) conditions for the detection of ppb levels of certain PAHs. Spiked samples are used to verify the applicability of the chosen extraction technique to each new sample type. A 5 to $25 \mathrm{uL}$ aliquot of the extract is injected into an HPLC, and compounds in the effluent are detected by UV and fluorescence detectors.

\subsection{LEVEL D DEILTERABLES:}

The following information should be included in the data package. This information should be accompanied by all raw data, including chromatograms and control charts.

QC Summary Package:

Form II or surrogate recoveries

Form III or MS/MSD recoveries

Form IV or Method Blank Summary

Form III or LCS

Internal COC Forms

Sample Data:

Form I or Sample Analysis Results

Standards Data:

Form VI or Initial Calibration Data

Form VII or Calibration Verification Data

Form VIII or PAH Analytical Sequence

Form $\mathrm{X}$ for Positively Identified Compounds

Raw QC Data:

Blank Data

MS Data

MSD Data 


\subsection{TECHNICAL HOLDING TMMES}

\section{A. Reviow Items}

Form I and chain-of-custody (COC) form.

\section{B. Objoctive}

The objective is to ascertain the validity of results based on the holding time of the sample from time of collection to time of sample extraction and analysis.

\section{Criteria}

Soil samples should be collected in amber glass containers, and tightly sealed with a Teflon-lined cap. Samples should be preserved by cooling to a temperature of $4^{\circ} \mathrm{C} \pm 2^{\circ} \mathrm{C}$. All samples must be extracted within $14 \mathrm{~d}$ of collection, analyzed within $40 \mathrm{~d}$ of extraction and must be stored at $4^{\circ} \mathrm{C} \pm 2^{\circ} \mathrm{C}$, away from light.

\section{Evaluation}

Technical holding times are established by comparing the sampling date and time on the COC form with date and time of extraction on Form I. To determine if the samples were analyzed within the holding time after extraction, compare the date and time on the sample extraction sheet and those on Form I.

\section{E. Action}

If technical holding times are exceeded, qualify all positive results as estimated "J" and samples at the quantitation limit as estimated "UJ." Document in the data review narrative that holding times were exceeded. If holding times are grossly exceeded (greater than two times the defined holding time), the reviewer must use professional judgement to determine the reliability of the data and the effects of additional storage on the sample results. The reviewer may determine that nondetect data are unusable " $R$."

If deficiencies in the COC documentation are noted, they should be reported in the DVR as previousty outlined. Note that a problem could arise if any of the affected data are to be used in litigation.

Any noted deficiencies which do (or could) affect the data on a chemical basis can be considered "major" deficiencies. As an example, general requirement deficiencies which prevent the reviewer from determining the date of sample collection, date of extraction, or date of analysis, and preclude determination of technical holding time, would be considered major. The inability of a reviewer to determine the date or time of sample analysis due to general requirements deficiencies will prevent the linking of the sample with a specific calibration, method blank, or other QC measures. Upon discovery of a "major" general requirements deficiency, the data package review should be discontinued, if time permits, and the laboratory should be immediately contacted. Data review should not continue until the "major" deficiency has been resolved by the laboratory. 


\subsection{INSTRUMENT CALIBRATION AND CALIBRATION VERIFICATION}

\section{A. Review Items}

Form VI, Form VII, analytical sequence and RT windows, chromatograms, and quantitation reports.

\section{B. Objective}

Instrument performance and calibration verification criteria are established to ensure that adequate chromatographic resolution and instrument sensitivity are achieved by the chromatographic system. Initial calibration consists of five standards.

ICV ensures that the instrument is capable of producing accurate analytical results at the start of the sample measurement run. CCV ensures that the initial calibration remains valid throughout the sample measurement run. These criteria are not sample-specific. Conformance is determined using standard materials; therefore, these criteria should be met in all circumstances.

\section{Criteria}

RT windows are used in qualitative identification. Three injections are made of all single component standard mixtures and multiresponse products throughout the course of a 72-h period. RT windows for each compound of interest should be set at \pm 3 times the standard deviation of the compound-specific mean RT (unless otherwise noted in the work plan). Daily adjustment of RT windows is based on daily RT for each compound in the standard. If the standards do not fall within the RT windows, the associated sample results should be carefully evaluated. All samples injected after the last in-control standard are potentially affected.

For the affected samples, check to see if chromatograms contain any peaks within an expanded window surrounding the expected RT window of the PAH of interest.

If no peaks are present either within or close to the RT window of the deviant target PAH, there is usually no effect on the data. Nondetected values can be considered valid.

Appropriate standard concentrations must be used for the initial calibration so that the project required quantitation limits for target compounds listed in Table 6.8 of the Project Plan for the Background Soil Characterization Project at the Oak Ridge Reservation, Oak Ridge, Tennessee (Energy Systems 1992), are bracketed by the initial calibration linear range.

If the affected sample chromatograms contain peaks which may be of concern (i.e., above the CRQL and either close to or within the expected RT window of the PAH of interest) and if no additional effort is warranted by the reviewer, qualify all positive results and quantitation limits as unusable "R." The narrative should emphasize the possibility of either false negatives or false positives, as appropriate.

If the affected sample chromatograms contain peaks which may be of concern (i.e., above the CRQL and either close to or within the expected RT window of the PAH of interest), then in some cases, additional effort is warranted by the reviewer (e.g., if the data are needed 
on a priority basis and if the peak(s) present might represent a level of concern for that particular PAH). In these situations, the reviewer may undertake the following additional efforts to determine a usable RT window for the affected samples.

The reviewer should examine the data package for the presence of three or more standards containing the PAH of interest that were run within a daily analytical sequence during which the sample was analyzed.

If three or more such standards are present, the mean and standard deviation of the RT window can be re-evaluated.

If all standards and MSs fall within the revised window, the valid positive or negative sample results can be determined using this window.

The narrative should identify the additional efforts taken by the reviewer and the resultant impact on the data usability. In addition, the support documentation should contain all calculations and comparisons generated by the reviewer.

The laboratory must use the External Calibration Procedure for quantitation.

If Calibration Factors are used for sample quantitation:

For initial calibration, all \%RSD must be less than or equal to $20 \%$.

Check the raw data to verify the reported \%RSD values are correct, using the following formula:

Calculation of \%RSD: $\quad \%$ RSD $=\frac{\text { Standard Deviation }}{\text { Mean }} * 100$

For continuing calibration, all \%D must be less than $15 \%$.

Check the raw data to verify the reported $\% \mathrm{D}$ values are correct, using the following formula:

$$
\% \mathrm{D}=[(\mathrm{R} 1-\mathbf{R} 2) / \mathrm{R} 1] * 100
$$

Where: $\mathbf{R} 1=$ Calibration factor from first analysis

R2 = Calibration factor from succeeding analysis

If the \%RSD of the calibration factor is less than $20 \%$ over the working range, linearity through the origin can be assumed, and the average calibration factor can be used in place of a calibration curve.

$$
\text { Calibration factor }=\frac{\text { Total area of peak }}{\text { Mass injected (ng) }}
$$


If linear regression is used for sample quantitation:

Verification of the calibration curve is required, and the correlation coefficient must be greater than or equal to 0.995 .

In the primary analysis, all standards are analyzed at the beginning of the $72-\mathrm{h}$ period, followed by the proper sample/standard sequence. The midlevel standard must be repeated after every 10 samples.

Verify that all standards were analyzed in the daily analytical run.

If the proper type and number of standards have not been analyzed, data may be affected. The data reviewer must use professional judgement to determine severity of the effect and qualify the data accordingly.

\section{Evaluation}

Review appropriate records to ensure that instrument performance criteria were met, and the proper number of calibrations were performed in the proper time frame.

\section{E. Action}

If the criteria for initial calibration are not met, qualify all associated quantitative results as estimated "J." If the criteria for continuing calibration are not met, qualify all associated quantitative results as estimated "J." If the criteria for continuing calibration are not met in the confirmation analysis, use professional judgement as to data reliability.

\subsection{BLANKS}

\section{A. Review Items}

Forms I and IV and raw data (chromatograms, RICs, quantitation reports, and data system printouts).

\section{B. Objective}

The objective of blank analyses is to determine the existence and magnitude of contamination problems resulting from laboratory performance. The criteria for evaluation of blanks apply to any blank associated with samples (e.g., method blanks). If problems with any blank exist, all associated data must be carefully evaluated to determine whether or not there is inherent variability in the data, or if the problem is an isolated occurrence not affecting other data.

\section{Criteria}

No contaminants should be present in blanks. Blanks should be carried through the entire sample preparation and analysis process. Blanks will be analyzed for every sample set, for each matrix type, or once in every batch of samples (up to 20 samples), whichever is more frequent. 


\section{Evaluation}

Review the results of all associated blanks, Form Is, and raw data, and verify that the results were accurately reported. Ensure that the proper number of blanks was analyzed, at the proper frequency.

Verify that the all blank analyses contain less than the CRQL of the analyte or interfering peak.

Verify that method blank analyses have been reported per matrix, per concentration level, to analyze samples, and for each extraction batch.

Verify that an instrument blank analysis has been performed following a sample analysis which contains analytes at high concentration(s).

\section{E Action}

Action in the case of unsuitable blank results depends on the circumstances and origin of the blank No positive sample results should be reported unless the concentration of the compound in the sample exceeds 5 times $(5 X)$ the amount in any blank for that compound. In instances where more than one blank is associated with a given sample, qualification should be based upon a comparison with the associated blank having the highest concentration of a contaminant. The results must not be corrected by subtracting any blank value.

If a compound is found in a blank but not found in the sample, no action is taken.

If a compound is found in a blank and the associated sample, the following $5 \mathrm{X}$ rule applies:

- When the concentration of that compound is greater than or equal to the CRQL but less than five times the highest concentration found in any blank, consider the result as a nondetect and report it with a " $U$ " qualifier.

- When the concentration of that compound is less than the CRQL and less than five times the highest concentration found in any blank, report the result and the CRQL with a "U" qualifier.

- When the concentration of the compound is greater than of equal to five times the highest concentration found in any blank, consider the result as positive, and no qualifier is required.

Sample analytes not detected or detected at levels less than CRQL are reported as the CRQL with a "U" qualifier.

The following are examples of applying the blank qualification guidelines. Certain circumstances may warrant deviations from these guidelines.

- If gross contamination exists (i.e., saturated peaks), all compounds affected should be qualified as unusable " $R$," due to interferences, in all samples affected. 
- If inordinate amounts of other organic compounds are found at low levels in the blanks, it may be indicative of a problem at the laboratory and should be noted in the data review comments.

\subsection{MATRXX SPIKEMATRIX SPIKE DUPLCATE (MS/MSD)}

\section{A. Review Items}

Form III, chromatograms, and quantitation reports.

\section{B. Objective}

These data are generated to determined the precision and accuracy of the analytical method. These data alone cannot be used to evaluate the precision and accuracy of individual samples.

\section{Criteria}

\begin{tabular}{lcc} 
MS COMPOUND & \% RECOVERY & RPD $^{\mathbf{b}}$ \\
\cline { 2 - 3 } Acenaphthene & D-124 & 50 \\
Acenaphthylene & D-139 & 50 \\
Anthracene & D-126 & 50 \\
Benzo(a)anthracene & $12-135$ & 50 \\
Benzo(a)pyrene & D-128 & 50 \\
Benzo(b)fluoranthene & $6-150$ & 50 \\
Benzo(g,h,i)perylene & D-116 & 50 \\
Benzo(k)fluoranthene & D-159 & 50 \\
Chrysene & D-199 & 50 \\
Dibenzo(a,h)anthracene & D-110 & 50 \\
Fluoranthene & $14-123$ & 50 \\
Fluorene & D-142 & 50 \\
Indene(1,2,3-cd)pyrene & D-116 & 50 \\
Naphthalene & D-122 & 50 \\
Phenanthrene & D-155 & 50 \\
Pyrene & D-140 & 50
\end{tabular}

'Criteria were taken from Table 3 of SW-846 Method 8310 (9/1986) which were adapted from 40 CFR Part 136 for Method 610.

' Internal laboratory limit.

D. Evaluation

Inspect results for the MS/MSD percent recovery (\%R) and RPD.

Verify transcriptions from raw data and verify calculations. 
Calculation for percent recovery:

$$
\% \text { Recovery }=\quad \frac{\text { Concentration (or amount) found }}{\text { Concentration (or amount) spiked }} * 100
$$

Calculation for RPD:

$$
\mathrm{RPD}=\frac{[\mathrm{MSR}-\mathrm{MSDR}]}{(1 / 2)(\mathrm{MSR}+\mathrm{MSDR})} * 100
$$

Where: RPD = Relative Percent Difference

MSR = Matrix Spike Recovery

MSDR = Matrix Spike Duplicate Recovery

\section{E. Action}

No action is taken on MS/MSD data alone. However, using informed professional judgement, the data reviewer may use the MS and duplicate results in conjunction with other QC criteria and determine the need for some qualifications of the data.

The data reviewer should first try to determine to what extent the results of the MS/MSD affect the associated data. This determination should be made with regard to the MS/MSD sample itself as well as specific analytes for all samples associated with the MS/MSD.

In those instances where it can be determined that the results of the MS/MSD affect only the sample spiked, then qualifications should be limited to this sample alone. However, it may be determined through the MS/MSD results that a laboratory is having a systematic problem in the analysis of one or more analytes, which affects all associated samples.

\subsection{LABORATORY CONTROL SAMPLES}

\section{A. Review Items}

Form III, surrogate compounds plotted on separate control charts, quantitation reports and chromatograms.

\section{B. Objective}

Data for LCSs are generated to provide information on the accuracy of the analytical method and the laboratory performance.

\section{Criteria}

LCSs are analyzed at a frequency of once per 20 samples per SDG. The LCS must be prepared and analyzed concurrently with the samples in the SDG.

LCS percent recoveries must be within the QC limits established by the laboratory in the Project Plan for the Background Soil Characterization Project at the Oak Ridge Reservation, 
Oak Ridge, Tennessee (Energy Systems 1992). The LCS must meet the recovery criteria for the sample data to be accepted.

The criteria for surrogate recovery and internal standard performance also apply.

\section{Evaluation}

Ensure that each sample is analyzed in a batch in which a LCS has been performed. Any LCS exceeding internal QC limits set by the laboratory for a given sample matrix shall require all data from the associated batch of samples to be closely inspected.

If no analytical problems are found, data analyzed with the out-of-control point shall be discussed.

If problems are found in the analytical data, ensure that samples associated with the batch were reanalyzed and data from the analysis reported.

If holding times are exceeded in the reanalysis, both sets of data shall be presented.

\section{E. Action}

If the LCS criteria are not met, then the laboratory performance and method accuracy are in question. Professional judgement should be used to determine if the data should be qualified or rejected. The following guidance is suggested for qualifying sample data for which the associated LCS does not meet the required criteria.

Action on the LCS recovery should be based on both the number of compounds that are outside of the recovery criteria and the extent to which it was outside of the criteria.

If the LCS recovery criteria are not met, then the LCS results should be used to qualify sample data for the specific compounds that are included in the LCS solution. Professional judgement should be used to qualify data for compounds other than those compounds that are included in the LCS. Professional judgement to qualify non-LCS compounds should take into account the compound class, compound recovery efficiency, analytical problems associated with each compound, and comparability in performance of the LCS compound to the non-LCS compound.

Action on noncompliant surrogate recovery and internal standard performance should follow the procedures provided in the appropriate sections of this guideline. Professional judgement should be used to evaluate the impact that noncompliance for surrogate recovery and internal standard performance in the LCS has on the associated sample data.

If the LCS results are outside internal laboratory limits and if MS results are outside the QC limits, the data shall be qualified as follows:

If the LCS results are below internal laboratory limits, the data shall be qualified as follows:

- Qualify nondetects for samples associated with the LCS as estimated "UJ." 
- Qualify positive results for samples associated with the LCS as estimated "J." follows:

If the LCS results are above internal laboratory limits, the data shall be qualified as

- Nondetects for samples associated with the LCS will not be qualified.

- Qualify positive results for samples associated with the LCS as estimated "J."

If the LCS results are below internal laboratory limits and if MS/MSD results are below the QC limits, the data shall be qualified as follows:

- Qualify nondetects for samples associated with the LCS as estimated "UJ."

- Qualify positive results for samples associated with the LCS as estimated "J."

If the LCS results are above internal laboratory limits and if MS/MSD results are above the QC limits, the data shall be qualified as follows:

- Nondetects for samples associated with the LCS will not be qualified.

- Qualify positive results for samples associated with the LCS as estimated "J."

\subsection{SURROGATE RECOVERY}

\section{A Review Items}

Form II, chromatograms, and quantitation reports.

\section{B. Objective}

Laboratory performance of individual samples is established by means of spiking activities. All samples are spiked with the surrogate compound decafluorobiphenyl before sample preparation. The results of this spike must be carefully evaluated as the sample itself may produce, effects due to such factors as interferences and high concentrations of analytes. Because the effects of the sample matrix are frequently outside the control of the laboratory and may present relatively unique problems, the evaluation and review of data based on specific sample results is frequently subjective and demands analytical experience and professional judgement.

\section{Criteria}

The surrogate recovery limits for sample and blank recoveries are 50 to $150 \% \mathrm{R}$ (internal laboratory recovery limits). 


\section{Evaluation}

Check raw data (e.g., chromatograms and quantitation lists) to verify the recoveries on the Surrogate Recovery Form II.

If recoveries are not within limits, check raw data for possible interferences which may have affected surrogate recoveries.

Check the surrogate recovery form to determine if the laboratory has failed to perform satisfactorily if surrogate recoveries are out of specification with no evidence or reinjection or re-extraction.

Verify that no blanks have surrogates outside the criteria.

If there are two or more analyses for a particular fraction the reviewer must determine which are the best data to report. Considerations should include surrogate recovery, technical holding times, and comparison of the values of the Appendix $\mathrm{IX}^{5}$ compounds reported in each fraction.

\section{E. Action}

If any surrogate recovery is out of specification but greater than $10 \%$ recovery, qualify positive results as estimated "J" and qualify negative results with the CRQL as estimated "UJ."

If any surrogate shows less than $10 \%$ recovery, qualify positive results as estimated "J" and nondetects as unusable "R."

If any blank has surrogates out of specification, qualify results using professional judgement.

If zero recovery is reported, the reviewer should examine the sample chromatograms and to determine if the surrogate may be present but slightly outside its RT window. If this is the case, in addition to assessing surrogate recovery for quantitative bias, the overriding consideration is to investigate qualitative validity of the analysis.

If the surrogate is not present, qualify positive results as estimated "J" and nondetects as unusable "R."

\subsection{COMPOUND IDENTIFICATION}

\section{A. Review Items}

Forms I, VI and VI, chromatograms, RT check and quantitation reports.

\footnotetext{
${ }^{5}$ Refers to Federal Register, Volume 52, No. 131, July 9, 1987.
} 


\section{B. Objective}

Qualitative criteria for compound identification have been established to minimize the number of erroneous identifications of compounds. Erroneous identification can either be a false positive (reporting a compound present when it is not) or a false negative (not reporting a compound that is present).

\section{Criteria}

RTs of reported compounds must fall within the calculated RT windows for the chromatographic column.

\section{Evaluation}

Review Form I, the associated raw data chromatograms and data systems printouts. Confirm reported positive detects, using appropriate RTs and RT windows, and verify that the compounds listed as "nondetected" are correct.

\section{E. Action}

If the qualitative criteria were not met, all reported positive detects should be qualified as unusable "R."

If the misidentified peak was sufficiently outside the target PAH RT window, then the CRQL can be reported.

If the misidentified peak poses an interference with potential detection of a target peak, then the reported value should be considered as qualified at the estimated quantitation limit and qualified as estimated "UJ."

\subsection{COMPOUND QUANITTATION AND REPORTED CRQLS}

\section{A Review Items}

Form I, sample preparation log sheets, case narrative and quantitation reports.

\section{B. Objective}

The objective is to ensure that the reported quantitation results and CRQLs are accurate.

\section{Criteria}

Compound quantitation, as well as the adjustment of the CRQL, must be calculated according to the appropriate SOP. 


\section{Evaluation}

Verify that the method quantitation limits reported by the laboratory are less than or equal to the corresponding project required quantitation limits listed in Table 6.8 of the Project Plan for the Background Soil Characterization Project at the Oak Ridge Reservation, Oak Ridge, Tennessee (Energy Systems 1992). If sample dilution is necessary due to elevated target compound concentrations, or if interference related to the sample matrix is observed, method quantitation limits reported by the laboratory may exceed the required limits.

Raw data should be examined to verify the correct calculation of all sample results reported by the laboratory. Check that the correct final volume of the sample extract was $1.0 \mathrm{~mL}$ for this analysis. Quantitation reports, chromatograms, and sample preparation log sheets should be compared to the reported positive sample results and quantitation limits.

Check a few of the detected compounds for the correct quantification.

Calculation of Concentration: $n g / g=(A x)(A)(V t)(D)$

$$
(\mathrm{As})(\mathrm{Vi})(\mathrm{W})
$$

Where: $A x=$ Response for the analyte in the sample, units may be in area counts or peak height.

As $=$ Response for the external standard, units same as for $\mathrm{Ax}$.

$\mathrm{D}=$ Dilution factor, if the dilution was made on the sample before analysis. If no dilution was made, $D=1$, dimensionless.

$A=$ Amount of standard injected (ng)

$\mathrm{Vt}=$ Volume of total extract (uL)

$\mathrm{Vi}=$ Volume of extract injected (uL)

$\mathrm{W}=$ Weight of sample extracted (g). The wet weight or dry weight may be used, depending upon the specific application of the data.

Verify that the CRQLs have been adjusted to reflect all sample dilutions, concentrations, splits, clean-up activities, and dry-weight factors that are not accounted for by the method.

\section{E. Action}

If the method quantitation limits reported by the laboratory exceed corresponding project required detection limits, and no sample dilutions were necessary or matrix related interference observed, professional judgement should be used to assess the validity of the elevated sample results. The problem should be noted in the validation report and brought to the attention of the validation project manager so that appropriate corrective action may be initiated.

Quantitation limits affected by large, off-scale peaks should be qualified as unusable "R." If the interference is on-scale, the reviewer can provide an estimated quantitation limit "UJ" for each affected compound. 


\subsection{SYSTEM PERFORMANCE}

\section{A. Review Items}

Form III, and chromatograms

\section{B. Objective}

During the following Instrument Performance QC checks (e.g., blanks, tuning, calibration), changes may occur in the system that degrade the quality of the data. While this degradation would not be directly shown by QC checks until the next required series of analytical QC runs, a thorough review of the ongoing data acquisition can yield indicators of instrument performance.

\section{Criteria}

There are no specific criteria for system performance. Professional judgement should be used to assess the system performance.

\section{Evaluation}

Abrupt, discrete shifts in the RIC baseline may indicate a change in the instrument's sensitivity or the zero setting. A baseline shift could indicate a decrease in sensitivity in the instrument or an increase in the instrument zero, possibly causing target compounds at or near the detection limit to be nondetects. A baseline "rise" could indicate problems such as a change in the instrument zero, a leak, or degradation of the column.

Poor chromatographic performance affects both qualitative and quantitative results. Indications of substandard performance include the following:

high RIC background levels, excessive baseline rise at elevated temperature, extraneous peaks, and

peak tailing or peak splitting that may result in inaccurate quantitation.

\section{E. Action}

Professional judgement must be used to qualify the data if it is determined that system performance has degraded during sample analyses. Any degradation of system performance which significantly affected the data should be documented for action.

\subsection{OVERALL ASSESSMENT OF DATA FOR A CASE}

\section{A Review Items}

Entire data package, data review results, QAPjP, and SAP. 


\section{B. Objective}

The overall assessment of a data package is a brief narrative in which the data reviewer expresses concerns and comments on the quality and, if possible, the usability of the data.

\section{Criteria}

Assess the overall quality of the data.

\section{Evaluation}

Evaluate any technical problems which have not been previously addressed.

Review all available materials to assess the overall quality of the data, keeping in mind the additive nature of analytical problems.

If appropriate information is available, the reviewer may assess the usability of the data to assist the data user in avoiding inappropriate use of the data. Review all available information [e.g., QAPjP (specifically the Data Quality Objectives), SOP, communication with data user or sampler concerning the intended use and desired quality of this data].

\section{E. Action}

Use professional judgement in qualifying data which were not qualified based on the QC criteria previously discussed.

Write a brief narrative which gives the user an indication of the analytical limitations of the data and the consistency of that data with the laboratory certification statement. If sufficient information on the intended use and required quality of the data are available, the reviewer should include his/her assessment of the usability of the data within the given contract. 


\section{VALIDATION OF SULFATE DATA}

\subsection{METHOD SUMMARY}

Validation guidelines for sulfate are based on those for Wet Chemistry and Sulfates given in the BSCP Project Plan (Energy Systems 1992) and AESG SOP 7703, Attachment 9E, as well as on requirements of the method itself. Review of raw data is included.

In SW-846, Method 9038, sulfate ion is converted to a barium sulfate suspension under controlled conditions. The resulting turbidity is determined by a nephelometer, filter photometer, or spectrophotometer and compared with a curve prepared from a standard sulfate solution.

\subsection{LEVEL D DELIVERABLES}

The following information should be included in the data package. This information should include all raw data, including copies of relevant logbook pages and control charts.

Presentation of data for this project is on CLP Inorganics forms.

QC Summary Package:

Initial and Continuing Calibration - Form II (Part 1)

Blanks - Form III

Spike Sample Recovery - Form VA

Duplicates - Form VI (These should be MSDs according to the method)

LCS - Form VI

Reporting Limit - Form X

Preparation Log - Form XIII

Run Log - Form XIV

Raw data, including the calibration curve and its correlation coefficient

Sample Data:

Form I

Raw Data

Other Information:

$\mathrm{COC}$ 


\subsection{TECHNICAL HOLDING TIMES}

\section{A. Review ltems}

COC

Form XIII

Raw data

\section{B. Objective}

The objective is to ascertain the validity of results based on the holding time of the sample from time of collection to time of analysis.

\section{Criteria}

Technical requirements for sample holding times have only been established for water matrices. Holding times for soils are under investigation. This project has specified that the holding time for water samples, $28 \mathrm{~d}$, be applied to soil samples. Preservation of the samples consists of cooling to $4 \pm 2^{\circ} \mathrm{C}$.

\section{Evaluation}

Technical holding times are established by comparing the sample collection date on the $\mathrm{COC}$ to the date of preparation on Form XIII and in the raw data.

Verify that the COC or copies of log-in records indicate that the samples were received intact and cooled. If the samples were not at $4 \pm 2{ }^{\circ} \mathrm{C}$ or there were any problems with the samples noted upon receipt, data could be unrepresentative.

\section{E Action}

Ensure that the maximum allowable holding time of $28 \mathrm{~d}$ was not exceeded and samples were kept at $4 \pm 2^{\circ} \mathrm{C}$.

1. Due to limited information concerning the effects of temperature and holding times on soil samples, professional judgement may sometimes override these guidelines. Generally, if technical holding times are exceeded, qualify all detected results as estimated "J," and document in the data review narrative that holding times were exceeded.

2. If technical holding times are grossly exceeded ( $>2 \mathrm{X}$ ), either on the first analysis or upon reanalysis, the reviewer must use professional judgement to determine the reliability of the data and the effect of additional storage on the sample results. The reviewer may determine that detected results are approximate and should be qualified with "J" but that nondetects are unusable, "R."

4. Whenever possible the reviewer should comment on the effect of exceeding the holding time on the resulting data in the data review narrative.

5. When contractual and/or technical holding times are exceeded, this should be noted as an action item for the analytical coordinator and project manager. 
6. The reviewer should also be aware of the scenario in which the laboratory has exceeded the technical holding times but met contractual holding times. In this case, the data reviewer should notify the analytical coordinator (who informs the project manager) that shipment delays have occurred so that the field problem can be corrected. The reviewer may pass this information on to the laboratory's project manager, but should explain than contractually the laboratory met the requirements.

\subsection{INITIAL AND CONTINUING CALIBRATION}

\section{A. Review Items}

\section{Raw Data}

Form 2A

\section{B. Objective}

Compliance requirements for satisfactory initial calibration are established to ensure that the measurement system is capable of producing acceptable quantitative data. Initial calibration establishes a means of quantification via the calibration curve and the initial and CCV standards provide assurance that the curve and instrument are providing correct results.

\section{Criteria}

Ensure that a standard curve based on a blank and a minimum of three standards, bracketing sample concentration, is performed hourly. The correlation coefficient must meet or exceed 0.995 before the analysis of samples. It is recognized that the correlation coefficient is not an invariable indicator of linearity. However, it is accepted that 0.995 is an achievable value and that linearity is satisfactory when that value is met. If the confidence limits for the individual points are $95 \%$, then it follows that the confidence limit for the correlation coefficient is also $95 \%$.

An independent initial calibration check (verification) standard must be analyzed after calibration and the result must be 90 to $110 \%$ of the true value.

Continuing calibration check (verification) standards must be analyzed if more than 15 samples are analyzed before it is time for a new calibration curve to be established. The results must be 90 to $110 \%$ of the true value.

D. Evaluation

1. Check raw data to ensure that at least three standards and a blank were used for the calibration curve.

2. Check raw data to ensure that the calibration was performed hourly.

3. Check raw data to ensure that the correlation coefficient for each calibration curve was at least 0.995 . 
4. Check Form IIA to ensure that the initial and continuing calibration check or verification standards were within 90 to $110 \%$ of the true value.

E. Action

1. If the minimum number of standards was not used for initial calibration, qualify data as unusable (R).

2. If the instrument was not calibrated hourly before sample analysis, qualify data as unusable (R).

3. If the correlation coefficient is less than 0.995 :

a. Qualify associated sample results greater than or equal to the reporting limit as estimated (J).

b. Qualify associated sample results less than the reporting limit as unusable (R).

4. If the initial calibration check or verification standard was not within 90 to $110 \%$ of the true value,

5. If the ICV or CCV \%R falls outside the acceptance windows, use professional judgement to qualify all associated data. The following guidelines are suggested:

a. If the ICV or CCV \%R falls outside the acceptance windows but within the ra 'ges or 75 to $89 \%$ or 111 to $125 \%$, qualify the results greater than reporting limit as estimated (J).

b. If the ICV or CCV \%R is wit ange of 111 to $125 \%$, results less than reporting limit are acceptable.

c. If the ICV or CCV \% R is 75 to $89 \%$, qualify the results less than reporting limit as estimated (UJ).

d. If the ICV or CCV \% R is less than $75 \%$, qualify all positive results as unusable (R).

e. If the ICV or CCV \%R is greater than $125 \%$, qualify results greater than reporting limit as unusable (R); results less than reporting limit are acceptable.

\subsection{BLANKS}

\section{A Review Items}

\section{Form I}

Form III

Raw Data

Note: For the BSCP the only laboratory blanks are method blanks. The method does not specify blank analysis. 


\section{B. Objective}

The objective of laboratory (or field) blank analyses is to determine the existence and magnitude of contamination problems resulting from laboratory (or field) activities. The criteria for evaluation of laboratory blanks apply to any blank associated with the samples (e.g., method blank, rinsate blank). If problems exist with any blank, all associated data must be carefully evaluated to determine whether there is an inherent variability in the data. or if the problem is an isolated occurrence not affecting other data.

\section{Criteria}

1. The criteria for evaluation of blanks applies to any blank associated with the samples, including method, field and rinsate blanks.

2. Verify that field and rinsate blanks have been performed at the frequency indicated by the project.

3. Verify that an associated method blank has been performed with each sample per matrix.

4. No contamination should be present in any blanks.

D. Evaluation

1. Review the results of all associated blanks (Form III, Form I for samples and for associated field and rinsate blanks, if identified)

E. Action

1. Sample results greater than reporting limit but less than 5 times the amount in any blank should be qualified as (U).

2. Results must not be corrected by subtracting any blank values.

3. If the concentration in the sample is less than or equal to the concentration found in the blark, the result is considered as a nondetect and flagged as such (U).

4. If the concentration in the sample is greater than five times the concentration found in the blank, the result is considered positive and no flag is required.

\subsection{LABORATORY CONTROL SAMPLES}

\section{A. Review Items}

Form VII

Raw Data 


\section{B. Objective}

Data for LCSs are generated to provide information on the accuracy of the analytical method and laboratory performance.

\section{Criteria}

The primary criteria for sulfate LCS recovery are internal laboratory limits. Any LCS exceeding internal QC limits set by the laboratory for a given sample matrix shall require all data from the associated batch of samples to be closely inspected.

If LCS control charts or similar evidence of internal limits are not received, evaluation is based on limits of 80 to $120 \% R$.

\section{Evaluation}

1. Ensure that each sample is analyzed in a batch in which an LCS has been performed.

2. Review Form VII and verify that results fall within control limits.

3. Check raw data to verify the reported recoveries on Form VII. Recalculate several of the recoveries.

\section{E. Action (assume aqueous LCS)}

If internal laboratory limits are used and no analytical problems are found, data analyzed with the out-of-control point shall be discussed.

If internal laboratory limits are used and problems are found in the analytical data, ensure that samples associated with the batch were reanalyzed and data from reanalysis reported. If holding times are exceeded in the reanalysis, both sets of data shall be presented.

If the LCS results are outside internal laboratory limits and if the MS results are outside the laboratory limits, the data shall be qualified as follows:

1. Qualify nondetects for all samples associated with the LCS as unusable (R).

2. Qualify positive results for all samples associated with the LCS as estimated (J).

If the 80 to $120 \%$ recovery limit is used, the following actions apply:

1. If the LCS recovery for any analyte falls within the range of 50 to $79 \%$ or greater than $120 \%$, qualify the results greater than the reporting limit as estimated (J).

2. If results are less than the reporting limit and the LCS recovery is greater than $120 \%$, the data are acceptable.

3. If results are less than the reporting limit and the LCS recovery falls within the range of 50 to $79 \%$, qualify the data for the affected analytes as estimated (UJ). 
4. If LCS recovery results are less than $50 \%$, qualify the data for these samples as unusable (R).

\subsection{MATRIX SPIKE/MATRDX SPIKE DUPLICATES}

\section{A Review Items}

\section{Form V}

Form VI

Raw data

\section{B. Objectives}

Data for MSs and MSDs are generated to determine long-term precision and accuracy of the analytical method on various matrices. These data alone cannot be used to evaluate the precision and accuracy of individual samples. However, when exercising professioral judgement, MS/MSD data should be used in conjunction with information on other deficiencies.

\section{Criteria}

1. An MS/MSD is specified in the project plan for each 10 samples. The reporting format is for an MS and a sample duplicate. Therefore, MS and duplicate evaluations are conducted separately.

2. The primary criteria for sulfate MS recovery and duplicate precision are internal laboratory limits. Any MS or duplicate exceeding internal QC limits set by the laboratory for a given sample matrix shall require all data from the associated batch of samples to be closely inspected.

3. If control charts or similar evidence of internal limits are not received, evaluation of spike recoveries is based on limits of 75 to $125 \%$. However, spike recovery limits do not apply when sample concentration exceeds the spike concentration by a factor of 4 or more.

4. If control charts or similar evidence of internal limits are not received, evaluation of duplicates is based on limits of plus or minus $20 \%$ (35\% for soil) for the RPD for sample values greater than 5 times the reporting limit. A control limit of plus or minus the reporting limit (plus or minus two times the reporting limit for soil) shall be used for sample values less than 5 times the reporting limit, including the case when only one of the duplicate sample values is less than 5 times the reporting limit.

D. Evaluation

1. Ensure that an MS and duplicate have been associated with each sample.

2. Review raw data with reported data to detect transcription and calculation errors. Recheck several calculations. 
3. For MSs, review Form V and verify that results fall within specified limits.

4. For duplicates, review Form VI and verify that results fall within specified limits.

E. Action

1. If internal laboratory control limits for the MS were reported and MS recoveries are outside those limits, and the LCS was also outside limits, the data shall be qualified as follows:

a. Qualify nondetects for all samples associated with the MS as unusable (R).

b. Qualify positive results for all samples associated with the MS as estimated (J).

2. If the $\mathbf{7 5}$ to $125 \%$ recovery limit for the MS is used, the following actions apply:

a. If the spike recovery is greater than $125 \%$ and the reported sample results are less than reporting limit, the data are acceptable.

b. If the spike recovery is greater than $125 \%$ or less than $75 \%$ and the sample results are greater than the reporting limit, qualify the data for these samples as estimated (J).

c. If the spike recovery falls within the range of 30 to $74 \%$ and the sample results are less than reporting limit, qualify the data for these samples as estimated (UJ).

d. If the spike recovery results fall less than $30 \%$ and the sample results are less than reporting limit, qualify the data for these samples as unusable (R).

3. If the duplicate analysis results for a particular analyte fall outside the appropriate control windows, qualify the results for that analyte in all associated samples of the same matrix as estimated (J).

\subsection{SAMPLE RESULT VERIFICATION}

\section{A. Review Items}

Form I

Form XIV

Raw data

\section{B. Objective}

The objective is to ensure that the reported results are accurate. 


\section{Criteria}

1. Most criteria are general: that computations, rounding, and similar operations are processed correctly; that unusual occurrences be satisfactorily explained or the analysis repeated.

2. Samples below the reporting limit are to be reported as the limit value and the qualifier "U." Values higher than the limit are not to be reported with a "U" unless an explanation of the higher reporting limit is made. Corrections for percent solids and mass must be considered.

\section{Evaluation}

1. Examine the raw data for any anomalies (e.g., baseline shifts, negative absorbances, omissions, legibility).

2. Verify that there are no transcription or reduction errors (e.g., dilutions, percent solids, sample weights) on one or more samples.

3. Verify that results fall within the calibrated range.

\section{E. Action}

If there are any discrepancies found, the laboratory may be contacted by the reviewer to obtain additional information that could resolve any differences. If a discrepancy remains unresolved, the reviewer may determine that qualification of the data is warranted.

\subsection{OVERALL ASSESSMENT OF DATA FOR A CASE}

It is appropriate for the data reviewer to make professional judgements and express concerns and comments on the validity of the overall data for a case. This is particularly appropriate when there are several QC criteria out of specification. The additive nature of QC factors out of specification is difficult to assess in an objective manner, but the reviewer has a responsibility to inform the user concerning data quality and data limitations to assist that user in avoiding inappropriate use of the data, while not precluding any consideration of the data at all. If qualifiers other than those used in this document are necessary to describe or qualify the data, it is necessary to thoroughly document and explain the additional qualifiers used. The data reviewer would be greatly assisted in this endeavor if the data quality objectives were provided. The cover form and supplementary documentation must be included with the review. 


\section{DATA VALIDATION OF ANALYTES BY NEUTRON ACTIVATION ANALYSIS (NAA)}

\subsection{METHOD SUMMARY}

In NAA, a sample is irradiated with neutrons. The neutrons interact with target nuclei in nuclear reactions that result in the emission of radiation. Gamma radiation is most commonly monitored. The energies and intensities of the gamma emissions can be used to provide both qualitative and quantitative information about the elemental composition of a sample.

The following elements were determined by NAA for the BSCP:

\begin{tabular}{|c|c|c|c|}
\hline $\begin{array}{l}\text { aluminum } \\
\text { antimony } \\
\text { arsenic } \\
\text { barium } \\
\text { cadmium } \\
\text { cerium } \\
\text { chromium } \\
\text { cobalt } \\
\text { europium }\end{array}$ & $\begin{array}{l}\text { gallium } \\
\text { gold } \\
\text { hafnium } \\
\text { iron } \\
\text { lanthanum } \\
\text { lutetium } \\
\text { magnesium } \\
\text { manganese } \\
\text { mercury }\end{array}$ & $\begin{array}{l}\text { potassium } \\
\text { rubidium } \\
\text { samarium } \\
\text { scandium } \\
\text { selenium } \\
\text { silver } \\
\text { sodium } \\
\text { terbium } \\
\text { thorium }\end{array}$ & $\begin{array}{l}\text { titanium } \\
\text { tungsten } \\
\text { uranium } \\
\text { vanadium } \\
\text { ytterbium } \\
\text { zinc }\end{array}$ \\
\hline
\end{tabular}

NAA is not a routine EPA procedure, although it is commonly used for analysis of many kinds of environmental samples, including soil. Therefore, guidelines for Level E QC, used for unconventional methods, were used in validating the NAA data. Professional judgement must be exercised in situations not described in the procedure.

\subsection{DELIVERABLES}

Check for the following "one-time" deliverables (i.e., this information is only provided once; it does not have to be present in each SDG or batch).

- Procedure

- Detailed forms of all equations used in calculations, including elemental concentrations (except uranium) uranium concentrations interference corrections minimum detectable activity (MDA) calculation

- List of interference corrections

- Efficiency values for detectors used

- Identification of all standards and LCS

- Laboratory notebook containing all needed information about standard preparation

- Peak searches and nuclide specific activity calculations for the standards 
The following items should be present in each batch; form numbers refer to those actually used by NAA group in package preparation:

- Signed chain-of-custody form

- Case narrative

- Form I for each sample in the batch, listing all elements except uranium

- Form IB, listing results for uranium by delayed neutron counting

- Form 2, providing blank information

- Form 3, containing LCS data

- Form 4, containing spike recovery information

- Form 5B, containing duplicate data

- Form 6A-C, containing sample data such as mass, irradiation and count time, etc.

- Form 7, containing CCV data

- Peak searches and unknown reports for one representative sample, for each of the three counting regimes, to be used for validation of calculations

\subsection{TECHNICAL HOLDING TIMES}

\section{A. Review Items}

COC forms and sample preparation information.

\section{B. Objective}

The objective is to ascertain the validity of results based on the holding time of the sample from time of collection to time of sample analysis.

\section{Criteria}

There are no holding times prescribed for soils. Half-life considerations are not relevant for NAA because the sample activity is induced in the sample at the time of irradiation.

Samples are to be stored at $4^{\circ} \mathrm{C}$. However, only extreme conditions would be expected to have any effect on these analytes, so it is not expected that data qualification would be warranted based on storage temperature deviations.

\section{Evaluation}

Compare sampling date on $\mathrm{COC}$ form with date and time of analysis on Form 6A-C.

E. Action

No qualification expected based on holding times or sample storage conditions. 


\subsection{INSTRUMENT CALIBRATION}

\section{A. Review items}

Peak searches from standards and representative samples. Efficiency information either from tables or from the instrument print-outs for the standards.

\section{B. Objective}

Instrument energy and counting efficiency criteria are established to ensure that the instrument is capable of producing accurate analytical results.

\section{Criteria}

Full initial calibration information was not required. The peak searches can be used to verify that peaks of the correct energies are observed. Check to see that efficiency values are reasonable. Typical values for germanium detectors can range from $10^{-2} \%$ to a few percent, depending on the detector itself, the geometry of counting, and the energy of the gamma ray being observed. Check to see that peak energies reported on peak searches are within 0.5 to $1.0 \mathrm{keV}$ of the expected value. Typically, standards will contain peaks ranging from around 80 to $2.0 \mathrm{MeV}$.

\section{Evaluation}

Check efficiency and energy values.

\section{E. Action}

If efficiency values are not available, or if energy calibration is off by more than the amount specified above, qualify the data as unusable (R).

\subsection{SAMPLE RESULTS}

\section{A Review Items}

Form I results, raw data, equations.

\section{B. Objective}

The purpose of reviewing and calculating a representative sample result is to verify that the calculations have been performed correctly. There may be minor differences in handcalculated results and computer-calculated results due to differences in equations used to fit efficiency data, number of significant figures carried, etc.

\section{Criteria}

Sample concentrations from Form I should agree with results calculated using equations provided by the laboratory. Soil results should be reported in $\mathrm{mg} / \mathrm{kg}$. 
General equation for calculations:

$$
\begin{gathered}
w_{x}=w_{s} \times \frac{\text { Activity }_{x}}{\text { Activity } y_{s}} \\
w_{x}=w_{\alpha} \times \frac{\left[\frac{\text { counts }_{x} \times e^{\lambda t}}{\left[\frac{(e)(\gamma \text { ray abundance })(\text { count time })}{\text { counts, } \times e^{\lambda t}}\right]}\right.}{\left.\frac{m g}{(e)(\gamma \text { ray abundance })(\text { count time })}\right]}=\frac{w_{x}}{\text { sample mass }}
\end{gathered}
$$

Where: $x=$ unknown

$\mathrm{s}=$ standard

$\lambda=$ decay constant $=0.693 /$ half-life of radionuclide

$t=$ time of decay in same units as $\lambda$

$e=$ detector efficiency

For uranium calculations, net neutron counts are substituted for activity in the first equation above.

Equation used for calculating detection limits:

$$
M D A=\frac{4.66 \sqrt{s_{b}}}{\text { (Recovery) (Mass) (Count eff.) (Branch. ratio) (Decay factor) (Act. conv.) } \sqrt{c t}}
$$

$$
\text { Decay factor }=e^{-\frac{0.693}{\left(t_{1}-t_{2}\right) / t_{1 / 2}}}
$$

Where: ct $\quad=$ sample count time (analyzer live time for counting period),

$$
S_{b} \quad=\text { number of counts, }
$$

$t_{i} \quad=$ clock (real) time for counting period,

$t_{\mathrm{s}} \quad=$ decay time,

$t_{1 / 2} \quad=$ half-life of radionuclide, and

Act. conv. $=2.22$.

\section{Evaluation}

At least one result from each of the three counting regimes (short, medium, and long) should be verified. Compare calculated results with Form I results.

\section{E. Action}

If results for a given element cannot be reproduced, qualify the data as unusable (R). $\mathrm{C}$ ntinue checking other elements in the counting regime to determine whether the error is ipecific to that element or occurs for all elements. 


\subsection{INTERFERENCES}

\section{A Review Items}

List of interference corrections.

\section{B. Objective}

The most common type of interference in NAA is spectral, where the energies of two or more gamma rays are so close that they cannot be resolved by the detector and software system. If the interfering elemer " has a "clean" peak (i.e., one that does not suffer from overlap with any other peak), a correction for the contribution of the interfering element to the problem peak can be made.

\section{Criteria}

Verify the presence of the list of interferences. Use the data from the representative sample to evaluate the effect of the interference on the analyte.

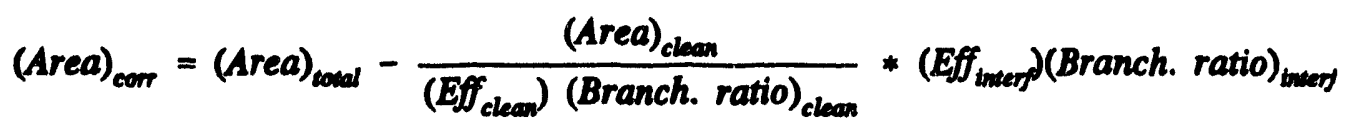

D. Evaluation

Check the calculation for any significant interferences.

E. Action

If interference corrections have not been made, qualify associated data as unusable (R).

\subsection{BI_ANKS}

\section{A Review Items}

\section{Form 2.}

\section{B. Objective}

The objective of the blank analysis is to determine the existence and magnitude of contamination problems arising from laboratory manipulations or sample containers. For this data, it is acceptable to subtract the blank from raw counts for the uranium determinations.

\section{Criteria}

Blanks should be carried through the entire sample preparation and analysis procedure. There should be one blank in each batch of samples. Blank activity in each peak of interest should be less than $5 \%$ of the typical analyte level. 
D. Evaluation

Verify that a blank is reported with each batch. Review blank activities and compare to the activities of the representative sample peak search.

E. Action

If the blank activities are less than 5\% of typical sample activities, no action is taken. If blank activities are from 5 to $30 \%$ of analyte levels, qualify the data as estimated (J). If blank activities are more than $30 \%$ of analyte levels, qualify the data as unusable (R).

\subsection{LABORATORY CONTROL SAMPLES}

\section{A. Reviow Items}

Form 3, identities and true values for LCS.

\section{B. Objective}

LCS data are used to provide information on the accuracy of the analytical method and the laboratory performance.

\section{Criteria}

LCSs must be analyzed at a frequency of once per 20 samples. The reported values for analytes must be within 80 to $120 \%$ of the true value.

\section{Evaluation}

Verify calculation of $\% \mathrm{R}$ using data reported on Form 3.

Ensure that each sample batch and counting regime have at least one LCS, and that all elements that are reported are found in at least one LCS.

Verify that reported values are within 80 to $120 \%$ of the true values.

\section{E. Action}

If an element is not present in any LCS, qualify the data for that element only as unusable (R).

If percent recovery for a given analyte is between $\mathbf{5 0}$ to $\mathbf{7 9 \%}$ in more than half of the LCS, qualify all associated data as estimated (J). If percent recovery is from 121 to $149 \%$, qualify all detected values as estimated $(J)$.

If the percent recovery for a given analyte is less than $50 \%$, reject all data. If recovery is more than $150 \%$, reject all detected values. 


\subsection{MATRX SPIKES}

\section{A. Review Items}

Form 4 results, spike addition data

\section{B. Objective} matrix.

MS data provide information on the accuracy of the analytical method for the sample

\section{Criteria}

One MS should be analyzed per batch. Recoveries should be from 75 to $125 \%$, except for analyte concentrations more than 4 times the spike amount. In that case, spike recoveries are not applicable. Field blanks should not be used for the MS.

\section{Evaluation}

Verify that the spike was run at the required frequency. Verify calculation of spike recovery reported on Form 4. Note that, for NAA data, all values should be converted to mass before calculation.

\section{E. Action}

If analyte concentrations are greater than 4 times the spike amount, recovery limits are not applicable and no qualification of data should be done.

If $\% \mathrm{R}$ is less than $10 \%$, qualify all data as unusable ( $R$ ).

If $\% R$ is between 10 to $74 \%$, qualify all data as estimated (J).

If $\% R$ is between 126 to $200 \%$, qualify all detected data as estimated (J).

If $\% \mathbf{R}$ is greater than $200 \%$, qualify all detected data as unusable (R).

\subsection{DUPLICATES}

\section{A. Review Items}

\section{Form 5B}

\section{B. Objective}

Duplicate data provide information on the precision of the analytical method for the sample matrix. 


\section{Criteria}

Duplicate RPD limits of $100 \%$ (from the EPA Region II guidelines) are used. There should be one duplicate analyzed per batch. Field blaniss should not be used for the duplicate.

\section{Evaluation}

Verify that duplicates were analyzed at the required frequency. Verify results for \%RPD reported on Form 5B.

E. Action

If $\%$ RPD is greater than $100 \%$, qualify all data as estimated (J).

\subsection{OVERALL ASSESSMENT OF DATA}

\section{A. Review Items}

Entire data package

\section{B. Objective}

The overall assessment of a data package is a brief narrative in which the data reviewer expresses concerns and comments on the quality and usability of the data.

\section{Criteria}

Assess overall quality of the data.

D. Evaluation

Evaluate any technical problems that have not been previously addressed.

Review all available materials to assess overall quality of the data, keeping in mind the additive nature of analytical problems.

\section{E. Action}

Use professional judgement in qualifying data not specifically covered by the guidelines above. 


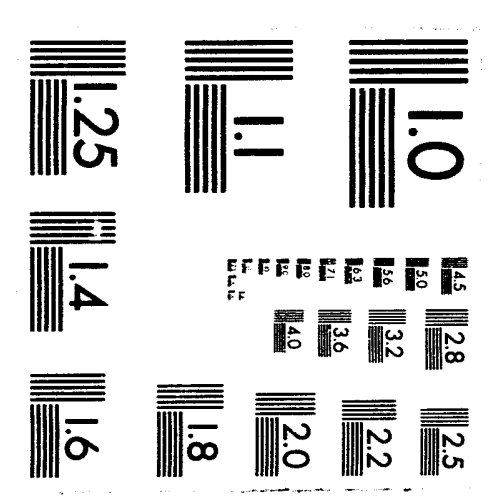





\section{DATA VALIDATION OF INORGANICS BY ICP/MS METHOD}

These guidelines are intended to address ICP/MS analysis results by draft Miethod 6020 CLP-M, Version 7.0. Some modifications are required for data by SW-846 Method 6020 . The applicability of these methods to analytes other than those specified in the method has not been defined.

It is expected that the inorganics CLP forms are an appropriate reporting mechanism for most of the data needed for validation, although some additional information may be required, as noted in the guidelines. The CLP protocol refers to forms, but the forms do not appear to have been made available.

\subsection{HOLDING TIMES AND PRESERVATION (COC AND FORM I)}

\section{A. Criteria}

1. Holding time is measured from the time of collection to the time of analysis. (Compare the Date Sample Collected on the COC to the Date of Analysis on Form I.)

2. There is no holding time criterion for soil samples; however, water holding times may be applied to soil samples if desired. Preservation of soil samples consists of storage at 4 $\pm 2^{\circ} \mathrm{C}$ from time of collection to time of analysis.

3. Holding time for aqueous samples is a maximum of 6 months; samples must be preserved to $\mathrm{pH}$ less than 2. Samples for dissolved metals must be filtered immediately upon collection, before addition of preservative.

Note: Recovery is very poor for mercury; ICP/MS should be considered only as a screening method for high quantities of mercury in the sample. This is a checklist for Level D validation; therefore, analysis for $\mathrm{Hg}$ is not applicable.

4. Examine the COC and prep logs to determine if samples were preserved at the proper $\mathrm{pH}$.

\section{B. Action}

1. If the criteria for holding times and preservation are not met, qualify all results greater than IDL as estimated (J) and results less than IDL as estimated (UJ).

2. If holding times are exceeded, the reviewer must use professional judgement to determine the reliability of the data and the effects of additional storage on the sample results. The expected bias would be low, and the reviewer may determine that results less than IDL are unusable (R). 


\subsection{CALIBRATION (FORM II)}

\section{A. Criteria}

1. Initial Calibration

a. Instruments are to be calibrated daily and each time the instrument is set up.

b. The tuning solution must be run at least four times with a RSD of less than $10 \%$ for all analytes.

c. Conduct mass calibration and resolution checks using the tuning solution. The intensities and ratios must be within the windows established.

Note: The method contains recommended response factor criteria for the checks in Item C. These recommendations will be the guidelines to be followed in validation unless further information is provided by EPA or the data indicate that the recommendations are unreasonable.

d. The tuning solution must be analyzed at the beginning of each run before calibration and after the mass calibration and resolution checks are performed.

e. The calibration must include a calibration blank and at least one calibration standard.

- Each integration during calibration and sample analysis must be reported, but the average of the multiple integrations is used for the reported value. A minimum of two replicate integrations is required for both calibration and sample analysis. The raw data must include the concentration of elements in each integration as well as the average. If different detector configurations are used, the raw data must indicate which detector configuration applies to them.

f. A memory test must be performed on the tuned and calibrated instrument before any analyses are performed. All analytes in the blank run after the memory test solution must be at concentrations < contract required detection limit (CRDL).

g. All masses which would affect data quality must be monitored to determine potential effects from matrix components on the analyte peaks.

\section{ICV and CCV}

Analysis results must fall within the control limits of 90 to $110 \%$ Recovery (\%R) of the true value for all analytes.

\section{B. Action}

1. If the tuning solution was not run at the appropriate time, at least 4 times with an RSD of $<10 \%$, in general the data will have to be rejected; in some cases, such as if the RSD is only slightly exceeded, professional judgement may determine that the data can be 
qualified as estimated (J). A faulty initial calibration is very detrimental to the level of confidence in data quality.

2. If the inten $:{ }^{\circ}$ es and resolution checks are not within the established windows, associated data are qualified unusable $(R)$.

3. If the minimum number of standards, as defined above, were not used for initial calibration, or if the instrument was not calibrated daily and each time the instrument was set up, qualify the data as unusable (R).

4. If only a single integration is used for an analysis, or if the associated detector configuration is not specified, data are qualified as estimated $(J)$ or, for nondetects, as estimated nondetects (UJ).

5. If the memory test is not performed, qualify all data as estimated (J) or, for nondetects, as estimated nondetects (UJ). If the blank following the memory test solution shows contamination, qualify data for that analyte as estimated (J) or, for nondetects, as estimated nondetects (UJ).

6. If review of the raw data indicates effects from matrix interferences, professional judgement must be used to determine the usability of the data.

7. If the ICV or CCV \% R falls outside the acceptance windows, use professional judgement to qualify all associated data. The following guidelines are suggested:

- If the ICV or CCV \%R falls outside the acceptance windows but within the ranges or 75 to $89 \%$ or 111 to $125 \%$ qualify the results greater than IDL as estimated (J).

- If the ICV or CCV \%R is within the range of 111 to $125 \%$, results less than IDL are acceptable.

- If the ICV or CCV \%R is 75 to $89 \%$, qualify the results less than IDL as estimated (UJ).

- If the ICV or CCV \%R is less than $75 \%$, qualify all positive results as unusable (R).

- If the ICV or CCV \% R is greater than $125 \%$, qualify results greater than IDL as unusable (R); results less than IDL are acceptable.

\subsection{BLANKS (FORM I AND FORM II)}

\section{A. Criteria}

1. The criteria for evaluation of blanks applies to any blank associated with the samples, including method, field, and rinsate blanks.

2. Verify that field and rinsate blanks have been performed at the frequency indicated by the project. 
3. Verify that an associated method blank has been performed with each sample per matrix.

4. No contamination should be present in any blanks.

B. Action

1. Sample results greater than IDL but less than 5 times the amount in any blank should be qualified as (U).

2. Results must not be corrected by subtracting any blank values.

\subsection{ICP INTERFERENCE CHECK SAMPLE (ICS) (FORM IV)}

\section{A. Criteria}

1. An ICS must be run at the beginning of each sample analysis run or once every $12 \mathrm{~h}$ (whichever is more frequent).

2. Results for the ICS Solution A analysis must not exceed the CRDL.

3. Results for the ICS Solution $A B$ analysis must fall within plus or minus $10 \%$ of the true value or $\pm 2 \mathrm{X} \mathrm{CRDL}$, whichever is greater for any analyte. (Analytical values are not required for the analytes present in ICS A.)

4. Recalculate from the raw data several of the recoveries and verify that the recalculated values agree with the laboratory reported values on Form IV.

5. Check the ICS raw data for results with an absolute value greater than IDL for those analytes which are not present in the ICS solution.

6. Extensive corrections for interferences are to be expected.

\section{B. Action}

1. For samples with concentrations of interference sources which are comparable to or greater than their respective levels in the ICS:

- If the ICS recovery for an element is greater than $110 \%$ and the sample results are less than IDL this data is acceptable for use.

- If the ICS recovery for an element is greater than $110 \%$ and the sample results are greater than IDL, qualify the affected data as estimated (J).

- If the ICS recovery for an element falls between 50 to $89 \%$ and the sample results are greater than IDL, qualify the affected data as estimated (J).

- If sample results are less than IDL, and the ICS recovery for that analyte falls within the range of 50 to $89 \%$, the possibility of false negatives may exist. Qualify the data for these samples as estimated (UJ). 
- If ICS recovery results for an element fall less than 50\%, qualify the affected data as unusable (R).

2. If results greater than IDL are observed for elements which are not present in the EPA provided ICS solution, the possibility of false positives exists. An evaluation of the associated sample data for the affected elements should be made. For samples with comparable or higher levels of interfering compounds and with analyte concentrations that approximate those levels found in the ICS (false positives), qualify sample results greater than IDL as estimated (J).

3. If negative results are observed for elements that are not present in the EPA provided ICS solutions, and their absolute value is greater than IDL, the possibility of false negatives in the samples may exist. If the absolute value of the negative result is greater than IDL, an evaluation of the associated sample data should be made. For samples with comparable or higher levels of interfering compounds, qualify results for the affected analytes less than IDL as estimated (UJ).

4. In general, the sample data derived from uncorrected equations can be accepted if the concentrations of interference sources such as $\mathrm{C}, \mathrm{Cl}, \mathrm{Mo}, \mathrm{Zr}$, and $\mathrm{W}$ are below levels that show an effect on the analyte level. If interferents contained in the ICS are present in the sample at concentrations greater than the level in the ICS, or other elements likely to cause interference are present in the sample, the reviewer should investigate the possibility of additional interference effects. When an interference source is present, the sample elements impacted must be flagged to indicate the percentage interference correction applied to the data or else the uncorrected interference by virtue of the elemental equation used for quantitation.

Therefore, estimate the concentration produced by an interfering element. If the estimate is greater than 2 times the CRDL and also greater than $10 \%$ of the reported concentration of the affected element, qualify the affected results as estimated (J).

\subsection{LABORATORY CONTROL SAMTLE (FORM VI)}

\section{A. Criteria}

1. All aqueous LCS results must fall within the control limits of 80 to $120 \% \mathrm{R}$, except $\mathrm{Sb}$ and $\mathrm{Ag}$ which have no control limits.

2. All solid LCS results must fall within the control limits established by the EPA. This information is available from Environmental Monitoring Support Laboratory, Las Vegas.

\section{B. Action}

1. Review Form VII and verify that results fall within the control limits.

2. Check the raw data (ICP printout, strip charts, bench sheets) to verify the reported recoveries on Form VII. Recalculate several of the recoveries. 


\section{Aqueous LCS}

- If the LCS recovery for any analyte falls within the range of 50 to $79 \%$ or greater than $120 \%$, qualify the results greater than IDL as estimated (J).

- If results are less than IDL and the LCS recovery is greater than $120 \%$, the data are acceptable.

- If results are less than IDL and the ICS recovery falls within the range of 50 to $79 \%$, qualify the data for the affected analytes as estim-ted (UJ).

- If LCS recovery results are less than $50 \%$, qualify the data for these samples as unusable (R).

\section{Solid LCS}

- If the solid recovery for any analyte falls outside the EPA control limits, qualify all sample results greater than IDL as estimated (J).

- If the LCS results are higher than the control limits and the sample results are less than IDL, the data are acceptable.

- If the LCS results are lower than the control limits, qualify all sample results less than IDL as estimated (UJ).

\subsection{DUPLICATE SAMPLE ANALYSIS (FORM VI)}

\section{A. Criteria}

1. Duplicates are indicators of laboratory precision.

2. Samples identified as field blanks cannot be used for duplicate sample analysis.

3. A control limit of plus or minus $20 \%$ ( $35 \%$ for soil) for the RPD shall be used for sample values greater than 100 times the IDL.

\section{B. Action}

1. Review Form VI and verify that results fall within the control limits.

2. Check the raw data and recalculate several of the RPDs as reported on Form VI.

3. Verify that the field blank was not used for the duplicate analysis.

4. If the duplicate analysis results for a particular analyte fall outside the appropriate control windows, qualify the results for that analyte in all associated samples of the same matrix as estimated $(\mathrm{J})$. 
5. If the field blank was used for duplicate analysis, all other QC data must be carefully checked and professional judgement exercised when evaluating the data. This information must be included in the validation notes.

\subsection{MATRIX SPIKE SAMPLE ANALYSIS (FORM V)}

\section{A. Criteria}

1. Samples identified as field blanks cannot be used for spiked sample analysis.

2. Spike recovery (\%R) must be within the limits of 75 to $125 \%$. The spike addition must produce a minimum signal level of $100 \mathrm{X}$ and a maximum of $1000 \mathrm{X}$ the IDL and must be at the levels prescribed in the method. Acceptance criteria do not apply if the concentration of the analyte in the sample is $>4 \mathrm{X}$ the spike level.

3. Review Form $\mathrm{V}$ and verify that results fall within the specified limits.

4. Check raw data and recalculate several of the \% R values as reported on Form $\mathrm{V}$.

5. Verify that the field blank was not used for the spike analysis.

6. If spike recovery is outside limits and the sample concentration is less than $4 \mathrm{X}$ the spike level, a post-digestion spike and a spiked dilution of the sample are analyzed. Review results of post-digestion spikes to ensure that low recoveries were due to matrix interferences and check that diluted values, corrected for the dilution, were the results that were reported for the analyte in question.

\section{B. Action}

1. If the spike recovery is greater than $125 \%$ and the reported sample results are less than IDL, the data is acceptable.

2. If the spike recovery is greater than $125 \%$ or less than $75 \%$ and the sample results are greater than IDL, qualify the data for these samples as estimated (J).

3. If the spike recovery falls within the range of 30 to $74 \%$ and the sample results are less than IDL, qualify the data for these samples as estimated (UJ).

4. If the spike recovery results fall less than $30 \%$ and the sample results are less than IDL, qualify the data for these samples as unusable (R).

5. If the field blank was used for MS analysis, all other QC data must be carefully checked and professional judgement exercised when evaluating the data. This information must be included on the validation notes. 


\subsection{SERIAL DILUTION (FORM IX)}

\section{A. Criteria}

1. If the analyte concentration is sufficiently high (concentration in the original sample is minimally a factor of 100 above the IDL), an analysis of a 5-fold dilution must agree within $\pm 10 \%$ of the original results.

2. Check the raw data and recalculate the $\% \mathrm{D}$ to verify the results as reported on Form IX.

3. Check the raw data for evidence of negative interference (i.e, results of the diluted sample are significantly higher than the original sample).

B. Action

1. When criteria are not met, qualify the associated data as estimated (J).

2. If evidence of negative interference is found, use professional judgement to qualify the data.

\subsection{SAMPLE RESULT VERIFICATION (FORM XIII)}

\section{A. Criteria}

1. Analyte quantitation must be calculated according to the appropriate SOW.

2. Examine the raw data for any anomalies (i.e., baseline shifts, negative absorbances, omissions, legibility, etc.)

3. Verify that there are no transcription or reduction errors (e.g., dilutions, percent solids, sample weights) on one or more samples.

4. Verify that results fall within the linear range of the instrument (Form XIII).

5. Ensure that the electron channel multiplier is not suffering from fatigue, as evidenced by constantly changing response factors.

\section{B. Action}

If there are any discrepancies found, the laboratory may be contacted by the reviewer to obtain additional information that could resolve any differences. If a discrepancy remains unresolved, the reviewer may determine that qualification of the data is warranted. 


\subsection{INTERNAL STANDARDS}

\section{A. Criteria}

A minimum of three internal standards must be present in all standards and samples at an identical level. The three internal standards must bracket the mass range and must include one internal standard from each of the following mass ranges: 1 to 70,71 to 125 , and 126 to 250 . The intensity of the internal standard must be within 30 to $120 \%$ of the intensity of that internal standard in the initial calibration standard. If it is not, the sample must be diluted 5-fold and reanalyzed with a new addition of internal standard until the internal standard intensities fall within the window.

\section{B. Action}

1. If the mass range is not represented by an internal standard, qualify the sample result "R."

2. If the internal standard intensity is not within 30 to $120 \%$ of that of the calibration standard and the sample has not been diluted and reanalyzed:

- $\quad$ Positive results for analytes quantitated using that IS are qualified as estimated "J."

- Nondetects for analytes quantitated with that IS are qualified as the CRDL as estimated (UJ).

- If extremely low or erratic intensities are reported, or if performance exhibits a major, abrupt dropoff, nondetects should be qualified as unusable "R."

\subsection{OVERALL ASSESSMENT OF DATA FOR A CASE}

It is appropriate for the data reviewer to make professional judgements and express concerns and comments on the validity of the overall data for a case. This is particularly appropriate when there are several QC criteria out of specification. The additive nature of QC factors out of specification is difficult to assess in an objective manner, but the reviewer has a responsibility to inform the user concerning data quality and data limitations to assist that user in avoiding inappropriate use of the data, while not precluding any consideration of the data at all. If qualifiers other than those used in this document are necessary to describe or qualify the data, it is necessary to thoroughly document/explain the additional qualifiers used. The data reviewer would be greatly assisted in this endeavor if the data quality objectives were provided. The cover form and supplementary documentation must be included with the review. 


\section{DATA VALIDATION OF RADIONUCLIDES BY GAMMA SPECTROSCOPY}

\subsection{METHOD SUMMARY}

This method is a nondestructive technique for determining gamma-emitting radionuclides in environmental samples. A multichannel analyzer system with a germanium detector is used to obtain gamma spectra.

\subsection{LEVEL D DELIVERABLES}

Signed COC form

Case narrative

Control charts

Method blank results

Sample results

Calibration information and calculations

Continuing calibration check information

Copy of run log

Raw data for all routine, blank, and QC samples, including instrument printouts, photocopied pages of laboratory notebooks, worksheets which refer to sample weights, dilutions, concentrations, data reduction, sample cleanup, instrument calibration logs, and standards preparation and tracing.

\subsection{TECHNICAL HOLDING TMMES}

\section{A. Review Items}

Form I, COC forms, sample prep logs, and instrument printouts.

B. Objective

The objective is to ascertain the validity of results based on the holding time of the sample from time of collection to time of sample analysis. 


\section{Criteria}

From a compliance standpoint, radiochemical samples are required to be analyzed within 6 months of sample collection. There is no technical qualification of data for missed holding times as such; however, the sample should be analyzed within four half-lives of the projectspecific radionuclide with the shortest half-life to maintain detection limits within a reasonable counting time.

The half-life multiplied by four is less than the 6 months compliance holding time for the following radionuclides of interest:

\begin{tabular}{ll} 
Radioisotope & Half-Life \\
\hline Chromium-51 & $27.70 \mathrm{~d}$ \\
Hafnium-181 & $42.40 \mathrm{~d}$ \\
Niobium-95 & $34.98 \mathrm{~d}$ \\
Ruthenium-103 & $39.24 \mathrm{~d}$ \\
Thorium-234 & $24.10 \mathrm{~d}$
\end{tabular}

Acid preservation is required for water samples. For this project, only the field blanks and rinsates are aqueous. No chemical preservation is specified for soil samples, so no qualification of data on that basis is required. Any impact on the data from unpreserved field QC samples would not be identified until the overall assessment (see Sect. 9.10).

Samples are to be stored at $4^{\circ} \mathrm{C}$. However, only extreme conditions wou'd be expected to have any effect on these analytes so it is not expected that data qualification would be warranted based on storage temperature deviations.

\section{Evaluation}

Technical holding times are established by comparing the sampling date and time on the COC form with date and time of analysis on the results form, if given, or else in the raw data.

\section{E. Action}

For the radionuclides with short half-lives listed above, in cases where the compliance time has not been exceeded but the analysis has taken place more than four half-lives since sample collection, check the sample counts to ensure that sufficient counting time has been allowed to reach the desired MDAs.

As indicated in the criteria section above, no action is required based on chemical preservation; technical judgement must be used to determine if extreme storage temperature deviations require the data to be qualified as "J."

If deficiencies in the COC documentation are noted, they should be reported in the DVR as outlined above. It should be noted that a problem could arise if any of the affected data are to be used in litigation.

Any noted deficiencies which do (or could) affect the data on a chemical basis can be considered "major" deficiencies. As an example, general requirement deficiencies which 
prevent the reviewer from deternuining the date of sample collection or date of analysis, and preclude determination of technical holding time, would be considered major. The inability of a reviewer to determine the date or time of sample analysis due to general requirements deficiencies may prevent the linking of the sample with a specific calibration, method blank, or other QC measures. Upon discovery of a "major" general requirements deficiency, the data package review should be discontinued and the laboratory should be immediately contacted. Data review should not continue until the "major" deficiency has been resolved by the laboratory.

\subsection{INSTRUMENT CALIBRATION}

\section{A. Review Items}

Forms and raw data that provide energy and efficiency output and calculations; standards logbook copies.

\section{B. Objective}

Instrument energy and counting efficiency criteria are established to ensure that the instrument is capable of producing accurate analytical results.

\section{Criteria}

1. Energy and Full Width at Half-Maximum (FWHM) Calibration. At a minimum, the calibration standard must cover the range of energies and be traceable to National Institute of Standards and Technology (NIST) or equivalent. A minimum of 1000 counts should be acquired in both peaks. The energy slope should be about $0.5 \mathrm{keV}$ per channel, and the offset $\leq 1$; the calculated FWHM at $1332.5 \mathrm{keV}$ should be within 0.05 of the rated FWHM of the detector. Calibration must be done at least annually, and checked daily by means of a check standard.

2. Efficiency Calibration. Count the NIST traceable calibration source in a particular geometry and at a reproducible source-to-detector orientation. Acquire at least 20,000 counts in each peak of interest. Efficiency is calculated as follows:

$$
E=\frac{X-B}{S * P}
$$

Where: $\mathrm{X}=$ gross count rate in $\mathrm{cpm}$

$\mathrm{B}=$ background count in $\mathrm{cpm}$

$S=$ activity of the source in dpm, and

$\mathbf{P}=$ gamma photon abundance in gamma emissions per disintegration.

Repeat the analysis of the traceable calibration standard using the newly calculated geometry. The calculated activity should agree to within $\pm 10 \%$ of the certified activity stated on the calibration certificate.

Spectral peaks for the standards should be properly resolved and should not contain spurious background increases or drops. 


\section{Evaluation}

Check the date of the original calibration.

Percent dead time is not considered a problem for environmental samples, due to the probability of low activity. However, if there is a particularly hot sample, ensure the percent dead time is not large enough to miss a significant number of sample counts.

\section{E Action}

If the initial calibration does not meet criteria, qualify the data as unusable.

If NIST traceable standards are not used or the standards are not traceable, qualify all associated data as estimated detected, "J" or estimated nondetected, "UJ."

If there is a particularly hot sample, assess the percent dead time and use professional judgement to qualify the data.

\subsection{DAILY INSTRUMENT CALIBRATION CHECK}

\section{A. Review Items}

Daily QC report and raw data.

\section{B. Objective}

Ensure the instrument has passed a daily check and calibration is current for the radionuclides of interest to ensures that the instrument is capable of producing accurate analytical results at the start of the sample measurement run. Daily calibration verification ensures that the initial calibration remains valid throughout the sample measurement run.

\section{Criteria}

Control limits for the energy calibration check standards and efficiency check results are $\pm 10 \%$. All calibration standards must be NIST traceable.

\section{Evaluation}

Verify that the instrument was calibrated properly and at the required frequency.

\section{E. Action}

If the energy calibration check standard or efficiency check result is outside control limits, qualify all results $\geq \mathrm{MDA}$ as estimated $(\mathrm{J})$ and all results $<\mathrm{MDA}$ as nondetect estimated (UJ). If NIST traceable standards are not used or the standards are not traceable, qualify all associated data as estimated detected, "J" or estimated nondetected, "UJ." 


\subsection{BACKGROUND CHECK}

\section{A. Review Items}

Raw data (background data printout).

B. Objective

Ensure the background check shows no shield contamination.

C. Criteria

Background determinations should be plotted on control charts. Background results must be within \pm 3 standard deviations of the mean background activities.

D. Evaluation

Evaluate the background and ensure that it is within \pm 3 standard deviations of the mean background activities.

\section{E. Action}

If the background counts are beyond 3 sigma of the mean background counts, qualify results 2 MDA as estimated (J) and results < MDA as nondetect estimated (UJ).

\subsection{BLANKS}

\section{A. Review Items}

Forms and raw data

\section{B. Objective}

The objective of blank analyses is to determine the existence and magnitude of contamination problems resulting from laboratory performance. The criteria for evaluation of blanks apply to any blank associated with samples (e.g., method blanks). If problems with any blank exist, all associated data must be evaluated carefully to determine whether or not there is inherent variability in the data, or if the problem is an isolated occurrence not affecting other data.

\section{Criteria}

No contaminants should be present in blanks. Blanks will be analyzed for every sample set, for each matrix type, or once in every batch of samples (up to 20 samples), whichever is more frequent. 


\section{Evaluation}

Review the results of all associated blanks, Form Is, and raw data and verify that the results were accurately reported. Ensure that the proper number of blanks was analyzed, at the proper frequency.

Verify that method blank (reagent blank) analyses have been reported in a way that allows them to be associated with the samples with which they were prepared and analyzed.

\section{E. Action}

Action in the case of unsuitable blank results requires a large amount of professional judgement. The overall assessment of blank contamination should be performed paying particular attention to all associated QC samples (e.g., comparing the background counts to the blank counts, since the values should be approximately the same).

If there is contamination present in the blank and in the associated samples, the reviewer should report the contamination in the validation narrative and use professional judgement to qualify the data.

If gross contamination exists in a blank sample and associated samples, all associated sample data should be qualified as unusable "R."

If inordinate amounts of other radionuclides are found at low levels in the blanks, it may be indicative of a problem at the laboratory and should be noted in the data review comments.

\subsection{DUPLICATES}

\section{A. Review Items}

Reporting forms and raw data.

\section{B. Objective}

These data are generated to determined the laboratory precision of the analytical method for the sample matrix.

\section{Criteria}

Duplicate RPD limits are $\pm 35 \%$ for soil samples for analyte concentrations $25 \mathrm{X}$ MDA. The limit is \pm MDA for concentrations $<5 X$ MDA. One duplicate should be analyzed per batch. Field blanks should not be used for the duplicate.

All standards must be NIST traceable. 


\section{Evaluation}

Inspect results for the RPD and determine if they are within control limits according to the formula:

Verify transcriptions from raw data and verify calculations.

$$
\text { \% RPD }=\frac{2 * \mid \text { Sample Value }- \text { Duplicate Value } \mid}{(\text { Sample Value }+ \text { Duplicate Value })} * 100
$$

\section{E Action}

If all RPDs are within limits, no qualification is required. If the duplicate was not analyzed at the correct frequency or was run on the field blank, note the fact in the comments.

In those instances where it can be determined that the results of the duplicate affect only the sample spiked, then qualifications should be limited to this sample alone. Otherwise, if duplicate analysis results are outside control limits, qualify all results in the batch as estimated ("J").

If standards are not NIST traceable, qualify all associated data as estimated detected, "J" or estimated nondetected, "UJ."

\subsection{COUNTS FOR SAMPLES: EVALUATION OF RESULTS, COUNTING ERROR, AND MDA}

\section{A. Review Items}

Sample results, raw data, counting errors, MDAs, background results, and case narrative.

\section{B. Objective}

The objective is to ensure that the reported sample results, counting errors, and MDAs are accurate.

C. Criteria

1. Radionuclide quantitation must be calculated according to the appropriate procedures specified in the contractual work plan.

2. Detection limits specified in the specific approved procedures must be met unless other detection limits are specified.

3. Analytical uncertainties must be reported with all results to qualify the data. Results and uncertainties must be reported for all required analyses regardless of the size or sign of the result. The reported uncertainty must include all uncertainties associated with the analysis. If the reported uncertainty only includes counting uncertainty, this fact must be documented in the case narrative. 
4. Appropriate aliquot sizes must be used in sample preparation to provide representative subsampling.

5. When samples are dry mounted for counting, mounting aliquots must be selected to keep the dry mounted weight to $\leq 5 \mathrm{mg} / \mathrm{cm}^{2}$.

D. Evaluation

1. The raw data shall be examined to verify the correct calculation of sample results reported on the sample data summary forms.

2. Examine the raw data for omissions, reduction, and transcription errors.

3. Verify some of the calculations (e.g., MDA activity, uncertainty, tracer recoveries and yields). If errors are found in the calculations, more results may be required to be recalculated to determine the extent and effect of the errors.

4. Verify that all analytical uncertainties have been copied and reported or otherwise documented.

5. Verify that all appropriate aliquot sizes have been used for sample preparation.

6. Verify that decay corrections have been calculated properly and that radioactive source reports (standards certificates) are present for the tracer and all spikes used.

\section{E. Action}

1. When significant errors are found in the calculations, contact the laboratory for a resubmittal of corrected results.

2. When inappropriate aliquot amounts are used, professional judgement should be used to qualify the data.

3. For net negative results that have uncertainties less than their absolute value, qualify the data as unusable. This is an indication of improper background subtraction.

4. When estimated detection limits are not met, a discussion should be provided in the validation report and the analytical coordinator should be notified.

5. When analytical uncertainties are not reported, qualify the results as estimated, "J."

6. When standards certificates are not present, all data should be qualified as estimated.

7. If calculations show errors that are not significant and do not affect the data, note calculation findings in the case narrative.

8. When tracer yields are below limits established in the QAPjP or by the laboratory, qualify detects associated with low tracer yields as estimated (J), and nondetects as unusable (R). 
9. When tracer yields are above limits established in the QAPjP or by the laboratory, qualify detects associated with high tracer yields as estimated (J), nondetects receive no qualification.

\subsection{OVERALL ASSESSMENT OF DATA FOR A CASE}

\section{A. Review Items}

Entire data package, data review results, QAPjP, and SAP.

\section{B. Objective}

The overall assessment of a data package is a brief narrative in which the data reviewer expresses concerns and comments on the quality and, if possible, the usability of the data.

\section{Criteria}

Assess the overall quality of the data.

\section{Evaluation}

Evaluate any technical problems which have not been previously addressed.

Review all available materials to assess the overall quality of the data, keeping in mind the additive nature of analytical problems.

If appropriate information is available, the reviewer may assess the usability of the data to assist the data user in avoiding inappropriate use of the data. Review all available information [e.g., QAPjP (specifically the Data Quality Objectives), SOP, communication with data user or sampler concerning the intended use and desired quality of this data].

\section{E. Action}

Use professional judgement in qualifying data which were not qualified based on the QC criteria previously discussed.

Write a brief narrative which gives the user an indication of the analytical limitations of the data and the consistency of that data with the laboratory certification statement. If sufficient information on the intended use and required quality of the data are available, the reviewer should include his/her assessment of the usability of the data within the given contract.

\subsection{CALCULATIONS}

The following calculations are provided for the reviewer's ready access.

Decay Correction is given by: 


$$
A=A_{0} * e^{\frac{-\ln 2}{z_{1 / 2}} * T}
$$

Where: $\mathrm{A}=$ Activity in pCi per unit volume

$A_{0}=$ Initial Activity of Standard in $\mathrm{pCi}$ per unit volume

$t_{1 / 2}=$ Radioactive Half-life (in minutes)

$\mathbf{T}=$ Amount of time (in minutes) from the decay date (on the certificate of analysis) until analysis date

Sample Activity

The activity of the sample is defined through the following relationship:

$$
A=\frac{X-B}{2.22 * E * V * Y}
$$

Where: $\mathrm{A}=$ Activity of isotope $i$ in picocuries $(\mathrm{pCi})$ per unit volume

$\mathrm{X}=$ Coun $^{+}$rate of isotope $i$ in counts per minute (cpm)

$\mathrm{B}=$ Background count rate (cpm) in the isotope $i$ region of interest

$\mathrm{E} \quad=$ Detector efficiency

$\mathrm{V}=$ Sample volume in liters or weight in grams

$2.22=$ Conversion factor from dpm to $\mathrm{pCi}$

$\mathrm{Y}=$ Chemical recovery for the analysis which is determined from the isotopic tracer, $j$, added to the sample

The chemical recovery factor is given by:

$$
Y=\frac{X-B}{D * E}
$$

Where: $Y=$ Chemical Yield as a decimal

$\mathrm{X}=$ Count rate of standard isotope, $j$, in cpm

$\mathrm{B}=$ Background count rate (cpm) in the isotope $j$ region of interest

$\mathrm{D}=$ Certified activity for isotope $j$

\section{Uncertainty (Standard Deviation)}

The sample uncertainty, based on counting statistics, is expressed as one standard deviation of the net count rate in Pci unit volume as follows:

$$
E_{r}=2 * \frac{\sqrt{\left[\left(\frac{(X * T)^{1 / 2}}{T}\right)^{2}+\left(\frac{(B * T)^{1 / 2}}{T}\right)^{2}\right]}}{2.22 * E * V * Y}
$$

Where: $\mathrm{E}_{\mathrm{r}} \quad=$ Counting Error

$\mathrm{X}=$ Count rate of isotope $i$ in counts per minute (cpm)

$\mathrm{B}=$ Background count rate $(\mathrm{cpm})$ in the isotope $i$ region of interest

$\mathrm{E} \quad=$ Detector efficiency 
$\mathrm{V}=$ Sample volume in liters or weight in grams

$2.22=$ Conversion factor from dpm to $\mathrm{pCi}$

$\mathrm{Y}=$ Chemical recovery for the analysis which is determined from the isotopic tracer, $j$, added to the sample

MDA Calculation

The MDA at the $95 \%$ confidence level expressed in $\mathrm{pCi}$ per unit volume is given by:

$$
M D A=\frac{2.71+4.66 \sqrt{B * T}}{2.22 * E * Y * T * V}
$$

Where: $2.71=$ Statistical factor (at $95 \%$ confidence level)

$4.66=$ Confidence factor (at $95 \%$ confidence level)

$\mathrm{B}=$ Background counting rate $(\mathrm{cpm})$

$2.22=$ Conversion factor from dpm to $\mathrm{pCi}$

$\mathrm{E} \quad=$ Detector efficiency

$\mathrm{V}=$ Sample volume in liters or weight in grams

$\mathrm{Y} \quad=$ Chemical recovery

$\mathrm{T} \quad=$ Sample counting time (in minutes) 


\section{DATA VALIDATION OF RADIONUCLIDES BY ALPHA SPECTROSCOPY}

\subsection{METHOD SUMMARY}

Isotopes are separated from the sample matrix through ion exchange. Further extraction and separation may be required, depending on the radionuclide being analyzed. The extract is electroplated for analysis by alpha spectroscopy. Quantification of the isotopes is performed by dividing the observed peak areas of the isotopes of interest by the peak area of the tracer isotope which was added to the sample. If the detector efficiency is known, isotope recovery can be calculated.

This guideline is designed to offer instruction on radiochemical data evaluation and review. It is designed to offer general guidance in subjective areas, due to the uniqueness of the data to be reviewed. While some areas may overlap, this review process will provide information on analytical limitations of data based on preapproved $\mathrm{QC}$ criteria.

\subsection{LEVEL D DEIUIVERABLES}

The following information should be included in the data package. This information should be accompanied by all raw data and control charts.

Sample Data:

Sample Analysis Results (including energy spectra and library matches)

Data System Printouts

Radionuclide Cleanup Data

Positively Identified Radionuclides

Standards Data:

Calibration Data

Daily Instrument Performance Check Data

Radioactive Source Reports (standards certificates)

Raw QC Data:

Blank Data

Blank Spike Data

MS Data

Duplicate Data

Tracer Data

Other Information:

Internal COC Forms

Decay Corrections 


\subsection{TECHNICAL HOLDING TIMES}

\section{A. Review Items}

Sample data summary form, Sample Traffic Report, COC, raw data, preparation logs, and SDG Narrative.

\section{B. Objective}

The objective is to ascertain the validity of results based on the holding time of the sample from time of collection to time of sample extraction and analysis.

\section{Criteria}

Technical requirements for sample holding times and preservation have only been established for water matrices. The holding times for soils are currently under investigation. When the results are available they will be incorporated into the data evaluation process. Additionally, results of holding time studies will be incorporated into the data review criteria as the studies are conducted and approved. Due to the affinity of some radionuclides to adsorb to the glass/plastic containers, water samples should be preserved as described below. The maximum holding time for radionuclides in water samples is as follows.

Plutonium: 6 months, when preserved in $2 \mathrm{M}$ nitric acid

Other radionuclides: 6 months, when preserved to $\mathrm{pH}<2$ in nitric acid

Note: Uranium may be required to be preserved with hydrochloric acid instead of nitric acid.

It is recommended that radionuclides in soil samples be extracted and analyzed within the same time frame as the water samples.

\section{Evaluation}

Technical holding times for sample analysis are established by comparing the sample collection date on the Sample Traffic Report with the dates of extraction/analysis on the Sample Analysis Results forms and the sample extraction sheets. Verify that the traffic report indicates that the samples were received intact and properly preserved. If the samples were not properly preserved or there were any problems with the samples upon receipt, then discrepancies in the sample condition could affect the data.

\section{E. Action}

1. If technical holding times are exceeded, qualify all detected radionuclide results as estimated "J" and estimated minimum detectable activities as estimated "UJ," and document in the data review narrative that holding times were exceeded.

2. If the samples were not properly preserved, all positive results should be qualified as estimated.

3. If technical holding times are grossly exceeded, either on the first analysis or upon reanalysis, the reviewer must use professional judgement to determine the reliability of 
the data and the effect of additional storage on the sample results. The reviewer may determine that detected radionuclide results or the associated estimated minimum detectable activities are approximations and should be qualified with "J" or "UJ," respectively. Due to the nature of the radionuclides analyzed by alpha spectroscopy, it is not likely that the reviewer may need to determine that nondetected radionuclide data are unusable, "R."

4. Due to limited information concerning holding times for soil samples, it is left to the discretion of the data reviewer to apply water holding time criteria to soil samples. Professional judgement is required to evaluate holding times for soil samples.

5. Whenever possible the reviewer should comment on the effect of exceeding the holding time on the resulting data in the data review narrative.

6. When holding times are exceeded, this should be noted as an action item for the analytical coordinator.

\subsection{INITIAL AND CONTINUING CALIBRATION}

\section{A. Review Items}

Forms, standard preparation logs, manual calculations, keV v. channel plots, centroid results, FWHM, efficiency, background results, and data system printouts.

\section{B. Objective}

Compliance requirements for satisfactory initial calibration are established to ensure that the instrument is capable of producing acceptable qualitative and quantitative data for radionuclides. Initial calibration demonstrates that the instrument is capable of acceptable performance at the beginning of the analysis. CCVs and system checks ensure that the initial calibration is still acceptable.

\section{Criteria}

Initial Calibrations are to be performed using NIST traceable standards and verifications are to be done using an NIST traceable standard or the instruments pulsar. The amount of standard must be more than 5 disintegrations per minute (dpm).

\section{Evaluation}

1. Verify that the calibration standards were analyzed at the proper frequency for each instrument used for analysis. Centroid, FWHM, and efficiency must be checked daily, while background must be checked weekly. Check the raw data and data system printouts for each standard to verify that each of the standards was analyzed at the required concentration levels.

2. Check the raw data and determine that the standard's concentration is greater than 5 dpm. 
3. Check the calculation of efficiencies and ensure that they were performed at least annually or when daily performance check demonstrates unacceptable change in the system efficiency, and were within the approved tolerance limits.

4. Review energy versus channel calibration to verify that it was performed at least quarterly or when daily performance checks demonstrated unacceptable change in energy gain or zero offset.

5. Verify activity was calculated from a net count rate.

6. Review error to confirm the standard deviations used to report errors.

7. Verify system background calculations were performed at least quarterly or whenever the performance check indicated an unacceptable change in system background.

8. Verify that tolerance limits that were exceeded were recalibrated.

9. Verify that NIST traceable standards were used to calibrate the instrument.

10. Percent dead time is not considered a problem for environmental samples, due to the probability of low activity. However, if there is a particularly hot sample, ensure the percent dead time is not large enough to miss a significant number of sample counts.

\section{E. Action}

1. If calibration was not followed as required, then professional judgement must be used to evaluate the effect of the noncompliance on the sample data. If the requirements for calibration were not met, then this should be written as an action item and given to the analytical coordinator for execution. If the noncompliance has a potential effect on the data, then the data should be qualified according to the professional judgement of the reviewer, and should be noted in the data review narrative. The following items are guidance used in making professional judgements.

a. If criteria are not met, then the quantitative results may not be accurate. Positive sample results for radionuclides that had calibration outside the tolerance limits should be qualified with "J." Nondetected target radionuclides may not be valid depending on the extent of the problem. Professional judgement should be used to qualify data as unusable, "R."

b. Potential effects on the sample data due to problems with calibration should be noted in the data review narrative. If the data reviewer has knowledge that the laboratory has repeatedly failed to comply with the requirements for frequency linearity plots, or the plots fail to meet criteria, the data reviewer should notify the analytical coordinator by writing an action item.

c. If activity was not calculated from a net count rate, the reviewer should calculate the rates and apply them to the sample results. If a change in rates cause a change in any results, note in the case narrative. 
d. If new background peaks are identified and no new background was established, the reviewer should use professional judgement in determining whether the background peaks may interfere with target isotopes, and qualify accordingly.

e. If tolerance limits are exceeded, qualify the data as estimated, "J," for detects, and as estimated nondetected, "UJ," for nondetects.

f. If there is a particularly hot sample, assess the percent dead time and use professional judgement to qualify the data.

\subsection{BLANKS}

\section{A. Review Items}

Blank Results forms, sample results, and data system printouts.

\section{B. Objective}

The purpose of laboratory (or field) blank analyses is to determine the existence and magnitude of contamination problems resulting from laboratory (or field) activities. The criteria for evaluation of blanks applies to any blank associated with the samples. If problems with a blank exist, all associated data must be evaluated carefully to determine whether or not there is an inherent variability in the data, or if the problem is an isolated occurrence not affecting other data.

\section{Criteria}

1. No significant contamination should be present in the blanks.

2. Frequency:

a. Reagent Blanks (Method Blanks) - A method blank analysis must be performed for each 20 samples of similar matrix in each SDG or whenever a sample extraction procedure is performed.

b. Instrument Background (Instrument Blanks) - An acceptable instrument blank must be run before the analysis of the environmental samples. This blank gives background radioactivity information.

c. Field Blanks - This blank may not always be required for analysis. However, when analyzed, no significant contamination should be present.

D. Evaluation

1. Review the results of all associated blanks, Sample Analysis Results forms, and associated data and data system printouts to evaluate the presence of radionuclides.

2. Verify that method blank analyses have been reported per SDG, per matrix, for each system used to analyze samples, and for each extraction batch. 
3. Verify that the instrument blank analysis has been performed as part of the continuing calibration.

4. Ensure the estimated MDA is sample specific, and not a generalized value.

E Action

Action in the case of unsuitable blank results requires a large amount of professional judgement. The overall assessment of blank contamination should be performed paying particular attention to all associated QC samples (e.g., comparing the background counts to the blank counts, since the values should be approximately the same).

If the appropriate blanks were - ot analyzed with the frequency described in the approved documentation, then the data revie . s should use professional judgement to determine if the associated sample data should be qualified. The reviewer may need to obtain additional information from the laboratory. The situation should be brought to the attention of the analytical coordinator who may determine that as action item be written and sent to the laboratory.

If there is contamination present in the blank and in the associated samples, the reviewer should report the contamination in the validation narrative and use professional judgement to qualify the data.

If gross contamination exists in a blank sample and asśociated samples, all associated sample data should be qualified as unusable "R."

If inordinate amounts of other radionuclides are found at low levels in the blanks, it may be indicative of a problem at the laboratory and should be noted in the data review comments.

\subsection{MATRIX SPIKESMATRXX SPIKE DUPLICATES}

\section{A Review Items}

MS results, spike volumes, and activities of standards used in spiking, raw data including count rates, and data system printouts.

\section{B. Objective}

Data for spikes are generated to determine precision and accuracy of the extraction/digestion method on various matrices. These data alone cannot be used to evaluate the precision and accuracy of individual samples. However, when exercising professional judgement, MS/MSD data should be used in conjunction with information on other deficiencies. 


\section{Criteria}

1. Spiked samples are analyzed at a frequency of at least 1 per 20 samples of each matrix.

2. Spike recovery control limits are 75 to $125 \%$. One MS should be analyzed per batch.

3. Field blanks should not be used for the MS.

4. All spikes must be NIST traceable.

Note: A MSD may not always be required.

\section{Evaluation}

1. Verify that spiked samples were analyzed at the required frequency and that results are provided for each sample matrix.

2. Inspect results for the spiked samples and verify that the results for recovery and RPD are within the advisory limits.

3. Verify transcriptions from raw data and check calculations, including decay corrections.

4. Check that the MS/MSD recoveries and RPD were calculated correctly.

5. Compare \%RSD results of nonspiked radionuclides against the spiked results.

6. Ensure that all spikes are NIST traceable.

\section{E. Action}

1. No action is taken on spiked sample data alone. However, using informed professional judgement the data reviewer may use the spiked sample results in conjunction with other QC criteria and determine the need for some qualification of the data.

2. The data reviewer should first try to determine to what extent the results of the MS/MSD affect the associated sample data. This determination should be made with regard to the spiked samples themselves, as well as specific analytes for all samples associated with the spiked samples.

3. In those instances where it can be determined that the results of the MS/MSD affect only the MS/MSD, then no qualification should be made. However, it may be determined through the MS/MSD results that a laboratory is having a systematic problem in the analysis of one or more analytes, which affects all associated samples. For example, if the recoveries for the MS/MSD are consistently low, this could be indicative of a systematic problem in the laboratory and recoveries should be examined in all associated samples.

4. The reviewer must use professional judgement to determine the need for qualification of positive results of nonspiked radionuclides. 
5. If all recoveries (\%R) are within limits, no qualification is required. If the MS/MSD were not analyzed at the correct frequency or were run on the field blanks, note the fact in the comments.

6. If $\% \mathrm{R}$ is greater than $125 \%$ or less than $75 \%$, results greater than the MDA are qualified as estimated, "J."

7. If $\% \mathrm{R}$ is less than $75 \%$, but greater than $30 \%$, qualify results less than the MDA as nondetect estimated ("UJ").

8. If $\% R$ is less than $30 \%$, qualify results less than the estimated MDA as unusable ("R") and results greater than or equal to the estimated MDA as estimated ("J").

9. If the standard certificate is not present, or is not NIST traceable, qualify the data as estimated.

Note: If a field blank was used for the spiked sample, a statement to that effect must be included for the analytical coordinator.

\subsection{DUPLICATES}

\section{A. Review Items}

Reporting forms and raw data.

\section{B. Objective}

These data are generated to determined the laboratory precision of the analytical method for the sample matrix.

\section{Criteria}

1. Duplicate RPD limits are $\pm 35 \%$ for soil samples for analyte concentrations $25 X$ estimated MDA. A control limit of $\pm 2 X$ the estimated MDA for duplicate sample concentrations less than $5 \mathrm{X}$ the estimated MDA must be established.

2. One duplicate should be analyzed per batch.

3. Field blanks should not be used for the duplicate.

4. All spikes must be NIST traceable.

D. Evaluation

1. Review results for the RPD and verify that they are within the approved control limits

2. Verify transcriptions from raw data and check calculations.

3. Verify that the standards used are NIST traceable. 


\section{E. Action}

1. If all RPDs are within limits, no qualification is required. If the duplicate was not analyzed at the correct frequency or was run on the field blank, note the fact in the data review report.

2. In those instances where it can be determined that the results of the duplicate affect only the sample spiked, then qualifications should be limited to this sample alone. Otherwise, if duplicate analysis results are outside control limits, qualify all results in the batch as estimated $(" \mathrm{~J} ")$.

3. If the standards used are not NIST traceable, qualify all associated data as estimated detected, "J" or estimated nondetected, "UJ."

\subsection{LABORATORY CONTROL SAMPLES/ BLANK SPIKES}

\section{A. Review Items}

Laboratory control charts, standards certificates, and associated raw data.

\section{B. Objective}

Data for LCS/blanks spikes are generated to provide information on the accuracy of the analytical method and the laboratory performance.

\section{Criteria}

1. LCSs are analyzed at a frequency of one per SDG.

2. The percent recoveries for the LCS/blank spike radionuclides must be within the approved QC limits. The LCS/blank spike must meet the recovery criteria for the sample data to be acceptable.

3. All spikes must be NIST traceable.

D. Evaluation

1. Verify that LCS/blank spike samples were analyzed at the required frequency.

2. Verify that the LCS/blank spike recoveries reported in are within the advisory limits.

3. Check that the LCS/blank spike recoveries were calculated correctly.

4. Verify transcriptions from raw data to the data summary forms.

5. Review control charts.

6. Verify that standards certificates are present and are NIST traceable. 


\section{E. Action}

If the LCS/blank spike criteria are not met, then the laboratory performance and method accuracy are in question. Professional judgement should be used to determine if the data should be qualified or rejected. The following guidance is suggested for qualifying sample data for which the associated LCS/blank spike does not meet the required criteria.

1. Action on the LCS/blank spike recovery should be based on both the number of radionuclides that are outside of the recovery criteria and the magnitude of the noncompliance.

2. If the LCS/blank spike recoveries criteria are not met, then the LCS/blank spike results should be used to qualify sample data for the specific radionuclides that are included in the LCS/blank spike solution. If the LCS/blank spike recovery is out on the high end, detected target radionuclides may be qualified "J." Nondetects require no qualification. If the LCS/blank spike recovery is out on the low end, detected target radionuclides may be qualified "J" and nondetects may be qualified "UJ." Professional judgement should be used to qualify data for radionuclides other than those radionuclides that are included in the LCS/blank spike. Professional judgement to qualify non-LCS/blank spike radionuclides should take into account the radionuclide class, radionuclide recovery efficiency, analytical problems associated with each radionuclide, and comparability in performance of the LCS/blank spike radionuclide to the non-LCS/blank spike radionuclide.

3. If more than half of the radionuclides in the LCS/blank spike are not within required advisory recovery criteria, then all of the associated detected target radionuclides should be qualified "J" and associated nondetected radionuclides should be qualified unusable.

4. It should be noted for analytical coordinator action if a laboratory fails to analyze a LCS/blank spike with each SDG, or if the reviewer has knowledge that a laboratory consistently fails to generate acceptable LCS/blank spike recoveries.

5. If the LCS results are below established or internal laboratory QC limits, and, if MS results are below established or internal laboratory QC limits, detects should be qualified as estimated,"J," and nondetects should be qualified as unusa' 's,"R."

6. If the LCS results are above established or internal laboratory QC limits, and, if MS results are above established or internal laboratory QC limits, detects should be qualified as estimated,"J," and nondetects should not be qualified.

7. If the LCS results are below established or internal laboratory QC limits, detects should be qualified as estimated,"J," and nondetects should be qualified as estimated, "UJ."

8. If the LCS results are above established or internal laboratory QC limits, detects should be qualified as estimated,"J," and nondetects should not be qualified.

9. If the standard certificate is not present, or is not NIST traceable, qualify the data as estimated. 


\subsection{TRACER RECOVERY}

\section{A. Review Items}

Raw data, detector efficiency, standards certificates, standards preparation log sheets, decay corrections.

\section{B. Objective}

Data review for tracer recoveries is to ensure the laboratory has corrected sample results based on tracer yield correctly.

\section{Criteria}

1. A tracer must be spiked into each sample.

2. A tracer standard must be NIST traceable.

3. Percent yields should be within QC limits as outlined in the QAPjP or established by the laboratory (whichever is applicable).

4. Sample values should be corrected for tracer yields.

D. Evaluation

1. Verify that standard certificates are present and NIST traceable.

2. Verify that decay corrections have been calculated correctly.

3. Verify that tracer yields have been calculated correctly.

4. Verify that tracer yields are within the QC limits established in the QAPjP or by the laboratory.

\section{E. Action}

1. If the tracer standard certificate is not present, or is not NIST traceable, qualify the data as estimated.

2. If decay corrections and dilutions have not been calculated correctly, the reviewer should perform some activity calculations using the correct value to determine the impact on sample results. If the error is gross, use professional judgement to qualify the data. The error should be discussed in the case narrative.

3. If low tracer yields are obtained, qualify all detects as estimated,"J," and all nondetects as unusable,"R."

4. If high tracer yields are obtained, qualify all detects as estimated, "J," and all nondetects as unusable,"R." 
Note: If a different tracer source is used (i.e., $\beta$, or $\gamma$ ), refer to that specific validation guideline.

\subsection{CHEMICAL SEPARATION SPECIFICITY}

\section{A. Review Items}

Forms, energy spectra, library matches, raw data and data system printouts.

\section{B. Objective}

Chemical separation specificity is the contract laboratory's ability to separate various radionuclides by chemical separation techniques. The chemical separation specificity can be verified for alpha spectroscopy measurements by observation of the alpha energy spectrum.

\section{Criteria}

1. There should be no radionuclides that interfere with the quantitation of the radionuclide of interest once the chemical separation process has been completed.

2. Energy of the radionuclide of interest must be within $40 \mathrm{keV}$ of the observed peak energy.

D. Evaluation

1. Check that the energy of the observed peak of interest is within $40 \mathrm{keV}$ of the energy for the radionuclide of interest.

2. Check the energy spectra for any peaks that overlap or that have associated peaks that may interfere with the peak of the radionuclide of interest.

3. When interfering radionuclides are present and can be correctied for from associated peaks in the spectrum, check to see if the peak area for the radionuclide of interest has been properly corrected.

\section{E. Action}

1. If the energy of the peak of interest is more than $40 \mathrm{keV}$ from the energy for the radionuclide of interest, qualify the results as unusable, "R."

2. If the alpha energy spectra contain any peaks that overlap with or have associated peaks that may interfere with the peak of the radionuclide of interest, and it is impossible to correct for the interference, qualify the results as unusable.

3. If the results have not been properly corrected for the interfering radionuclide, qualify the data as unusable, "R."

4. If energy spectra and library spectra have not been included in the package, professional judgement should be used for qualification of the data. 


\subsection{RADIONUCLIDE QUANTITATION AND ESTIMATED DETECTION LIMITS}

\section{A. Review Items}

Sample results, counting errors, estimated detection limits, counting efficiencies, background results, sample preparation log sheets, and the case narrative.

\section{B. Objective}

The objective is to ensure that the reported quantitation results are accurate and that the required detection limits have been met. When detection limit requirements are not met, the data quality objectives may have been compromised. All results must be evaluated relative to the uncertainty associated with the analysis.

Detection limits must be specified by the equations and confidence limits desired as well as being defined numerically. The estimated detection limit is related to the characteristics of the instrument. This limit is also known as the lower limit of detection, which is analogous to the instrument detection limit. The level of activity that is practically achievable with a given instrument, analytical method, and sample type is termed the MDA.

\section{Criteria}

1. Radionuclide quantitation must be calculated according to the appropriate procedures specified in the contractual work plan.

2. Detection limits specified in the specific approved procedures must be met unless other detection limits are specified.

3. Analytical uncertainties must be reported with all results to qualify the data. Results and uncertainties must be reported for all required analyses regardless of the size or sign of the result. The reported uncertainty must include all uncertainties associated with the analysis. If the reported uncertainty only includes counting uncertainty, this fact must be documented in the case narrative.

4. Appropriate aliquot sizes must be used in sample preparation to provide representative subsampling.

5. When samples are dry mounted for counting, mounting aliquots must be selected to keep the dry mounted weight to $55 \mathrm{mg} / \mathrm{cm}^{2}$.

D. Evaluation

1. The raw data shall be examined to verify the correct calculation of sample results reported on the sample data summary forms.

2. Examine the raw data for omissions, reduction, and transcription errors. 
3. Verify some of the calculations (e.g., MDA activity, uncertainty, tracer recoveries and yields). If errors are found in the calculations, more results may be required to be recalculated to determine the extent and effect of the errors.

4. Verify that all analytical uncertainties have been copied and reported or otherwise documented.

5. Verify that all appropriate aliquot sizes have been used for sample preparation.

6. Verify that decay corrections have been calculated properly and that radioactive source reports (standards certificates) are present for the tracer and all spikes used.

\section{E. Action}

1. When significant errors are found in the calculations, contact the laboratory for a resubmittal of affected data.

2. When inappropriate aliquot amounts are used, qualify the data using professional judgement.

3. For net negative results that have uncertainties less than their absolute value, qualify the data as unusable, "R." This is an indication of improper background subtraction.

4. When estimated detection limits are not met, a discussion should be provided in the validation report and the analytical coordinator should be notified.

5. When analytical uncertainties are not reported, qualify the results as estimated, "J."

6. When standards certificates are not present, all data should be qualified as estimated detected, "J," or estimated nondetected, "UJ."

7. If calculations show errors that are not significant and do not affect the data, note calculation findings in the case narrative.

8. When tracer yields are below limits established in the QAPjP or by the laboratory, qualify data associated with low tracer yields as estimated. Qualify detects associated with low tracer yields as estimated, "J," and nondetects as unusable (R).

9. When tracer yields are above limits established in the QAPjP or by the laboratory, qualify data associated with high tracer yields as estimated. Qualify detects associated with low tracer yields as estimated, "J," nondetects receive no qualification.

\subsection{SYSTEM PERFORMANCE}

\section{A Review Items}

QC data, sample results, and the case narrative. 


\section{B. Objective}

During instrument performance checks (e.g., blanks, calibration), changes may occur in the system that degrade the quality of the data.

While this degradation would not be directly shown until the next required series of analytical QC runs, a thorough review of the ongoing data acquisition can yield indicators of instrument performance.

\section{Criteria}

Professional judgement should be used to assess the system performance. Abrupt, discrete shifts in the background or detector response may indicate a change in gains or thresholds, or may indicate contamination.

Poor spectroscopic performance affects both qualitative and quantitative results. Indications of substandard performance include the following:

high background levels, shifts in energy calibration, extraneous peaks, and

loss of resolution.

\section{Evaluation}

Evaluate the raw data for each sample to determine if unexpected activity, extraneous peaks, loss of resolution, or loss of expected background peaks has occurred.

\section{E. Action}

Continued analytical activity with degraded performance suggests lack of attention or experience. Based on the instrument performance indicators, the data reviewer shall decide if the system has degraded to the extent of affecting data quality or validity. If data quality may have been affected, data shall be qualified using the reviewer's best professional judgement.

\subsection{OVERALL ASSESSMENT OF DATA FOR A CASE}

\section{A. Review Items}

Entire data package, data review results, and (if available) QAPjP, and SAP.

\section{B. Objective}

The overall assessment of a data package is a brief narrative in which the data reviewer expresses concerns and comments on the quality and, if possible, the useability of the data. 


\section{Criteria}

Assess the overall quality of the data.

Review all available materials to assess the overall quality of the data, keeping in mind the additive nature of analytical problems.

D. Evaluation

1. Evaluate any technical problems which have not been previously addressed.

2. Review all available materials to assess the overall quality of the data, keeping in mind the additive nature of analytical problems.

3. If appropriate information is available, the reviewer may assess the useability of the data to assist the data user in avoiding inappropriate use of the data. Review all available information, including the QAPjP (specifically the Data Quality Objectives), SAP, and communication with data user that concerns the intended use and desired quality of the data.

E. Action

1. Use professional judgement to determine if there is any need to qualify data which were not qualified based on the QC criteria previously discussed.

2. Write a brief narrative to give the user an indication of the analytical limitations of the data. Any inconsistency of that data with the SDG narrative should be noted for analytical coordinator action. If sufficient information on the intended use and required quality of the data are a available, the reviewer should include his/her assessment of the useability of the data within the given context.

\subsection{CALCULATIONS}

The following calculations are provided for the reviewer's ready access.

Decay Correction

$$
A=A_{0} *-e^{\frac{-\ln 2}{t_{1 / 2}} \cdot T}
$$

Where: $\mathrm{A}=$ Activity in $\mathrm{pCi}$ per unit volume

$A_{0}=$ Initial Activity of Standard in $\mathrm{pCi}$ per unit volume

$t_{1 / 2}=$ Radioactive Half-life (in minutes)

$\mathrm{T}=$ Amount of time (in minutes) from the decay date (on the certificate of analysis) until analysis date 
Percent Recovery

$$
\% R=\frac{L C S_{F}}{L C S_{T}} * 100
$$

Where: $\operatorname{LCS}_{\mathrm{p}}=$ measured LCS activity in $\mathrm{pCi} / \mathrm{g}$

LCS $_{\mathrm{T}}=$ true LCS activity in $\mathrm{pCi} / \mathrm{g}$

MS Recovery

$$
M S R=\frac{S S R-S R}{S A} * 100
$$

Where: MSR = matrix spike recovery

SSR $=$ spiked sample result

SR = sample result

SA $=$ amount of spike added

RPD

$$
R P D=\frac{|S R-S D R|}{1 / 2(S R+S D R)} * 100
$$

Where: RPD = Relaive Percent Difference

SR $\quad=$ Spike Recovery

SDR = Spike Duplicate Recovery

Sample Activity

The activity of the sample is defined through the following relationship:

$$
A=\frac{X-B}{2.22 * E * V * Y}
$$

Where: $\mathrm{A} \quad=$ Activity of isotope $i$ in picocuries $(\mathrm{pCi})$ per unit volume

$\mathrm{X}=$ Count rate of isotope $i$ in counts per minute (cpm)

$\mathrm{B}=$ Background count rate (cpm) in the isotope $i$ region of interest

$\mathrm{E} \quad=$ Detector efficiency

$\mathrm{V}=$ Sample volume in liters or weight in grams

$2.22=$ Conversion factor from $\mathrm{dpm}$ to $\mathrm{pCi}$

$\mathrm{Y} \quad=$ Chemical recovery for the analysis which is determined from the isotopic tracer, $j$, added to the sample 


$$
Y=\frac{X-B}{D * E}
$$

The chemical recovery factor is given by:

Where: $Y=$ Chemical Yield as a decimal

$\mathrm{X}=$ Count rate of standard isotope, $j$, in cpm

$B=$ Background count rate (cpm) in the isotope $j$ region of interest

$\mathrm{D}=$ Certified activity for isotope $j$

Uncertainty (Standard Deviation)

The sample uncertainty, based on counting statistics, is expressed as one standard deviation of the net count rate in Pci unit volume as follows:

$$
E_{r}=2 * \frac{\sqrt{\left[\left(\frac{(X * T)^{1 / 2}}{T}\right)^{2}+\left(\frac{(B * T)^{1 / 2}}{T}\right)^{2}\right]}}{2.22 * E * V * Y}
$$

Where: $\mathrm{E}_{\mathrm{r}} \quad=$ Counting Error

$\mathrm{X}=$ Count rate of isotope $i$ in counts per minute (cpm)

B $=$ Background count rate (cpm) in the isotope $i$ region of interest

$\mathrm{E} \quad=$ Detector efficiency

$\mathrm{V}=$ Sample volume in liters or weight in grams

$2.22=$ Conversion factor from dpm to $\mathrm{pCi}$

$\mathrm{Y}=$ Chemical recovery for the analysis which is determined from the isotopic tracer, $j$, added to the sample

MDA Calculation

The MDA at the $95 \%$ confidence level expressed in $\mathrm{pCi}$ per unit volume is given by:

$$
M D A=\frac{2.71+4.66 \sqrt{B * T}}{2.22 * E * Y * T * A_{D} * V}
$$

Where: $2.71=$ Statistical factor (at $95 \%$ confidence level)

4.66 = Confidence factor (at 95\% confidence level)

$\mathrm{B}=$ Background counting rate (cpm)

$2.22=$ Conversion factor from $\mathrm{dpm}$ to $\mathrm{pCi}$

$\mathrm{E} \quad=$ Detector efficiency

$\mathrm{V} \quad=$ Sample volume in liters or weight in grams

$\mathrm{Y} \quad=$ Chemical recovery

$\mathrm{T}=$ Sample counting time (in minutes)

$A_{D} \quad=$ Alpha decay abundance 


\section{DATA VALIDATION OF STRONTIUM-89 AND STRONTIUM-90}

\subsection{METHOD SUMMARY}

This procedure details the data validation criteria for strontium-89, 90 determined by ingrowth of yttrium-90 and low-background gas proportional counting. Three carriers (barium, calcium, and strontium) are added to the prepared sample for determination of strontium-89, 90. EDTA is added to the sample and the $\mathrm{pH}$ is adjusted to 3.8 to precipitate any magnesium present in the sample. The magnesium precipitate is removed through filtration. The $\mathrm{pH}$ is readjusted to 4.6 , complexing calcium. The sample is then transferred to a cation exchange column to elute the calcium. Strontium and barium are selectively eluted and the strontium is precipitated out as a carbonate. The strontium carbonate is then filtered, dried and then counted. This counting provides the total strontium activity in the sample and marks the beginning of the yttrium ingrowth. Following the determination of the total strontium activity, the sample is stored for approximately 2 weeks for the yttrium-90 ingrowth. After this time period the sample is then recounted. The results from the second count are used to determine the strontium- 90 activity. The strontium- 90 value is subtracted from the total strontium result determined in the first count to determine the strontium-89 value.

\section{LEVEL D DEILIVERABLES:}

The following information should be included in the data package. This information should be accompanied by all raw data, including copies of standards certification and control charts.

Sample Data:

Form IA/B or Sample Analysis Results

Form II or Chemical Recovery (carrier) Results

Standards Data:

Initial Calibration Data

Daily Instrument Performance Check Data

Raw QC Data:

Blank Data
MS Data
MSD Data
Duplicate Data
LCS
Self-Absorption Curves
Cross-talk Data


QC Summary Package:

Form III or MS/MSD recoveries

Form IV or Method Blank Summary

Form V or LCS recoveries

Form VI or Duplicate RPDs

Internal COC Forms

Background Determinations

Standard Certificates

Prep logs

\subsection{TECHNICAL HOLDING TIMES}

\section{A. Review Items}

Form I, chain-of-custody (COC) forms, sample preparation logs and instrument printouts.

\section{B. Objective}

The objective is to ascertain the validity of results based on the holding time of the sample from time of collection to time of sample extraction and analysis.

\section{Criteria}

All samples should be kept at $4^{\circ} \mathrm{C}$ until analyzed. Water samples should be acidified with nitric acid to a $\mathrm{pH}<2$ at the time of collection. All samples should be analyzed within 6 months.

\section{Evaluation}

Technical holding times are established by comparing the sampling date and time on the COC form with date and time of analyses on. Form I and the raw data (e.g., run logs). Examine the sample records to determine if the samples were preserved, by computing the length of time, in days, between sampling dates on COC forms with dates of analyses.

\section{E. Action}

If criteria for acidification were not met, qualify sample results $\geq$ to MDA as estimated (J) and results < MDA as nondetected estimated (UJ).

If technical holding times are exceeded, but less than one year, qualify sample results 2 MDA as estimated (J) and results < MDA as nondetect estimated (UJ). Document in the data review narrative that holding times were exceeded. If holding times are grossly exceeded (greater than two times the defined holding time), the reviewer must use professional judgement to determine the reliability of the data and the effects of additional storage on the sample results. The reviewer may determine that nondetect data are unusable (R). 
If deficiencies in the COC documentation are noted, they should be reported in the DVR as outlined above. It should be noted that a problem could arise if any of the affected data are to be used in litigation.

Any noted deficiencies which do (or could) affect the data on a chemical basis can be considered "major" deficiencies. As an example, general requirement deficiencies which prevent the reviewer from determining the date of sample collection, date of extraction, or date of analysis, and preclude determination of technical holding time, would be considered major. The inability of a reviewer to determine the date or time of sample analysis due to general requirements deficiencies will prevent the linking of the sample with a specific calibration, method blank, or other QC measures. Upon discovery of a "major" general requirements deficiency, the data package review should be discontinued and the laboratory should be immediately contacted. Data review should not continue until the "major" deficiency has been resolved by the laboratory.

\subsection{INSTRUMENT CALIBRATION AND DAILY INSTRUMENT PERFORMANCE CHECK}

\section{A. Review Items}

Raw calibration data, cross channel interferences (cross-talks), and self absorption data and associated self-absorption curves, efficiency curves, background and plateau curves.

\section{B. Objective}

Instrument calibration and daily performance criteria are established to ensure that the instrument is capable of producing acceptable quantitative data.

\section{Criteria}

The instrument calibration consists of choosing the proper operating voltage and the correct alpha discriminator setting. Daily instrument checks consist of analyzing a high activity alpha and a high activity beta source to document counting efficiency and cross channel interference. Sources must be NIST traceable. The gross counting system must be efficiency calibrated for each alpha and beta counting geometry annually or when the daily calibration verification indicates an unacceptable change in system efficiency. The alphadiscriminator must be set so that the count rate varies $\leq 5 \%$ over a 150 -volt operating range. A plateau curve and alpha-beta cross-talk factors must be established, and a performance check must be made after each P-10 counting gas bottle change. If an unacceptable change has occurred due to the new counting gas, then the new gas must be replaced. If, out of necessity, counting is performed using undesirable counting gas, a special calibration must be performed for that gas. This should be noted in the case narrative. The alpha into beta channel cross-talk must be $\leq 35 \%$ while the beta into alpha channel cross-talk must be $\leq 2 \%$. Since counting efficiencies are highly instrument dependent, at a minimum, the beta counting efficiency of the near $0 \mathrm{mg}$ solid standard must be $\geq$ to $40 \%$. Self-absorption relationships must be determined after a change in gas supply, after instrument problems, every 6 months, or if the absorption correction is included in an efficiency curve, a new curve must be developed when the daily performance check indicates an unacceptable change in system efficiency. Self-absorption curves must be determined for strontium-89, 90 and yttrium-90. 
The counter background should be checked daily or when routine performance check indicates an unacceptable range in instrument background. The daily background should be recorded and compared to the established background spectra used for background subtraction. The background should remain within 3 sigma of the established mean.

\section{Evaluation}

Verify that the instrument was calibrated properly and at the required frequency. Review the beta plateau curve and evaluate its shape and smoothness. In addition, review the daily calibration verification results including cross-talks. Review the near 0 mg solids counting efficiency. Ensure that self-absorption factors have been determined. These factors must be determined over the range of solids expected in the samples. It is recommended that the solids content not exceed $200 \mathrm{mg}$ total; $100 \mathrm{mg}$ total solids may be a more appropriate level.

Determine if the laboratory reported results were corrected for the alpha into beta channel cross-talk.

Verify some of the counting efficiencies for each self-absorption curve.

Ensure that there are standard certificates present for the calibration standards and they are NIST traceable.

Percent dead time is not considered a problem for environmental samples, due to the probability of low activity. However, if there is a particularly hot sample, ensure the percent dead time is not large enough to miss a significant number of sample counts.

\section{E. Action}

If the beta counting efficiency for the near $0 \mathrm{mg}$ solid standard is $<40 \%$, qualify all results as unusable (R).

If the count rate variation is $>5 \%$ over a 150 -volt operating range, then qualify results $<$ MDA as nondetected estimated (UJ) and results 2 MDA as estimated (J).

If the alpha into beta channel cross-talk is $>35 \%$, qualify results $\geq \mathrm{MDA}$ as estimated (J). No qualification is required for results < MDA.

If the beta into alpha channel cross-talk is $>2 \%$, qualify results $\geq$ MDA as estimated (J) and results < MDA as nondetect estimated (UJ).

If the self-absorption data are not provided, qualify results 2 MDA as unusable (R) and results $<$ MDA as unusable $(R)$.

If the background counts are beyond 3 sigma of the mean background counts, qualify results 2 MDA as estimated (J) and results $<$ MDA as nondetect estimated (UJ).

If standard certificates are not present and/or they are not NIST traceable, qualify all associated data as estimated. 
If there is a particularly radioactive sample, assess the percent dead time and use professional judgement to qualify the data.

\subsection{SAMPLE AND BACKGROUND RESULTS}

\section{A. Review Items}

Sample results, counting errors (uncertainties), MDAs, counting efficiencies, background results, sample preparation log sheets, and case narrative. Also, standard dilutions traced back to standard certificates and decay corrected.

\section{B. Objective}

The objective is to ensure that the reported sample results, counting errors and efficiencies, and MDAs are accurate.

\section{Criteria}

Compound quantitation including error and MDA are computed as shown below. Samples are counted twice; the first counting determines the total strontium activity while the second determines the yttrium-90 activity which is used to determine the strontium-90 activity.

\section{Evaluation}

Review Form I, and the associated raw data. Recalculate approximately $10 \%$ of the sample results to determine whether or not calculations were performed correctly. If calculation errors are found, recalculation of more results may be required to determine the extent of the error.

Note: Net negative results that have uncertainties greater than their absolute value indicate the sample count was less than background. Net positive results that have uncertainties larger than the results indicate the sample count was less than the critical level or less than $95 \%$ confidence of positive detection.

\section{E. Action}

If sample activities, counting efficiencies, or MDAs reported by the laboratory do not match those calculated by the validator, within rounding differences, the laboratory should provide corrected values. The correct values should be reported in the DVR.

When inappropriate aliquot sizes are used, qualify all affected results using professional judgement.

For net negative results that have uncertainties smaller than their absolute value, qualify the data as unusable "R."

When analytical uncertainties are not reported, qualify the results as estimated "J."

If any discrepancies are found, the laboratory may be contacted by the designated representative to obtain additional information that could resolve any differences. This is 
usually done through action items. If a discrepancy remains unresolved, the reviewer may determine that qualification of the data is warranted based on the reviewers professional judgement.

\subsection{BLANKS}

\section{A. Review Items}

Forms IA/B and IV and raw data.

\section{B. Objective}

The objective of blank analyses is to determine the existence and magnitude of contamination problems resulting from laboratory performance. The criteria for evaluation of blanks apply to any blank associated with samples (e.g., reagent blanks, field blanks,etc). If problems with any blank exist, all associated data must be evaluated carefully to determine whether or not there is inherent variability in the data, or if the problem is an isolated occurrence not affecting other data.

\section{Criteria}

Radionuclides should only be present in blanks below the MDA. Reagent blanks (method blanks) should be carried through the entire sample preparation and analysis process. Blanks will be analyzed for every sample preparation group or at least one of every 20 samples for each matrix type, whichever is more frequent.

\section{Evaluation}

Review the results of all associated blanks, Form Is, and raw data, and verify that the results were accurately reported. Ensure that the proper number of blanks were analyzed, at the proper frequency.

Verify that method blank analyses have been reported per matrix, per concentration level, to analyze samples, and for each extraction batch.

\section{E Action}

Action in the case of unsuitable blank results requires a large amount of professional judgement. The overall assessment of blank contamination should be performed paying particular attention to all associated QC samples (e.g., comparing the background counts to the blank counts, since the values should be approximately the same).

If there is contamination present in the blank and in the associated samples, the reviewer should report the contamination in the validation narrative and use professional judgement to qualify the data.

If gross contamination exists in a blank sample and associated samples, all associated sample data should be qualified as unusable "R." 
If inordinate amounts of other radionuclides are found at low levels in the blanks, it may be indicative of a problem at the laboratory and should be noted in the data review comments.

\subsection{MATRIX SPIKEMATRIX SPIKE DUPLICATES}

\section{A. Review Items}

Form III and associated raw data

\section{B. Objective}

These data are generated to determine the accuracy of the analytical method. These data alone cannot be used to evaluate the accuracy of individual samples.

\section{Criteria}

MSs and MSDs should be performed a minimum of 1 per 20 samples. Field blanks cannot be used for MS/MSDs. The recoveries for MS/MSDs must be 75 to $125 \%$. The RSD for aqueous samples should not be greater than $20 \%$ and not greater than $30 \%$ for solid samples. The recovery limits do not apply when sample concentration exceeds the spike concentration by a factor of 4 or more. The analytical spike must be NIST traceable.

\section{Evaluation}

Inspect results for the MS/MSD percent recovery (\%R) and RPD.

If MS/MSDs were not analyzed at the appropriate frequency, and if field blanks were used, note the deficiency in the DVR.

Ensure that the analytical spike is supported by a standard certificate and is NIST traceable.

\section{E. Action}

No action is taken on MS/MSD data alone. However, using informed professional judgement, the data reviewer may use the MS and duplicate results in conjunction with other QC criteria and determine the need for some qualifications of the data.

The data reviewer should first try to determine to what extent the results of the MS/MSD affect the associated data. This determination should be made with regard to the MS/MSD sample itself as well as specific analytes for all samples associated with the MS/MSD.

In those instances where it can be determined that the results of the MS/MSD affect only the sample spiked, then qualifications should be limited to this sample alone. However, it may be determined through the MS/MSD results that a laboratory is having a systematic problem in the analysis of one or more analytes, which affects all associated samples. 
If the analytical spike is not accompanied by a standard certificate and/or is not NIST traceable, qualify all associated data as estimated.

\subsection{LABORATORY CONTROL SAMPLES/BLANK SPIKE}

\section{A. Review Items}

Form V, control charts, raw data, and radioactive source report (standard certificates).

\section{B. Objective}

Data for LCS are generated to provide information on the accuracy of the analytical method and the laboratory performance.

\section{Criteria}

LCSs are analyzed at a frequency of one per 20 samples per SDG. The LCS must be prepared and analyzed concurrently with the samples in the SDG.

LCS percent recoveries must fall within the internal limits specified in the QAPjP. The LCS must meet the recovery criteria for the sample data to be accepted. The analytical spike must be NIST traceable.

\section{Evaluation}

Ensure that each sample is analyzed in a batch in which a LCS has been performed. Any LCS exceeding the QC limits set for a given sample matrix shall require all data from the associated batch of samples to be closely inspected.

If no analytical problems are found, data analyzed with the out-of-control point shall be discussed.

If problems are found in the analytical data, ensure that samples associated with the batch were reanalyzed and data from the analysis reported.

If holding times are exceeded in the reanalysis, both sets of data shall be presented.

Check the raw data to verify the reported recoveries and recalculate some of the \%Rs.

Ensure that the analytical spike is NIST traceable.

\section{E Action}

If the LCS criteria are not met, then the laboratory performance and method accuracy are in question. Professional judgement should be used to determine if the data should be qualified or rejected. The following guidance is suggested for qualifying sample data for which the associated LCS does not meet the required criteria.

If the LCS/Blank Spike exceeds established internal limits (or as specified in the QAPjP), qualify detects as estimated $(J)$ and nondetects receive no qualification. 

as "UJ."

If the LCS/ Blank Spike is below established limits, qualify detects as "J" and nondetects

If the LCS/Blank Spike results are below established limits and MS results are below established limits, qualify detects associated with the LCS as "J" and nondetects as "R."

If the LCS/Blank Spike results are above established limits and MS results are above established limits, qualify detects associated with the LCS as "J" and nondetects receive no qualification.

If LCSs were not analyzed at the appropriate frequency, note the deficiency in the DVR.

If the analytical spike is not NIST traceable, qualify the associated data as estimated.

\subsection{CARRIER RECOVERY}

\section{A. Review Items}

Form II, raw data and carrier preparation log sheets.

\section{B. Objective}

Data review for carrier recoveries is to ensure the laboratory has corrected sample results based on carrier recovery correctly.

\section{Criteria}

1. A carrier must be spiked into each sample.

2. A carrier standard must be NIST traceable.

3. Percent recoveries should be within QC limits as outlined in the QAPjP or established by the laboratory (whichever is applicable).

4. Sample values should be corrected for carrier recovery.

D. Evaluation

1. Verify that standard certificates are present and NIST traceable.

2. Verify that 6 replicates were prepared.

3. Verify that carrier recoveries have been calculated correctly.

4. Verify that carrier recoveries are within the QC limits established in the QAPjP or by the laboratory. 


\section{E. Action}

1. If the carrier standard certificate is not present, or is not NIST traceable, qualify all data as estimated.

2. If dilutions have not been calculated correctly, the reviewer should perform some activity calculations using the correct value to determine the impact on sample results. If the error is gross, use professional judgement to qualify the data. The error should be discussed in the case narrative.

3. If low carrier recoveries are obtained, qualify all detects as estimated, "J," and all nondetects as unusable, "R."

4. If high carrier recoveries are obtained, qualify all detects as estimated, "J," and all nondetects as unusable, "R."

\subsection{DUPLICATES}

\section{A. Review Items}

Form VI and raw data.

\section{B. Objective}

Duplicate analyses are indicators of laboratory precision based on each sample matrix.

\section{Criteria}

Samples identified as field blanks cannot be used for duplicate sample analysis. Ensure duplicates are analyzed at a frequency of one per 20 samples per SDG. Verify that the RPD was within $\pm 35 \%$ for sample values greater than or equal to $5 \mathrm{X}$ the MDA. Also, ensure that a control limit of $\pm 2 \mathrm{X}$ the MDA was used for duplicate sample comparison values less than $5 \mathrm{X}$ the MDA.

\section{Evaluation}

Check the raw data and recalculate: one or more RPD values using the following equation:

$$
\text { \%RPD }=\frac{2 *(S-D)}{(S+D)} * 100
$$

Where: $\mathbf{S}=$ first sample result, and

$\mathrm{D}=$ duplicate sample result.

Determine if results were correctly reported. Determine if a field blank was used for duplicate analysis. Review results and determine if results fall within the control limits. Also, determine if duplicates were analyzed at the proper frequency. 


\section{E. Action}

If duplicates were not analyzed at the appropriate frequency, and if field blanks were used, note the deficiency in the DVR.

If either result is $\leq$ to the MDA, then no duplicate comparison is made.

If duplicate analysis results are outside the appropriate limits, qualify results for that analyte in all associated batch samples as estimated (J).

\subsection{OVERALL ASSESSMENT OF DATA FOR A CASE}

\section{A. Review Items}

Review results from Sects. 11.2 through 11.9.

\section{B. Objective}

The overall assessment of a data package is a brief narrative in which the data reviewer expresses concerns and comments on the quality and, if possible, the usability of the data.

\section{Criteria}

Assess the overall quality of the data.

\section{Evaluation}

Evaluate any technical problems which have not been previously addressed.

Review all available materials to assess the overall quality of the data, keeping in mind the additive nature of analytical problems.

If appropriate information is available, the reviewer may assess the usability of the data to assist the data user in avoiding inappropriate use of the data. Review all available information [e.g., QAPjP (specifically the Data Quality Objectives), SOP, communication with data user or sampler concerning the intended use and desired quality of this data].

\section{E. Action}

Use professional judgement in qualifying data which were not qualified based on the QC criteria previously discussed.

Write a brief narrative which gives the user an indication of the analytical limitations of the data and the consistency of that data with the laboratory certification statement. If sufficient information on the intended use and required quality of the data are available, the reviewer should include his/her assessment of the usability of the data within the given contract. 


\subsection{CALCULATIONS}

The following calculations are provided for the reviewer's ready access.

Cross-talk

$$
\begin{aligned}
& X_{A}=100 * \frac{B}{A} \\
& X_{1}=100 * \frac{A}{B}
\end{aligned}
$$

Where: $X_{A}=$ alpha into beta channel cross-talk,

$X_{B}=$ beta into alpha channel cross-talk,

$A=$ alpha counts for a standard, and

$B=$ beta counts for a standard.

Counting Efficiencies for each Self-Absorption Curve

$$
E=\frac{(X-B)}{S}
$$

Where: $\mathrm{E}=$ counting efficiency in cpm/dpm,

$X=$ count rate of a standard used in cpm,

$B=$ background count rate in cpm, and

$S=$ true activity of the standard used in dpm.

Strontium-89 Efficiency

$$
\text { Efficiency }=\frac{C P M_{0}}{D P M_{c}}
$$

Where: $\mathrm{CPM}_{\mathrm{o}}=$ observed counts per minute of the standard, and

$\mathrm{DPM}_{\mathrm{c}}=$ decay corrected disintegration rate of the calibration standard.

Decay Correction

$$
A=A_{0} * e^{\frac{-t_{2}}{t_{12}} * T}
$$

Where: $\mathrm{A}=$ decay corrected activity

$A_{0}=$ initial activity,

$\ln 2=$ natural $\log$ of 2 ,

$t_{12}=$ half-life of the radionuclide,

$\mathrm{T}=$ time of decay (same units as $\mathrm{t}_{12}$ ), and

e $\quad=2.71828$ 
Chemical Recovery

$$
\text { Chemical Recovery }=\frac{W_{,}}{W_{c} * V_{c}}
$$

Where: $W_{1}=$ weight of the sample precipitate $(\mathrm{mg})$,

$\mathrm{W}_{\mathrm{c}}=$ strontium carrier calibration $(\mathrm{mg} / \mathrm{ml})$, and

$V_{c}=$ volume of carrier used $(\mathrm{ml})$.

Strontium-90 Activity Concentration

$$
s^{20} p C i / \text { unit }=\frac{(A * B)-(C * D)}{[1+E * F] A-[1+E * G] C} * \frac{1}{2.22 * H * I * J}
$$

Where: $A=S r-89$ decay factor from time of collection to time of

B = net cpm of total Sr on second count,

C $=$ Sr-89 decay factor from the time of collection to the time of second count,

D = net cpm of total Sr on first count,

$\mathrm{E}=$ ratio of $\mathrm{Y}-90 / \mathrm{sr}-90$ counting efficiencies,

$F=Y-90$ ingrowth factor from the time of separation to the time of last count,

$\mathrm{G}=\mathrm{Y}-90$ ingrowth factor from the time of separation to the time of first count,

$\mathrm{H}=\mathrm{Sr}-90$ counting efficiency,

$I$ = chemical recovery, and

$\mathrm{J}$ = sample volume/weight.

Deriving these variables as shown,

$$
\begin{gathered}
A, C=e^{\frac{-\ln 2}{T_{12}} \cdot T} \\
F, G=1-e^{\frac{-\ln 2}{S_{12}} \cdot T}
\end{gathered}
$$

Strontium-89 Activity Concentration

$$
S r^{89} p \text { Ci/unit }=\frac{D-[1+G * E] * L}{A} * \frac{1}{2.22 * I * K * J}
$$

Where: $\mathrm{K}=\mathrm{Sr}-89$ counting efficiency and

$$
\mathrm{L}=\mathrm{Sr}-90 \text { net } \mathrm{cpm} \text {. }
$$


MS Recovery

$$
\% R=\frac{S S R-S R}{S A} * 100
$$

Where: SSR = spiked sample result,

SR = sample result, and

SA $\quad=$ amount of spike added.

RPD

$$
R P D=\frac{|S R-S D R|}{1 / 2(S R+S D R)} * 100
$$

Where: SR = spike recovery and

SDR = spike duplicate recovery

Percent Recovery

$$
\% R=\frac{L C S_{F}}{L C S_{T}} * 100
$$

Where: $\operatorname{LCS}_{\mathrm{F}}$ (found) = measured LCS activity in $\mathrm{pCi} / \mathrm{g}$, and $\mathrm{LCS}_{\mathrm{T}}$ (true) = measured LCS activity in $\mathrm{pCi} / \mathrm{g}$. 


\section{DATA VALIDATION OF RADIONUCLIDES USING LIQUID SCINTILLATION COUNTING}

\subsection{METHOD SUMMARY}

This method is a liquid scintillation process for determining alpha, beta, and gammaemitting radionuclides in analytical samples. In the liquid scintillation process, samples are dissolved in a "cocktail" containing fluors. Alpha, beta, or gamma emissions interact with these fluors, thereby producing photons of light that can be detected by a counter and then analyzed. The counter measures the intensity of the light pulses, determines the emission energy, and counts the number of pulses to determine activity.

\section{LEVEL D DELIVERABLES}

Signed COC form

Case narrative

Calibration information and calculations, including quench data and curve

Control chart of LCSs

Method blank results

Sample and background results

MS results

Duplicate analysis results

Copies of run logbooks, preparation logbooks, and laboratory bench sheets

Raw data for all routine, blank, and QC samples, including instrument printouts, photocopied pages of laboratory notebooks, worksheets which refer to sample weights, dilutions, concentrations, data reduction, sample cleanup, sample prep logs and worksheets, instrument calibration logs, and standards preparation and tracing.

\section{TECHNICAL HOLDING TIMES}

\section{A. Review Items}

COC forms, analysis dates, sample prep logs, and instrument printouts. 


\section{B. Objective}

The objective is to ascertain the validity of results based on the holding time of the sample from time of collection to time of sample analysis.

\section{Criteria}

From a compliance standpoint, radiochemical samples are required to be analyzed within 6 months of sample collection. There is no technical qualification of data for missed holding times as such; however, the sample should be analyzed within four half-lives of the projectspecific radionuclide with the shortest half-life to maintain detection limits within a reasonable counting time.

The half-life multiplied by four is less than the 6 months compliance holding time for promethium (Pm)-147, which has a half life of $41.3 \mathrm{~d}$.

Water samples should be acidified with nitric acid to a $\mathrm{pH}$ of $<2$ at the time of sample collection unless being analyzed for tritium. Water samples requiring tritium analysis should have a separate container collected for this purpose and should not be acidified. Water samples requiring acidification that were not acidified at the time of collection must be acidified by the laboratory within $5 \mathrm{~d}$ of collection. After laboratory acidification, water samples should be held in their original containers for a minimum of $16 \mathrm{~h}$ before transfer or analysis. No chemical preservation is specified for soil samples, so no qualification of data on that basis is required. Any impact on the data from unpreserved field QC samples would not be identified until the overall assessment (see Sect. 12.10).

Samples are to be,stored at $4^{\circ} \mathrm{C}$ until analyzed. However, only extreme conditions would be expected to have any effect on these analytes so it is not expected that data qualification would be warranted based on storage temperature deviations.

\section{Evaluation}

Technical holding times are established by comparing the sampling date and time on the COC form with date and time of analysis on the results form, if given, or else in the raw data.

\section{E. Action}

For Pm-147, which has a short half-life, when the compliance time has not been exceeded but the analysis has taken place more than four half-lives since sample collection, check the sample counts to ensure that sufficient counting time has been allowed to reach the desired MDAs. If holding times are exceeded, the reviewer shall use professional judgement to determine the reliability of the data and the effects of additional storage on sample results. Technical judgement must be used to determine if extreme storage temperature deviations require the data to be qualified.

Due to the limited information concerning holding times for soil samples, it is left to the professional judgement of the data reviewer whether to apply water holding time criteria to soil samples. If the data are qualified when water holding time criteria are applied to soil samples, it shall be clearly documented in the review. 
If the criteria for acidification were not met, qualify sample results $\geq \mathrm{MDA}$ as estimated "J" and results < MDA as unusable "R."

If deficiencies in the COC documentation are noted, they should be reported in the DVR as outlined above. It should be noted that a problem could arise if any of the affected data are to be used in litigation.

Any noted deficiencies which do (or could) affect the data on a chemical basis can be considered "major" deficiencies. As an example, general requirement deficiencies which prevent the reviewer from determining the date of sample collection or date of analysis, and preclude determination of technical holding time, would be considered major. The inability of a reviewer to determine the date or time of sample analysis due to general requirements deficiencies may prevent the linking of the sample with a specific calibration, method blank, or other QC measures. Upon discovery of a "major" gen sral requirements deficiency, the data pacikage review should be discontinued, if time permits, and the laboratory should be immediately contacted. Data review should not continue until the "major" deficiency has been resolved by the laboratory.

\section{INSTRUMIENT CALIBRATION}

\section{A. Review Items}

Calibration results and associated raw data, including count values for quenched and unquenched standards, standards logbook copies.

\section{B. Objective}

The objective is to ensure that the instrumentation is capable of producing acceptable quantitative data.

\section{Criteria}

Instrument calibration consists of three general procedures: System Normalization and Calibration (SNC), Instrument Performance Assessment (IPA), and quench determination.

The SNC procedure should be performed daily using a NIST traceable unquenched standard. The procedure first involves individually adjusting each photomultiplier tube (PMT) to one half of the normal reading for the standard. Then the PM.Ts are turned on to check that the total count rates are correct. If the count rates are incorrect, both tubes must be proportionally adjusted until the correct count rates are obtained.

The IPA procedure should be performed daily following the SNC procedure, and should utilize NIST-traceable unquenched standards for the radionuclides that are to be analyzed for. The IPA determines instrument background count rate plus unquenched counting efficiency. During the IPA procedure, standards are counted several times to determine a chi-squared figure of merit. Figure of merit and counting efficiency control limits, including frequency criteria, are specified in the performing laboratory's SOP. 
The chi-square figure of merit, $\mathrm{Chi}^{2}$, is calculated as follows:

$$
\mathrm{Chi}^{2}=\frac{1}{\mathrm{M}} \sum_{\mathrm{i}=1}^{\mathrm{n}}\left(\mathrm{C}_{1}-\mathrm{M}\right)^{2}
$$

Note that

$$
M=\frac{1}{n} \sum_{i=1}^{n} C_{i}
$$

Where: $\mathbf{n}=$ number of times a standard is counted,

$M=$ mean of the $\mathbf{n}$ standard count, and

$C_{1}=$ the measured counts for a standard.

The quench determination, or external calibration check, follows the IPA procedure and should be performed quarterly. The quench determination consists of determining the reduction in count rate due to chemical and color interferences by analyzing a set of NISTtraceable quenched standards for the radionuclides of interest.

Counting efficiencies are calculated as follows:

$$
E=\frac{(X-B)}{S}
$$

Where: $E=$ system counting efficiency in $\mathrm{cpm} / \mathrm{dpm}$,

$X=$ count rate of a quenched standard in cpm,

$B=$ background count rate in cpm, and

$\mathrm{S}=$ activity of a quenched standard in $\mathrm{dpm}$.

\section{Evaluation}

Determine if the instrument was calibrated at the appropriate frequency and if all required figure of merit and efficiency criteria specified in the performing laboratory's SOP were met.

Percent dead time is not considered a problem for environmental samples, due to the probability of low activity. However, if there is a particularly hot sample, ensure the percent dead time is not large enough to miss a significant number of sample counts.

\section{E. Action}

If standards are not identified for the initial calibration, or if SNC and IPA calibration procedures were not performed at the appropriate frequency, qualify all associated sample results as unusable "R."

If the chi-square figure of merit results were below the required control limits, or if the standards were not distributed over the energy range of interest, qualify all associated results Z MDA as estimated "J" and results < MDA as nondetect estimated "UJ." 
If efficiency results for radionuclides are outside of required control limits (90 to $110 \%$ of initial calibration value), qualify all associated results $\geq \mathrm{MDA}$ as estimated "J" and results < MDA as nondetect estimated "UJ."

If there is a particularly hot sample, assess the percent dead time and use professional judgement to qualify the data.

\section{BLANKS}

\section{A. Review Items}

Method blank results, corresponding raw data, and sample results.

\section{B. Objective}

The objective of blank analyses is to determine the existence and magnitude of contamination problems resulting from laboratory performance. The criteria for evaluation of blanks apply to any blank associated with samples (e.g., method blanks).

Ensure that all associated blanks were analyzed and that background determinations have been performed. Ensure blank and background determinations contain no positive hits for target analytes.

\section{Criteria}

No contaminants should be present in blanks. Reagent blanks should be carried through the entire sample preparation and analysis process. Blanks will be analyzed for every sample set, for each matrix type, or once in every batch of samples (up to 20 samples), whichever is more frequent.

\section{Evaluation}

Review the results of all associated blanks, including raw data, and verify that the results were accurately reported. Ensure that the proper number of blanks was analyzed, at the proper frequency.

Verify that method blank analyses have been reported in a way that allows them to be associated with the samples with which they were prepared and analyzed.

\section{E. Action}

Action in the case of unsuitable blank results requires a large amount of professional judgement. The overall assessment of blank contamination should be performed paying particular attention to all associated QC samples (e.g., comparing the background counts to the blank counts, since the values should be approximately the same).

If there is contamination present in the blank and in the associated samples, the reviewer should report the contamination in the validation narrative and use professional judgement to qualify the data. 
If gross contamination exists in a blank sample and associated samples, all associated sample data should be qualified as unusable "R."

If inordinate amounts of other radionuclides are found at low levels in the blanks, it may be indicative of a problem at the laboratory and should be noted in the data review comments.

\section{QUANTITATION, COUNTING ERROR, MINIMUM DETECTIBLE ACTIVITY, AND COUNTING EFFICIENCY}

\section{A Review Items}

Sample results, raw data, counting errors, MDAs, background results, sample preparation log sheets, counting efficiencies, and case narrative.

\section{B. Objective}

The objective is to ensure that the reported sample results, counting errors, and MDAs are accurate.

\section{Criteria}

Quantitation, including error and MDA, is performed as follows: Sample-specific counting efficiencies are not determined for this analysis.

Quantitation

$$
A=\frac{X-B}{2.22 * E * V * Y}
$$

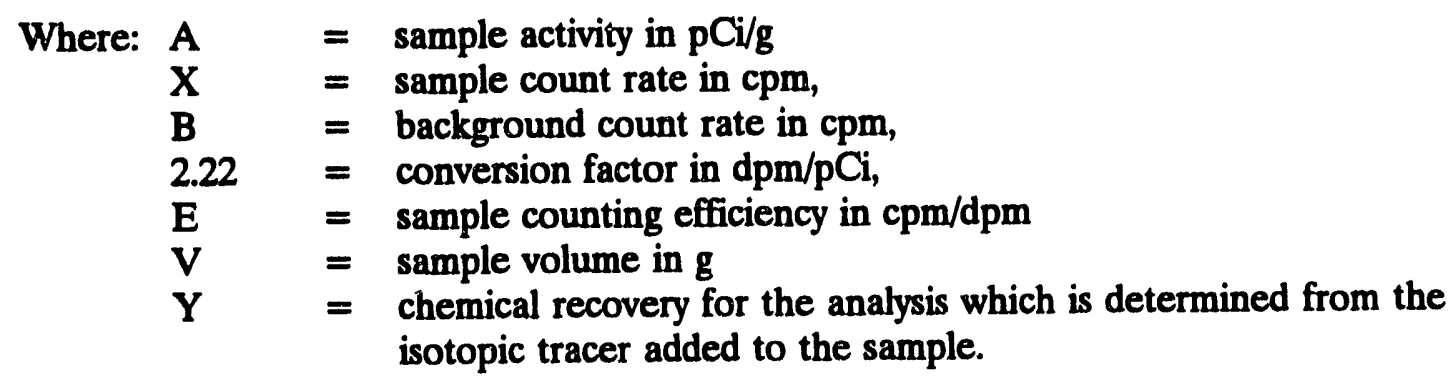

Counting Error

$$
E_{r}=2 * \frac{\sqrt{\left[\left(\frac{(X * T)^{1 / 2}}{T}\right)^{2}+\left(\frac{(B * T)^{1 / 2}}{T}\right)^{2}\right]}}{2.22 * E * V * Y}
$$

Where: $E=20$ counting error

$T=$ count time in minutes 
The chemical recovery factor is given by:

$$
Y=\frac{X-B}{D * E}
$$

Where: $\mathbf{Y}=$ Chemical Yield as a decimal

$\mathrm{X}=$ Count rate of standard isotope, $j$, in cpm

$\mathrm{B}=$ Background count rate (cpm) in the isotope $j$ region of interest

$\mathrm{D}=$ Certified activity for isotope $j$

Minimum Detectible Activity

$$
M D A=\frac{2.71+4.66 * \sqrt{B * T}}{2.22 * E * V * T * Y}
$$

Where: $2.71=$ Statistical factor (at $95 \%$ confidence level)

$4.66=$ Confidence factor (at $95 \%$ confidence level)

\section{Evaluation}

Raw data for approximately $10 \%$ of the sample results should be examined to determine whether or not the calculations performed by the laboratory were correct.

\section{E. Action}

If sample activities, MDAs, counting errors, or counting efficiencies reported by the laboratory do not match those calculated by the validator, within rounding differences, then all sample results should be recalculated. Correct values should be included in the DVR.

\section{LABORATORY CONTROL SAMPLES}

\section{A. Review Items}

Raw data, LCS control charts, and associated data.

\section{B. Objective}

Data for LCS are generated to provide information on the accuracy of the analytical method and the laboratory performance.

\section{Criteria}

LCSs are analyzed at a frequency of once per 20 samples per SDG. The LCS must be prepared and analyzed concurrently with the samples in the SDG. LCS \%Rs must fall within the control limits of $80-120$. 
D. Evaluation

Ensure that each sample is analyzed in a batch in which a LCS has been performed. Any LCS exceeding internal QC limits set by the laboratory for a given sample matrix shall require all data from the associated batch of samples to be closely inspected.

Check the raw data to verify the reported recoveries. Recalculate one or more \%Rs using the following equation:

$$
\begin{aligned}
& \% \mathrm{R}=\frac{\mathrm{LCS}_{\mathrm{p}}}{\mathrm{LCS}_{\mathrm{T}}} * 100 \\
& \text { Where: } \operatorname{LCS}_{\mathrm{p}}=\text { measured LCS activity in } \mathrm{pCi} / \mathrm{g} \text {, and } \\
& \text { LCS }_{\mathrm{T}}=\text { true LCS activity in } \mathrm{pCi} / \mathrm{g} \text {. }
\end{aligned}
$$

If no analytical problems are found, data analyzed with the out-of-control point shall be discussed.

If problems are found in the analytical data, ensure that samples associated with the batch were reanalyzed and data from the analysis reported.

If holding times are exceeded in the reanalysis, both sets of data shall be presented.

\section{E. Action}

If all \%Rs are within control limits, then no qualification is required.

If $\%$ Rs $>120$, no qualification is required for results < MDA, and results 2 MDA are qualified as estimated "J."

If $50 \leq \% \mathrm{R}<80$, qualify results $2 \mathrm{MDA}$ as estimated "J" , and results $<\mathrm{MDA}$ as nondetect estimated "UJ." "J."

If $\% \mathrm{R}<50$, quality results $<\mathrm{MDA}$ as unusable " $\mathrm{R}$ " and results $2 \mathrm{MDA}$ as estimated

If the LCS results are below internal laboratory limits and if MS/MSD results are below the QC limits, the data shall be qualified as follows:

- Qualify nondetects for samples associated with the LCS as estimated "UJ."

- Qualify positive results for samples associated with the LCS as estimated "J."

If the LCS results are above internal laboratory limits and if MS/MSD results are above the QC limits, the data shall be qualified as follows:

- Nondetects for samples associated with the LCS will not be qualified.

- Qualify positive results for samples associated with the LCS as estimated "J." 
If LCSs were not run at the appropriate frequency, note the deficiency in the DVR.

\section{MATRDX SPIKE}

\section{A. Review Items}

MS results, associated raw data including count rates, spike volumes, and activities of standards used in spiking.

\section{B. Objective}

These data are generated to determine the accuracy of the analytical method on the sample matrix.

\section{Criteria}

Spike recovery control limits are 75 to $125 \%$. One MS should be analyzed per batch. Field blanks should not be used for the MS.

\section{Evaluation}

Inspect results for the MS percent recovery (\%R) and determine if they are within control limits according to the formula:

$$
M S R=\frac{S S R-S R}{S A} * 100
$$

Where: $\begin{array}{ll}\text { MSR } & =\text { matrix spike recovery } \\ \text { SSR } & =\text { spiked sample result } \\ \text { SR } & =\text { sample result } \\ \text { SA } & =\text { amount of spike added }\end{array}$

Determine if MSs were analyzed at the proper frequency and if field blanks were used for MSs.

\section{E. Action}

If all recoveries (\%R) are within limits, no qualification is required. If the MS was not analyzed at the correct frequency or was run on the field blank, note the fact in the DVR.

In those instances where it can be determined that the results of the MS affect only the sample spiked, then qualifications should be limited to this sample alone.

If $R>125 \%$, no qualification is required for results $<\mathrm{MDA}$, and results $2 \mathrm{MDA}$ are qualified as estimated "J."

If $30 \% \leq R<75 \%$, qualify results $2 \mathrm{MDA}$ as estimated "J" and qualify results $<$ MDA as nondetect estimated "UJ." 

"J."

If $\% \mathrm{R}<30 \%$, qualify results $<\mathrm{MDA}$ as unusable " $\mathrm{R}$ " and results $2 \mathrm{MDA}$ as estimated

\section{DUPLICATES}

\section{A. Review Items}

Sample and duplicate results and raw data.

\section{B. Objective}

These data are generated to determined the laboratory precision of the analytical method for the sample matrix.

\section{Criteria}

Duplicate RPD limits are $\pm 35 \%$ for soil samples for analyte concentrations $\geq 5 X$ MDA. The limit is \pm 2 times the MDA for concentrations < 5 X MDA. One duplicate should be analyzed per batch. Field blanks should not be used for the duplicate. Only the sample analyzed in duplicate should be qualified.

If either result $\leq \mathrm{MDA}$, then no duplicate comparison is made. If both results are $\geq 10$ times their MDA, then the RPD $\leq 20$. If both results are 2 their MDA but $<10$ times their MDA, then RPD < larger MDA.

\section{Evaluation}

Inspect results for the RPD and determine if they are within control limits according to the formula:

$$
R P D=\frac{|S R-S D R|}{1 / 2(S R+S D R)} * 100
$$

$$
\begin{aligned}
& \text { Where: RPD = Relative Percent Difference } \\
& \text { SR } \quad=\text { Spike Recovery } \\
& \text { SDR = Spike Duplicate Recovery }
\end{aligned}
$$

Verify transcriptions from raw data and verify calculations.

\section{E. Action}

If all RPDs are within limits, no qualification is required. If the duplicate was not analyzed at the correct frequency, note the fact in the DVR.

In those instances where it can be determined that the results of the duplicate affect only the sample spiked, then qualifications should be limited to this sample alone. Otherwise, if duplicate analysis results are outside control limits, qualify all results $\geq \mathrm{MDA}$ as in the batch as estimated "J" and results < MDA as nondetected estimated "UJ." 


\section{OVERALL ASSESSMENT OF DATA FOR A CASE}

\section{A Review Items}

Entire data package, data review results, QAPjP, and SAP.

\section{B. Objective}

The overall assessment of a data package is a brief narrative in which the data reviewer expresses concerns and comments on the quality and, if possible, the usability of the data.

\section{Criteria}

Assess the overall quality of the data. The accuracy and precision of the data must be discussed. Any guidance regarding limitation of the data must also be supplied. If numerous QC deficiencies were present with none having resulted in the data being rejected, then professional judgement must be used in rejecting data.

\section{Evaluation}

Evaluate any technical problems which have not been previously addressed.

Review all available materials to assess the overall quality of the data, keeping in mind the additive nature of analytical problems.

If appropriate information is available, the reviewer may assess the usability of the data to assist the data user in avoiding inappropriate use of the data. Review all available information [e.g., QAPjP (specifically the Data Quality Objectives), SOP, communication with data user or sampler concerning the intended use and desired quality of this data].

\section{E. Action}

Use professional judgement in qualifying data which were not qualified based on the QC criteria previously discussed.

Write a brief narrative which gives the user an indication of the analytical limitations of the data and the consistency of that data with the laboratory certification statement. If sufficient information on the intended use and required quality of the data are available, the reviewer should include his/her assessment of the usability of the data within the given contract. 


\section{DATA VALIDATION OF TOTAL URANIUM BY PULSED LASER PHOSPHORIMETRY}

\subsection{METHOD SUMMARY}

This method is for determining total uranium in water samples. If the sample is nonaqueous, it must be acid-digested and filtered fist. The uranium analyzer uses a pulsed laser to induce phosphorescence in the sample. The phosphorescence is received by the detector, a decay curve is generated over a series of time gates, and a decay curve is generated. A linear regression is performed, and the uranium concentration is generated.

\section{LEVEL D DELIVERABLES}

Signed COC form

Case narrative

Control chart of LCSs

Method blank results

Sample results

Calibration information and calculations

Copy of run log

Raw data for all routine, blank, and QC samples, including instrument printouts, photocopied pages of laboratory notebooks, worksheets which refer to sample weights, dilutions, concentrations, data reduction, sample cleanup, sample prep logs and worksheets, instrument calibration logs, and standards preparation and tracing.

\subsection{TECHINICAL HOLDING TIMES}

\section{A. Review Items}

Form I, COC forms, sample prep logs, and instrument printouts.

\section{B. Objective}

The objective is to ascertain the validity of results based on the holding time of the sample from time of collection to time of sample analysis. 


\section{Criteria}

From a compliance standpoint, radiochemical samples are required to be analyzed within 6 months of sample collection. There is no technical qualification of data for missed holding times as such.

Acid preservation is required for water samples. For this project, only the field blanks and rinsates are aqueous. No chemical preservation is specified for soil samples, so no qualification of data on that basis is required. Any impact on the data from unpreserved field QC samples would not be identified until the overall assessment (see Sect. 13.9).

Samples are to be stored at $4^{\circ} \mathrm{C}$. However, only extreme conditions would be expected to have any effect on these analytes so it is not expected that data qualification would be warranted based on storage temperature deviations.

\section{Evaluation}

Technical holding times are established by comparing the sampling date and time on the $\mathrm{COC}$ form with date and time of analysis on the results form, if given, or else in the raw data.

\section{E. Action}

As indicated in the Sect. $\mathrm{C}$ above, no action is required based on chemical preservation; technical judgement must be used to determine if extreme storage temperature deviations require the data to be qualified as "J."

If deficiencies in the COC documentation are noted, they should be reported in the DVR as outlined above. Note that a problem could arise if any of the affected data are to be used in litigation.

Any noted deficiencies which do (or could) affect the data on a chemical basis can be considered "major" deficiencies. As an example, general requirement deficiencies which prevent the reviewer from determining the date of sample collection or date of analysis, and preclude determination of technical holding time, would be considered major. The inability of a reviewer to determine the date or time of sample analysis due to general requirements deficiencies may prevent the linking of the sample with a specific calibration, method blank, or other QC measures. Upon discovery of a "major" general requirements deficiency, the data package review should be discontinued and the laboratory should be immediately contacted. Data review should not continue until the "major" deficiency has been resolved by the laboratory.

\subsection{INSTRUMENT CALIBRATION}

\section{A. Review Items}

Raw data 


\section{B. Objective}

Instrument intensity and calibration range, standard lifetime, and linearity criteria are established to ensure that the instrument is capable of producing accurate analytical results.

\section{c. Criteria}

1. A minimum of a blank and two standards (e.g., 30 and $1000 \mathrm{ppb}$ ) must be used to calibrate the instrument for high and low ranges.

2. Calibration must be done at least daily, or, if the instrument has been turned off, before analysis of a sample batch.

3. $\mathrm{pH}$ of the standards must be $<2.0$.

4. Background is determined by measuring a blank. Acceptance criteria for the blanks are an intensity of $<700$ for the low range and $<10$ for the high range.

5. Evaluate the standard. The lifetime must be $>200 \mu$ s and the $r^{2}$ value $>0.99$.

6. All calibration standards must be NIST traceable.

\section{Evaluation}

Check that the raw data (or compiled, if available) meet the criteria listed above.

Percent dead time is not considered a problem for environmental samples, due to the probability of low activity. However, if there is a particularly hot sample, ensure the percent dead time is not large enough to miss a significant number of sample counts.

\section{E. Action}

If the initiai caibration does not meet criteria, qualify the data as unusable (R).

If the correlation coefficient squared $\left(r^{2}\right)$ is less than 0.99 , qualify the results greater than the MDA as estimated (J) and the results less than the MDA as estimated undetected (UJ).

If NIST traceable standards have not been used, qualify all associated data as estimated detected, "J" or estimated nondetected, "UJ."

If there is a particularly hot sample, assess the percent dead time and use professional judgement to qualify the data. 


\subsection{INSTRUMENT CALIBRATION CHECK}

\section{A. Review Items}

Raw data

\section{B. Objective}

Ensure the instrument has passed a calibration verification check with standards from a different stock solution than that used for the calibration standards. Calibration verification ensures that the initial calibration is valid.

\section{Criteria}

Control limits for the calibration check standard are $\pm 10 \%$.

NIST traceable check standards must be used.

\section{Evaluation}

Verify that the instrument calibration was performed properly and was within limits.

Verify that NIST traceable standards were used.

\section{E. Action}

If the calibration check standard is outside control limits but within 75 to $89 \%$ or 111 to $125 \%$, qualify all results $\geq$ MDA as estimated (J).

If the calibration check standard is 75 to $89 \%$, qualify the results less than the MDA as estimated (UJ).

If the calibration check standard is 111 to $125 \%$, the results less than the MDA are acceptable.

If the calibration check standard is less than $75 \%$, qualify all results as unusable (R).

If the calibration check standard is greater than $125 \%$, qualify the results greater than the MDA as unusable (R); results less than the MDA are acceptable.

If NIST traceable standards were not used, qualify all associated data as estimated detected, "J" or estimated nondetected, "UJ." 


\subsection{BLANKS}

\section{A Review Items}

Forms and raw data

\section{B. Objective}

The objective of blank analyses is to determine the existence and magnitude of contamination problems resulting from laboratory performance. The criteria for evaluation of blanks apply to any blank associated with samples (e.g., method blanks). If problems with any blank exist, all associated data must be evaluated carefully to determine whether or not there is inherent variability in the data, or if the problem is an isolated occurrence not affecting other data.

\section{Criteria}

No contaminants should be present in blanks. Reagent blanks should be carried through the entire sample preparation and analysis process. A method blank (reagent blank) will be analyzed for every sample set, for each matrix type, or once in every batch of samples (up to 20 samples), whichever is more frequent.

\section{Evaluation}

Review the results of all associated blanks, reporting forms, and raw data, and verify that the results were accurately reported. Ensure that the proper number of blanks was analyzed, at the proper frequency.

Verify that method blank analyses have been reported in a way that allows them to be associated with the samples with which they were prepared and analyzed.

\section{E. Action}

Action in the case of unsuitable blank results requires a large amount of professional judgement. The overall assessment of blank contamination should be performed paying particular attention to all associated QC samples (e.g., comparing the background counts to the blank counts, since the values should be approximately the same).

If there is contamination present in the blank and in the associated samples, the reviewer should report the contamination in the validation narrative and use professional judgement to qualify the data.

If gross contamination exists in a blank sample and associated samples, all associated sample data should be qualified as unusable "R."

If inordinate amounts of other radionuclides are found at low levels in the blanks, it may be indicative of a problem at the laboratory and should be noted in the data review comments. 


\subsection{LABORATORY CONTROL SAMPLES}

\section{A. Review Items}

Reporting forms, raw data, and control charts.

\section{B. Objective}

Data for LCSs are generated to provide information on the accuracy of the analytical method and the laboratory performance.

\section{Criteria}

LCSs are analyzed at a frequency of once per 20 samples per SDG. The LCS must be prepared and analyzed concurrently with the samples in the SDG.

LCS recoveries must be within 80 to $120 \%$. If the laboratory has provided control charts, this requirement is superseded by the requirement that the LCS must be within 30 of the center line.

The LCS must be prepared using a NIST traceable spike.

\section{Evaluation}

Ensure that each sample is analyzed in a batch in which a LCS has been performed. Any LCS exceeding internal QC limits set by the laboratory for a given sample matrix shall require all data from the associated batch of samples to be closely inspected.

If no analytical problems are found, data analyzed with the out-of-control point shall be discussed.

If problems are found in the analytical data, ensure that samples associated with the batch were reanalyzed and data from the analysis reported.

If holding times are exceeded in the reanalysis, both sets of data shall be presented.

Verify that NIST traceable spikes were used.

\section{E Action}

If the LCS criteria are not met, then the laboratory performance and method accuracy are in question. Professional judgement should be used to determine if the data should be qualified or rejected. The following guidance is suggested for qualifying sample data for which the associated LCS does not meet the required criteria.

Action on the LCS recovery should be based on the extent to which recovery is outside criteria. 

follows:

If the LCS results are below internal laboratory limits, the data shall be qualified as

- Qualify nondetects for samples associated with the LCS as estimated "UJ."

- Qualify positive results for samples associated with the LCS as estimated "J." follows:

If the LCS results are above internal laboratory limits, the data shall be qualified as

- Nondetects for samples associated with the LCS will not be qualified.

- Qualify positive results for samples associated with the LCS as estimated "J."

If the LCS results are below internal laboratory limits and if MS/MSD results are below the QC limits, the data shall be qualified as follows:

- Qualify nondetects for samples associated with the LCS as estimated "UJ."

- Qualify positive results for samples associated with the LCS as estimated "J."

If the LCS results are above internal laboratory limits and if MS/MSD results are above the QC limits, the data shall be qualified as follows:

- Nondetects for samples associated with the LCS will not be qualified.

- Qualify positive results for samples associated with the LCS as estimated "J."

If the LCS does not contain a NIST traceable spike source, qualify all associated data as estimated detected, "J" or estimated nondetected, "UJ."

\subsection{MATRDX SPIKE}

\section{A. Review Items}

Reporting forms and raw data

\section{B. Objective}

These data are generated to determined the accuracy of the analytical method on the sample matrix.

\section{Criteria}

Spike recovery control limits are 75 to $125 \%$. One MS should be analyzed per batch. Field blanks should not be used for the MS.

All analytical spikes must be NIST traceable. 


\section{Evaluation}

Inspect results for the MS percent recovery (\%R) and determine if they are within control limits according to the formula:

$$
M S R=\frac{S S R-S R}{S A} * 100
$$

Where: MSR = matrix spike recovery

SSR = spiked sample result

SR $=$ sample result

SA $\quad=$ amount of spike added

Verify transcriptions from raw data and verify calculations.

\section{E. Action}

If all recoveries (\%R) are within limits, no qualification is required. If the MS was not analyzed at the correct frequency or was run on the field blank, note the fact in the comments.

In those instances where it can be determined that the results of the MS affect only the sample spiked, then qualifications should be limited to this sample alone.

If $\% \mathrm{R}>124$, no qualification is required for results $<\mathrm{MDA}$, and results $2 \mathrm{MDA}$ are qualified as estimated ("J").

If $20 \leq \% \mathrm{R}<75$, qualify results $2 \mathrm{MDA}$ as estimated ("J") and qualify results $<$ MDA as nondetect estimated ("UJ"). ("J").

If $\% R<20$, qualify results $<$ MDA as unusable ("R") and results 2 MDA as estimated

If the MS does not contain a NIST traceable spike source, qualify all associated data as estimated detected, "J" or estimated nondetected, "UJ."

\subsection{DUPLICATES}

\section{A Review Items}

Reporting forms and raw data

\section{B. Objective}

These data are generated to determined the laboratory precision of the analytical method for the sample matrix. 


\section{Criteria}

Duplicate RPD limits are $\pm 35 \%$ for soil samples for analyte concentrations $\geq 5 \mathrm{X}$ MDA. The limit is \pm MDA for concentrations $<5 X$ MDA. One duplicate should be analyzed per batch. Field blanks should not be used for the duplicate.

The spike used must be NIST traceable.

\section{Evaluation}

Inspect results for the RPD and determine if they are within control limits according to the formula:

$$
R P D=\frac{|S R-S D R|}{1 / 2(S R+S D R)} * 100
$$

Where: RPD $=$ Relative Percent Difference

SR $\quad=$ Spike Recovery

SDR = Spike Duplicate Recovery

Verify transcriptions from raw data and verify calculations.

Verify that a NIST traceable spike was used.

\section{E. Action}

If all RPDs are within limits, no qualification is required. If the duplicate was not analyzed at the correct frequency or was run on the field blank, note the fact in the comments.

In those instances where it can be determined that the results of the duplicate affect only the sample spiked, then qualifications should be limited to this sample alone. Otherwise, if duplicate analysis results are outside control limits, qualify all results in the batch as estimated ("J").

If the spike or spike duplicate does not contain a NIST traceable spike source, qualify all associated data as estimated detected, "J" or estimated nondetected, "UJ."

\subsection{OVERALL ASSESSMENT OF DATA FOR A CASE}

\section{A. Review Items}

Entire data package, data review results, QAPjP, and SAP.

\section{B. Objective}

The overall assessment of a data package is a brief narrative in which the data reviewer expresses concerns and comments on the quality and, if possible, the usability of the data. 


\section{Criteria}

Assess the overall quality of the data.

D. Evaluation

Evaluate any technical problems which have not been previously addressed.

Review all available materials to assess the overall quality of the data, keeping in mind the additive nature of analytical problems.

If appropriate information is available, the reviewer may assess the usability of the data to assist the data user in avoiding inappropriate use of the data. Review all available information [e.g., QAPjP (specifically the Data Quality Objectives), SOP, communication with data user or sampler concerning the intended use and desired quality of this data].

\section{E. Action}

Use professional judgement in qualifying data which were not qualified based on the QC criteria previously discussed.

Write a brief narrative which gives the user an indication of the analytical limitations of the data and the consistency of that data with the laboratory certification statement. If sufficient information on the intended use and required quality of the data are available, the reviewer should include his/her assessment of the usability of the data within the given contract. 


\section{RELATED DOCUMENTS}

ASTM Method D 5174-91 Standard Test Method for Trace Uranium in Water by Pulsed Laser Phosphorimetry.

EcoTek Standard Operating Procedure RL-2323-A, Analysis of Total Uranium by Laser Phosphorimetry, EcoTek LSI.

Martin Marietta Energy Systems, Inc., for the U.S. Department of Energy. Project Plan for the Background Soil Characterization Project at the Oak Ridge Reservation, Oak Ridge, Tennessee. ES/ER/TM-26/R1, August 1992.

Rucker, T. L., and M. C. Johnson, Jr., Laboratory Data Validation Guidelines for Evaluating Radionuclide Analyses, Science Applications International Corporation (SAIC), Revision 04, September 1, 1992.

Standard Operating Procedure for Data Validation of Radionuclides Determined by Liquid Scintillation, Environmental Science and Engineering OR016/DVP-7, DVP Number 31 Revision 0.3, April 6, 1992.

U.S. Department of Energy, Office of the Assistant Secretary for Environment, Safety, and Health, Office of Environmental Audit. The Environmental Survey Manual, Appendix DPart 4 (Radiochemical Analysis Procedures). DOE/EH-0053, 2nd ed., January 1989.

U.S. Environmental Protection Agency (EPA) Method 901.1, USEPA-600/4-80-032, Standard Operating Procedure "Operation of the High Energy (50-2000keV) Gamma Spectroscopy System," EcoTek LSI.

U.S. Environmental Protection Agency (EPA). Test Method for Evaluating Solid Waste, Office of Solid Waste and Emergency Response (OSWER). EPA SW-846. 3rd edition. November 1986.

U.S. Environmental Protection Agency (EPA). Laboratory Data Validation Functional Guidelines for Evaluating Inorganics Analyses, Draft July 1988.

U.S. Environmental Protection Agency (EPA). Contract Laboratory Program National Functional Guidelines for Organic Data Review, Multi-Media, Multi-Concentration (OLM01.0) and Low Concentration Water (OLC01.0), Draft December 1990, Revised June 1991.

U.S. Environmental Protection Agency (EPA). Guidance for Data Useability in Risk Assessment (Part B), Final May 1992.

WPAFB Quality Assurance Project Plan, Methods for Analysis of Organic Constituents National Functional Guidelines for Organic Data Review. 
Appendix A

DATA ASSESSMENT FORMS 


\section{Background Soil Characterization Project Inorganic Data Assessment}

Document No.

Laboratory

Date Issued

AC: Action

No. of Samples

Sample Matrix

Authorized Reviewer's Signature

Peer Reviewer's Initials

Oversight Reviewer's Initials

Completion Date

\section{DATA ASSESSMENT SUMMARY}

1. Holding Times

2. Calibrations

3. Blanks

4. ICS

5. LCS

6. Duplicate Analysis

7. Matrix Spike

8. MSA

9. Serial Dilution

10. Sample Verification

11. Other QC

12. Overall Assessment

O - Den had no problems. M = Den qualified.

A A

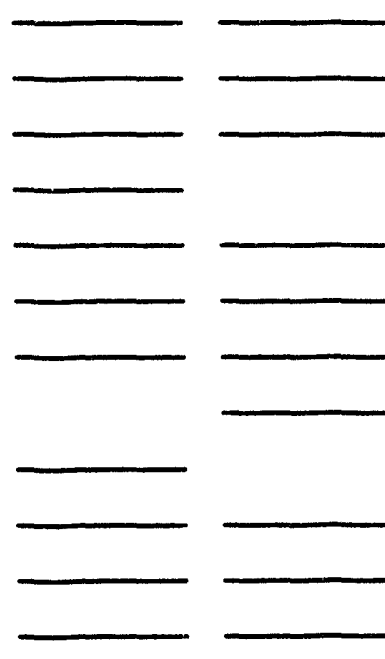

$Z=$ Dare unocecperable.

$X=$ Problems, but do not affect date
$\mathrm{I}_{8}$ Cyanide Sulfate

Action Items:

Areas of Concern:

Notable Performance: 


\section{Background Soil Characterization Project \\ Organic Data Assessment}

Document No.

Laboratory

Date Issued

AC: Action FY

No. of Samples
Sample Matrix

Authorized Reviewer's Signature

Peer Reviewer's Initials

Oversight Reviewer's Initials

Completion Date

\section{DATA ASSESSMENT SUMMARY}

1. Deliverables

2. Holding Times

3. GC/ECD IPC

4. Calibrations

5. Blanks

6. Surrogates

7. Matrix Spike/Dup.

8. Laboratory Control Samples

9. Pesticide Cleanup Checks

10. Compound Identification

11. Compound Quantitation \& Rep. CRQL

12. System Performance

13. Overall Assessment

0 - Dees had no probleins. $M=$ Den quelified.

HERB

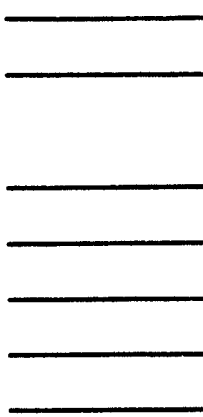

Action Items:

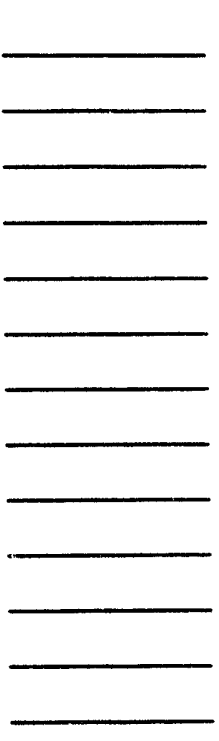

$T=$ Temporary

\section{Areas of Concern:}

Notable Performance: 


\section{Background Soil Characterization Project \\ Response requested within 3 working days of receipt.}

Doct. No.

\section{Laboratory}

Date Submitted

Data Assessment No.
Number of Sumples

Matrix

Reviewer/

Validator

Review/

Validation Date

\section{Action Items}

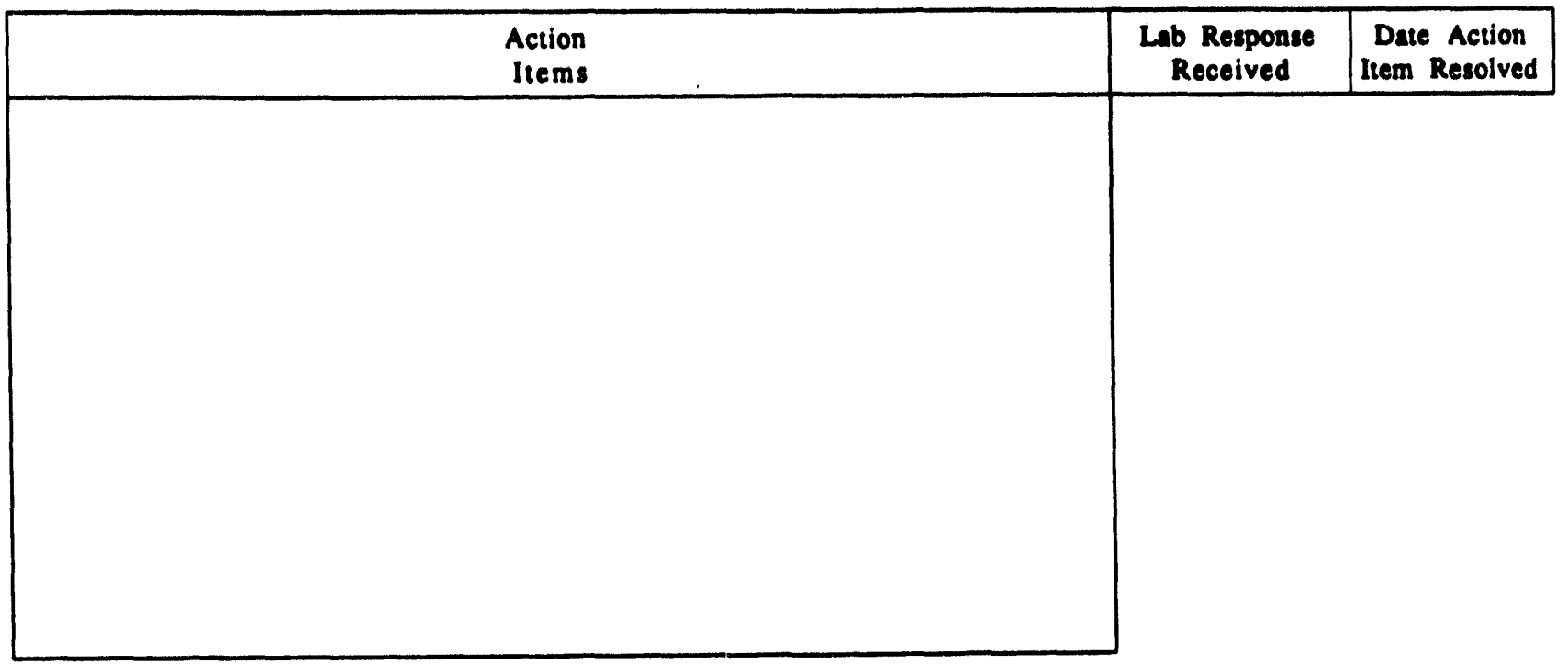

Name of Initiator

Date

Priated

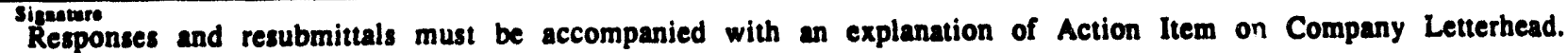


Appendix B

MULTIMEDIA, MULTICONCENTRATION CONTRACTUAL REQUIREMENTS AND EQUATIONS FOR PESTICIDE DATA REVIEW 


\section{Appendix B. MULTIMEDIA, MULTICONCENTRATION CONTRACTUAL REQUIREMENTS AND EQUATIONS FOR PESTICIDE DATA REVIEW}

\section{B.1 GC/ECD INSTRUMENT PERFORMANCE CHECK}

Check the Performance Evaluation Mixture calculations using equations II.2, II.3, and II. 4 to ensure correct calculation of DDT and Endrin breakdown. The breakdown of DDT and Endrin in both of the PEM injections must be less than $20.0 \%$, and the combined breakdown of DDT and Endrin must be less than $30.0 \%$.

$\%$ Breakdown DDT $=$ Amount found in ng (DDD + DDE) * 100

Amount in ng of DDT injected

$\%$ Breakdown Endrin =

$$
\text { Amount found in ng (Endrin aldehyde }+ \text { Endrin ketone) } * 100
$$

Amount of Endrin injected in $\mathbf{n g}$

Combined Breakdown $=\%$ Breakdown DDT $+\%$ Breakdown Endrin

All peaks in both the injections of the Performance Evaluation Mixture must be $100 \%$ resolved on both columns. The RPD of the calculated amount and the true amount for each of the single component pesticides and surrogates in the PEMs must be less than or equal to $25.0 \%$ from equation II.5.

$$
\mathrm{RPD}=\underbrace{\underline{\mid \mathrm{C}_{\text {nam }}-\mathrm{C}_{\text {calch }}}}_{\mathrm{C}_{\text {nom }}} * 100
$$

Where: $C_{\text {nom }}=$ True concentration of each analyte

$$
\mathrm{C}_{\text {calc }}=\begin{aligned}
& \text { Calculated concentration of each analyte from the analysis of the } \\
& \text { standard }
\end{aligned}
$$

\section{B.2 INITIAL CALIBRATION}

Retention time (RT) windows for each analyte and surrogate are calculated using Table B.1. Windows are centered around the mean absolute RT for the analyte established during the initial calibration. For example, for a given pesticide the mean RT is first determined from the initial calibration and found to be $12.69 \mathrm{~min}$. The RT window for this pesticide is \pm 0.05 min. Therefore, the calculated RT window would range from 12.64 to $12.74 \mathrm{~min}$. 
Table B.1. Retention Time Windows for Pesticide Target Compounds

\section{Pesticide Compounds}

alpha-BHC

beta-BHC

gamma-BHC

delta-BHC

Heptachlor

Aldrin

alpha-Chlordane

gamma-Chlordane

Heptachlor epoxide

Dieldrin

Endrin

Endrin aldehyde

Endrin ketone

DDD

DDE

DDT

Endosulfan I

Endosulfan 11

Endosulfan sulfate

Methoxychlor

Aroclors

Toxaphene

Tetrachloro-m-xylene

Decachlorobiphenyl
Retention Time Windows (in minutes) $\pm 0.05$

$\pm 0.05$

$\pm 0.05$

$\pm 0.05$

$\pm 0.05$

$\pm 0.05$

$\pm 0.07$

$\pm 0.07$

$\pm 0.07$

$\pm 0.07$

$\pm 0.07$

$\pm 0.07$

$\pm 0.07$

$\pm 0.07$

$\pm 0.07$

$\pm 0.07$

$\pm 0.07$

$\pm 0.07$

$\mathbf{\pm 0 . 0 7}$

$\pm 0.07$

$\pm 0.07$

$\pm 0.07$

$\pm 0.05$

$\pm 0.10$

The \%RSD of the calibration factors for each single component target compound must be less than or equal to $20.0 \%$. The \%RSD for the two surrogates must be less than or equal to $30.0 \%$. Up to two single component target compounds per column may exceed the $20.0 \%$ limit for \%RSD, but those compounds must have a \%RSD of less than or equal to $30.0 \%$. Calibration factors are calculated using equations III.5 and III.6.

$$
\begin{gathered}
\mathrm{CF}=\frac{\text { Peak Area (or Height) of the Standard }}{\text { Mass Injected (ng) }} \\
\overline{\mathrm{CF}}=\sum_{\mathrm{i}=1}^{\mathrm{n}} \frac{\mathrm{CF}}{\mathrm{n}}
\end{gathered}
$$

Where: $\overline{\mathrm{CF}}=$ Mean calibration factor of $\mathrm{n}$ values

$\mathrm{CF}_{\mathrm{i}}=\mathrm{i}^{\mathrm{t}}$ calibration factor

$\mathrm{n}=$ Total number of values 


\section{B.3 CONTINUING CALIBRATION}

The RT for each target compound and surrogate must be within RT window as calculated above using the mean absolute RT established during the three-point initial calibration. The relative percent difference of the calculated amount and the true amount for each of the compounds in the mid point concentration of the Individual Standard mixtures must be less than or equal to $25.0 \%$, using equation II.5.

\section{B.4 SURROGATE SPIKES}

The advisory limits for recovery of tetrachloro-m-xylene (TCMX) and decachlorobiphenyl (DCB) are 60 to $150 \%$ for soil samples. The surrogate percent recuvery is calculated using equation III.7. The RTs of both surrogates must be within the calculated RT windows, that is, TCMX must be within $\pm 0.05 \mathrm{~min}$. of the mean RT determined from the initial calibration and DCB must be within $\pm 0.10 \mathrm{~min}$. of the mean $\mathrm{RT}$ determined from the initial calibration.

Surrogate percent recovery (\%R)

$$
\% \mathrm{R}=\frac{\mathrm{Q}_{\mathrm{d}}}{\mathrm{Q}_{\mathrm{a}}} * 100
$$

Where: $Q_{d}=$ Quantity determined by analysis

$Q_{2}=$ Quantity added to sample/blank

\section{B.5 MATRX SPIKESMA' DIKE DUPLICATE}

The matrix spike/matrix $\iota_{i} \quad$ uplicate recovery and RPD requirements are listed in Table B.2. The matrix spike recoveries and RPD are calculated using equations III.8 and III.9.

Table B2. MS/MSD Contractual Requirements

\begin{tabular}{llccc} 
Compound & \%R Water & \%RPD Water & \%R Soil & \%RPD Soil \\
\hline gamma-BHC & 56 to 123 & 15 & 46 to 127 & 50 \\
Heptachlor & 40 to 131 & 20 & 35 to 130 & 31 \\
Aldrin & 40 to 120 & 22 & 34 to 132 & 43 \\
Dieldrin & 52 to 126 & 18 & 31 tc 134 & 38 \\
Endrin & 56 to 121 & 21 & 42 to 139 & 45 \\
4,4 '-DDT & 38 to 127 & 27 & 23 to 134 & 50
\end{tabular}


MS \% Recovery

$\% \mathrm{MS}=\frac{\mathrm{SSR}-\mathrm{SR}}{\mathrm{SA}} * 100$

Where: SSR = Spike sample result

SR = Sample result

SA $=$ Spike added

MS/MSD \% RPD

$\% \mathrm{RPD}=\frac{[\mathrm{MSR}-\mathrm{MSDR}]}{1 / 2(\mathrm{MSR}+\mathrm{MSDR})} * 100$

Where: MSR = Matrix spike recovery

MSDR = Matrix spike duplicate recovery

\section{B.6 PESTICIDE CLEANUP CHECK}

Every lot number of Florisil cartridges used for sample cleanup must be checked by spiking with 2,4,5-trichlorophenol and the midpoint concentration of Individual Standard Mixture A. The recoveries for all of the pesticides and surrogates in Individual Standard Mixture A must be within 80 to $120 \%$, the recovery of 2,4,5-trichlorophenol must be less than $5 \%$ and no peaks must interfere with the target analytes. Percent recovery is determined using equation III.7.

The GPC apparatus must be calibrated every $7 \mathrm{~d}$. The calibration is acceptable if the recovery of each single component analyte is within 80 to $110 \%$ and the Aroclor patterns match patterns previously generated by standards.

\section{B.7 TARGET COMPOUND IDENTIFICATION}

RTs of surrogates, matrix spikes, and reported compounds must fall within the RT windows established using the initial three-point calibration. 
ES/ER/TM-75

\section{DISTRIBUTION}

1. A. R. Barnard-Hatmaker

2. D. T. Bell

3. B. A. Berven

4. H. L. Boston

5. R. B. Cook

6. C. E. Daugherty

7. F. F. Dyer

8. T. O. Early

9. J. L. Engels

10. C. W. Francis

11. G. S. Fleming

12. S. B. Gadson

13. P. L. Goddard

14. J. T. Grumski

15. T. L. Hatmaker

16. S. E. Herbes

17. S. G. Hildebrand

18. S. K. Holladay

19. L. A. Hook

20. C. W. Kimbrough

21. B. L. Kimmel

22. T. M. Koepp

23. A. J. Kuhaida

24. S. Y. Lee

25-27. D. M. Matteo
28. C. W. McGinn

29. C. K. McGuffin

30. D. E. Miller

31. B. J. Montgomery (PGDP)

32. M. J. Norris

33. B. D. Nourse

34-35. P. T. Owen

36. J. G. Paar

37. L. M. Potter

38. M. R. Powell

39. L. Robinson

40. D. B. Shehee

41. S. H. Stow

42. R. E. Swaja

43. D. E. Vance

44. C. S. Walker

45-47. D. R. Watkins

48. R. K. White

49. P. S. Wood

50. Central Research Library

51-53. ESD Library

54. Laboratory Records Department

55. ORNL Patent Section

56-58. Central ER Doc. Mgmt. Center

59-60. ORNL ER Doc. Mgmt. Center

61. Office of Assistant Manager for Energy Research and Development, DOE Oak Ridge Operations Office, P.O. Box 2001, Oak Ridge, TN 37831-8600

62. G. W. Bodenstein, DOE Oak Ridge Operations Office, P.O. Box 2001, Oak Ridge, TN 37831-8541

63. D. M. Carden, DOE Oak Ridge Operations Office, P.O. Box 2001, Oak Ridge, TN 37831-8541

64. M. S. Ferre, DOE Oak Ridge Operations Office, P.O. Box 2001, Oak Ridge, TN 37831-8541

65. S. P. Riddle, DOE Oak Ridge Operations Office, P.O. Box 2001, Oak Ridge, TN 37831-8541

66-67. Office of Scientific and Technical Information, P.O. Box 62, Oak Ridge, TN 37831 

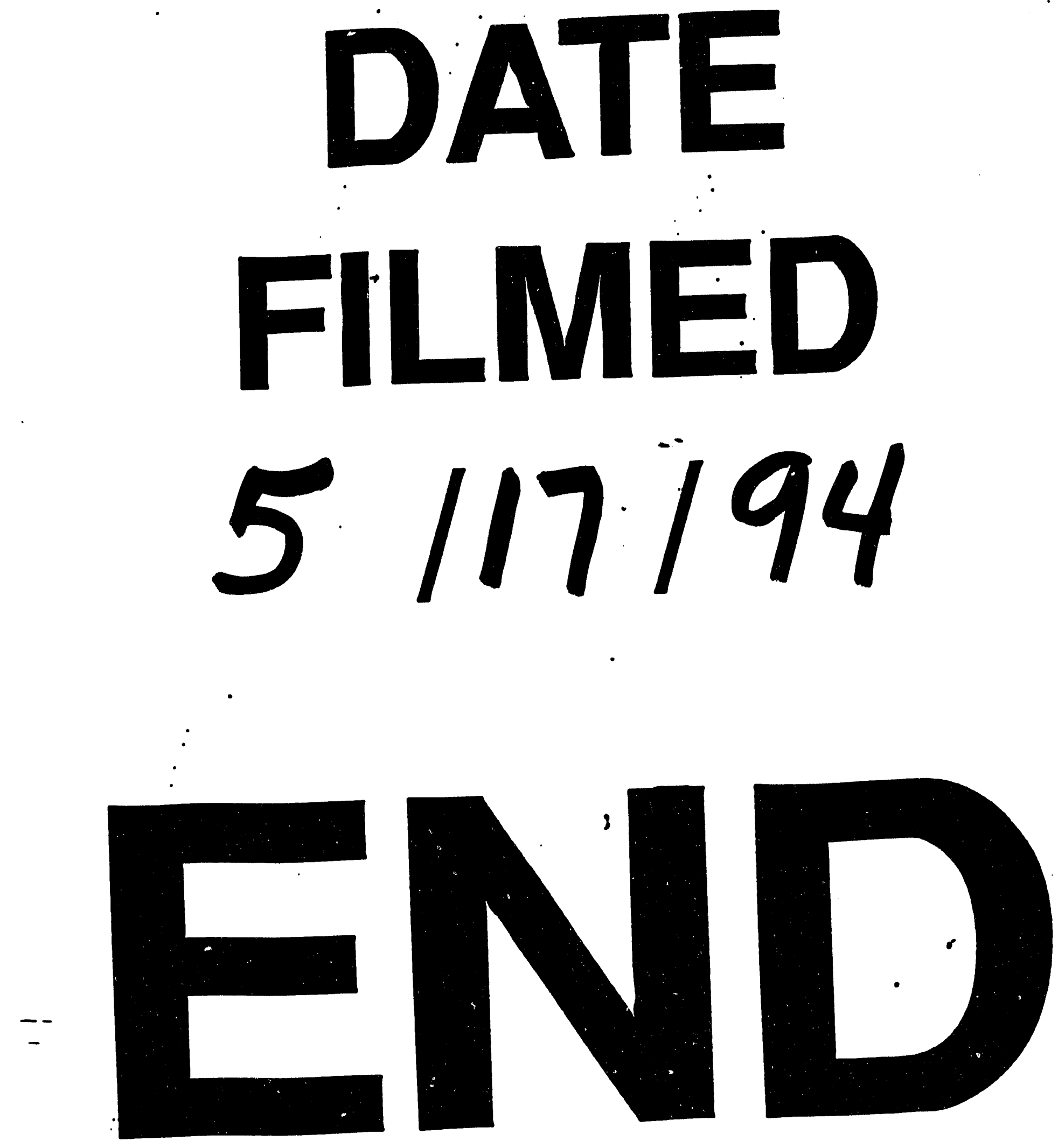


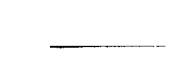

